DAVID MAYCON SCHIMITT ROSA

Interação rio aquífero: Um estudo de caso na Bacia do Ribeirão da Onça

Versão Corrigida

São Carlos, SP

2018 

DAVID MAYCON SCHIMITT ROSA

\title{
Interação rio aquífero: Um estudo de caso na Bacia do Ribeirão da Onça
}

\author{
Dissertação apresentada à Escola de Enge- \\ nharia de São Carlos, da Universidade de \\ São Paulo, como parte dos requisitos para \\ obtenção do título de Mestre em Ciências: \\ Engenharia Hidráulica e Saneamento.
}

\author{
Universidade de São Paulo - USP \\ Escola de Engenharia de São Carlos \\ Programa de Pós-Graduação em Hidráulica e Saneamento
}

Orientador: Prof. Tit. Edson Cezar Wendland

\author{
Versão Corrigida \\ São Carlos, SP \\ 2018
}


AUTORIZO A REPRODUÇÃO TOTAL OU PARCIAL DESTE TRABALHO, POR QUALQUER MEIO CONVENCIONAL OU ELETRONNICO, PARA FINS DE ESTUDO E PESQUISA, DESDE QUE CITADA A FONTE.

Ficha catalográfica elaborada pela Biblioteca Prof. Dr. Sérgio Rodrigues Fontes da EESC/USP com os dados inseridos pelo(a) autor(a).

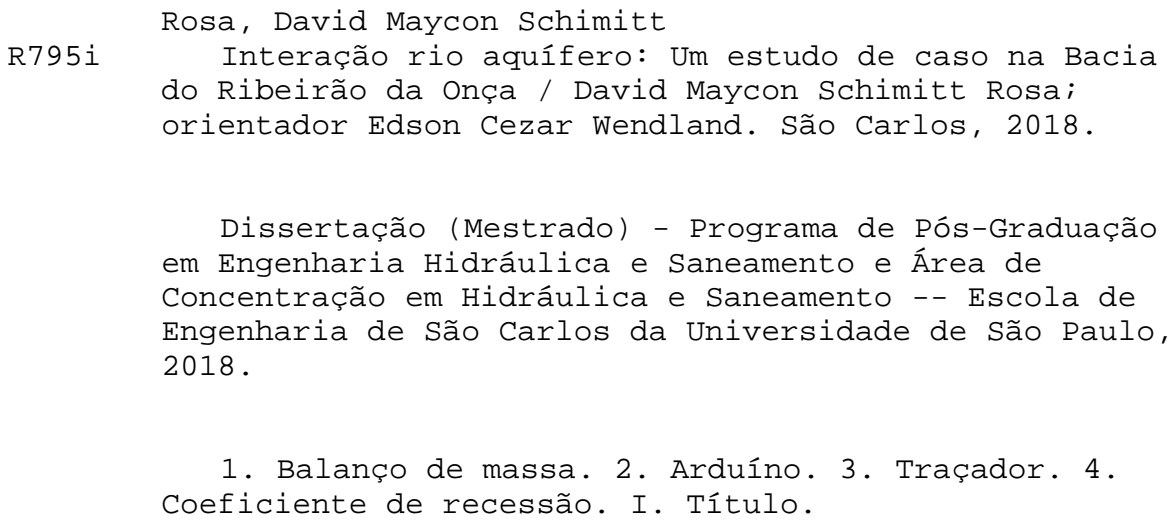

Eduardo Graziosi Silva - CRB - 8/8907 


\section{FOLHA DE JULGAMENTO}

Candidato: Engenheiro DAVID MAYCON SCHIMITT ROSA.

Título da dissertação: "Interação Rio Aquífero: um estudo de caso na Bacia do Ribeirão da Onça".

Data da defesa: 27/07/2018.

Comissão Julgadora:

Prof. Titular Edson Cezar Wendland

(Orientador)

(Escola de Engenharia de São Carlos/EESC)

Prof. Dr. Daniel Jadyr Leite Costa

(Universidade Federal de São Carlos/UFSCar)

Prof. Dr. Ademir Paceli Barbassa

(Universidade Federal de São Carlos/UFSCar)
Resultado:
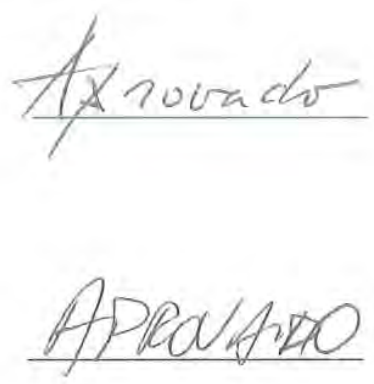

APROVADO.

Coordenador do Programa de Pós-Graduação em Engenharia Hidráulica e Saneamento:

Prof. Dr. Eduardo Mario Mendiondo

Presidente da Comissão de Pós-Graduação:

Prof. Associado Luís Fernando Costa Alberto 
Dedico este trabalho a todos os pais Que deixaram de viver seus sonhos Para viver os dos filhos.

E também a todos os entes queridos Que se foram e que nos deixaram saudades

Como a minha prima Letycia Amorim

Que cumpriu seu tempo entre nós. 


\section{Agradecimentos}

Agradeço primeiramente a Deus pela grande oportunidade e pelas experiências incríveis que me foram concedidas ao realizar este mestrado.

À minha amada e querida Mãe, que me ensinou o significado do amor, da compaixão e que abriu mão de muitas noites de sono e de muitos sonhos para um dia poder vivenciar momentos como este. Mãe, obrigado por todos os conselhos, ensinamentos que a senhora me ofereceu e por ter escolhido optar pela minha vida, quando a medicina nos desiludiu.

Ao meu amado e querido Pai, que como a minha mãe enfrentou muitas dificuldades para que conseguisse educar seu filho. O senhor me ensinou o significado de trabalho, paciência, determinação e com isto o sentido das responsabilidades. Muito obrigado pai, pelo amor, carinho e pela base sólida que foi capaz de me proporcionar. Desde cedo, tive a oportunidade de perceber o quanto o senhor suportou, para que eu pudesse ter as condições que o senhor não teve. As marcas do seu trabalho não ficaram apenas no seu corpo, meu pai, mas também no meu coração e agora graças ao esforço e toda a dedicação que vocês tiveram por mim, concluo este trabalho na Universidade de sua terra natal.

A eles, meus pais, que sempre foram presentes na minha formação, sempre me ajudaram em minhas dificuldades, sempre me acompanharam pelos momentos da minha vida e sempre foram mais do eu poderia imaginar, uma vida de agradecimentos ainda seria pouco.

Aos meus familiares, pelo apoio moral, principalmente aos meus tios Rodney e Lucy por estarem sempre atentos à minha jornada, pelas incontáveis caronas, pelos conselhos, pela amizade, pelo carinho e respeito que sempre recebi.

Às minhas avós, pelo carinho, todo amor e consideração durante a minha vida. Este momento não seria possível sem a participação delas.

À minha amada companheira, Ana C. Oliveira, pelo amor, dedicação e toda consideração e paciência que teve comigo durante o tempo que me restou para concluir o mestrado.

Ao meu professor e orientador, Dr.Edson Cezar Wendland, pela oportunidade e pelo aprendizado que seus ensinamentos me proporcionaram durante esta jornada. Por ter sido paciente para me auxiliar e educar durante a preparação da nossa pesquisa, além de nos unir em um grande grupo de pesquisa e por nos considerar como uma família. Levo o carinho, a saudade e a certeza de que repetiria a dose do mestrado com a sua orientação, agora mais maduro, mais marcado pelo tempo e pelos desafios da pesquisa.

Ao nosso querido técnico, Roberto Bérgamo, por toda a ajuda durante a pesquisa, 
pelo apoio motivacional, principalmente por ter me ajudado mais do que deveria durante a instalação do aparato experimental desta pesquisa. A você, R.Bérgamo, o meu carinho, respeito e toda a consideração pelo seu esforço e comprometimento com o nosso laboratório. Também ao Téu, caseiro da fazenda Monte Alegre, por ter nos auxiliado durante as instalações em campo.

Aos colegas de laboratório pela ajuda e amizade durante o período em que estive presente com eles. Em especial aos colegas que me ajudaram na instalação e preparo (dicas, sugestões, correções) da minha pesquisa: João, Jean, Gabriel, Jamil, Lívia, Andrés, Jaqueline, Davi, Murilo e Camilo.

Aos meus amigos e colegas, que provaram o quanto a companhia, a amizade, pode ser importante em nossa caminhada. Àqueles de infância que o tempo tratou em afastar, mas mesmo longe e em rumos diferentes, a consideração e o respeito prevalecem vivos na memória.

Ao grupo Mano do Céu e ao Beberico de Quem Bebe, pelos bons momentos e pelas risadas que foram capazes de nos proporcionar. Ao Bolete, Brunão, Fissa, Mineiro, Arlan, Nicolas, Presunto e outros não menos importantes, pela boa amizade e convivência durante este processo. É com o coração já cheio de saudade que levo comigo as lembranças desde os primeiros dias de aula neste programa e a esperança em podermos nos reunir no futuro.

Ao meus professores, que participaram da minha formação até à minha graduação. A vocês, o meu carinho e consideração, por esclarecer muitas dúvidas e me ajudarem a alcançar mais uma vitória. Fica o meu respeito e também consideração, ao meu amigo e professor Dr. Welitom Ttatom, pelos conselhos, oportunidades e pelas críticas construtivas durante a graduação. Ao Welitom e ao professor Dr.Aldecy de Almeida, que me ensinaram que a maior retribuição de um pesquisador e educador vai além de uma estabilidade financeira.

Agraço também à CAPES pelo apoio financeiro durante a concessão da bolsa de pesquisa e também à FAPESP pelo custeio dos materiais que foram empregados neste trabalho.

A todos vocês, sou imensamente grato por me ajudar a concluir mais esta etapa da minha vida.

Muito Obrigado! 




\section{Resumo}

\section{ROSA, D.M.S. Interação rio aquífero: Um estudo de caso na Bacia do Ribeirão}

da Onça. 2018.146 p. Dissertação (Mestrado) - Escola de Engenharia de São Carlos, Universidade de São Paulo, São Carlos, 2018.

A informação sobre a interação entre o rio e aquífero está, cada vez mais, sendo reconhecida como a ponto de entendimento relacionado com a disponibilidade hídrica superficial e a contaminação das águas subterrâneas, além de apresentar influência sobre ambientes hiporreicos. A percepção da importância dessa interação, atraiu o foco de diversos pesquisadores, para o tema. Assim, este trabalho teve como objetivo analisar a interação rio aquífero utilizando um balanço de massa do rio e o gradiente de temperatura entre a água do aquífero e do rio como traçador. Foram utilizados dados de vazão do Ribeirão da Onça, dividido em 3 sub-bacias. Para auxiliar neste monitoramento, foi montado um datalogger alternativo, utilizando a plataforma Arduíno, equipado com um sensor de distância ultrassônico. Também foram utilizadas informações de temperatura da base do ribeirão, como traçador, na sub-bacia 2, através de um termômetro e 4 termopares distribuídos em profundidades a cada $10 \mathrm{~cm}$ da base. O datalogger apresentou erro relativo de 3,5\% comparado ao transdutor de pressão utilizado. O melhor ajuste para a recessão do escoamento de base foi a quadrática de Boussinesq indicando um coeficiente de recessão $(\alpha)$ menor para a suba-bacia 3 e maior para a sub-bacia 2 . Além disso, o coeficiente de recessão médio para as áreas foi de 0,00388 $\mathrm{dia}^{-1}$, a espessura saturada média da camada saturada, obtida pela formulação quadrática de Boussinesq foi de $51 \mathrm{~m}$, e a transmissividade média da bacia foi igual a $131 \mathrm{~m}^{2}$. dia $\mathrm{a}^{-1}$. A contribuição de base para as sub-bacias 2 e 3 foram maiores que a da 1 , indicando maiores taxas de recarga nas sub-bacias 2 e do 3. A contribuição superficial e linear do escoamento de base para a sub-bacia 2 foi, em média, de $850 \mathrm{~mm} / d$ e $4 \mathrm{~m}^{3} / \mathrm{m}$.d, respectivamente. A comparação da temperatura da água do aquífero $30 \mathrm{~cm}$ abaixo da base do ribeirão, com a temperatura da base do ribeirão, apresentou uma diferença média de $2{ }^{\circ} \mathrm{C}$, além de revelar que a contribuição do aquífero para o ribeirão não foi uniforme, com alguns pontos em que o ribeirão, possivelmente, contribui para o aquífero. A análise dos hidrogramas obtidos através de um balanço de vazão no ribeirão, e a aplicação do gradiente de temperatura, se mostraram alternativas viáveis para o estudo da interação entre o rio e o aquífero.

Palavras-chave: Balanço de massa. Arduino. Traçador. Coeficiente de recessão. 



\section{Abstract}

ROSA, D.M.S. Stream - aquifer interaction: A study case in the Onça Creek Watershed. 2018.146 p. Dissertação (Mestrado) - Escola de Engenharia de São Carlos, Universidade de São Paulo, São Carlos, 2018.

Information about stream - aquifer interaction is increasly recognized as key to understand process related to surface water avalability, groundwater contamination and its influence on the fauna and flora of hyporeic enviroments. The perception of the importance of this interaction has attracted the focus of several researchers to the theme. Thereby, this work had as objective to analyze the interaction between a river and an aquifer by using both a mass balance and an evaluation of the temperature gradient between the water of the aquifer and the river. Three gaugings stations, installed along the main stream of an upland watershed called Ribeirão da Onça, provided the streamflow data used in this work. To assist in this monitoring, an alternative datalogger was installed, using the Arduino platform, equipped with an ultrasonic distance sensor. Temperature information from the creek base, as a physical tracer, was also used in the intermediaty catchement area, through a thermometer and 4 thermocouples distributed in depths every $10 \mathrm{~cm}$ of the river ground. The ultrassonic sensor presented a relative error of $3.5 \%$, compared to the pressure transducer used. The best fit for the quadratic formulation of Boussinesq indicated that coeficient recession $(\alpha)$ was less for the sub-basin 3 and bigger for subbasin 2 . In addition, the mean recession coefficient for the areas was 0.00388 day $^{-1}$, the mean saturated thickness of the saturated layer, obtained by the quadratic formulation of Boussinesq was $51 \mathrm{~m}$ and the mean transmissivity of the basin was equal to $131 \mathrm{~m}^{2} . d a y^{-1}$. The base contribution to the sub-basins 2 and 3 were bigger than sub-basin 1 showing bigger recharge rates in the sub-basins 2 and 3 . The surface and linear contribution of the baseflow to the sub-basin 2 was on average $850 \mathrm{~mm} / d$ and $4 \mathrm{~m}^{3} / \mathrm{m}$.d, respectively. Comparison of the water temperature of the aquifer $30 \mathrm{~cm}$ below the base of the creek with the temperature of the creek base showed an average gradient of $2{ }^{\circ} \mathrm{C}$ and also showed that the contribution of the aquifer to the creek is not uniform, with some points where the creek possibly contributes to the aquifer. The intergrated analysis of the hydrographs obtained through a flow balance in the stream and of the temperature gradient have proved to be feasible alternatives for the study of the stream aquifer interaction.

Keywords: Mass balance. Arduino. Tracer. Recession coefficient. 



\section{Lista de ilustrações}

Figura 1 - Desenho esquemático do ciclo hidrológico. . . . . . . . . . . . . . . 29

Figura 2 - Volume de controle para uma bacia hidrográfica. . . . . . . . . . . . 31

Figura 3 - Forma e características gerais de um hidrogama. . . . . . . . . . . . . 32

Figura 4 - Componente de velocidade medido por um perfilador acústico. . . . . . 33

Figura 5 - Desenho de um ADCP. . . . . . . . . . . . . . . . 34

Figura 6 - Propagação dos feixes de um ADCP. . . . . . . . . . . . . . . 34

Figura 7 - Calha Parshall para medição de vazão. . . . . . . . . . . . . . . 36

Figura 8 - Linha de energia em um vertedor. . . . . . . . . . . . . . . 39

Figura 9 - Vista frontal de um vertedor triangular. . . . . . . . . . . . . . 39

Figura 10 - Exemplo de caraterística de interação em um rio influente (A), em um rio efluente $(\mathrm{B})$ e em um rio hidraulicamente desconectado $(\mathrm{C})$. Há outro tipo de interação que acontece em eventos chuvosos no qual o nível de água do rio fica maior que o do aquífero e permite um armazenamento marginal (D). . . . . . . . . . . . . . . . . . 40

Figura 11 - Componentes de um hidrograma de um rio. . . . . . . . . . . . . . . . 41

Figura 12 - Modelos conceituais de aquíferos. . . . . . . . . . . . . . . . . . . 42

Figura 13 - Métodos manuais de separação do escoamento de base do escoamento superficial: (a) método da linha reta, (b) método da base fixa, (c) método da inclinação variável. . . . . . . . . . . . . . . . . . . . . . 44 46

Figura 14 - Regressão linear da constante $\alpha$. . . . . . . . . . . . . . . . . . 48

Figura 15 - Exemplo de caraterística de variação da temperatura em um rio efluente (A) e em um rio influente (B). . . . . . . . . . . . . . . . . . . 49

Figura 16 - Variação da temperatura do rio em diferentes estações do ano. . . . . . 50 Figura 17 - Distributed Temperature Sensor (DTS) sendo utilizado no ribeirão da

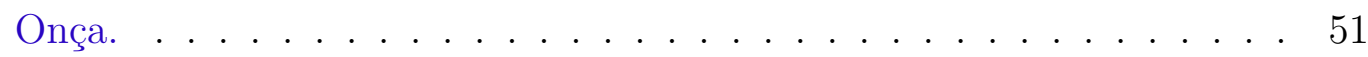

Figura 18 - Arduino Uno . . . . . . . . . . . . . . . . . . . . . 53

Figura 19 - Distribuição do Sistema Aquífero Guarani pela América do Sul. . . . . 57

Figura 20 - Mapa de localização da BRO . . . . . . . . . . . . . . . . . . 58

Figura 21 - Pontos de monitoramento na área de estudo na BRO . . . . . . . . . . 59

Figura 22 - Queda d'água na primeira afluência do ribeirão da Onça, localizado a cerca de 500 metros de distância da calha 1 para a calha 2 . . . . . . . 60

Figura 23 - Vista da sub-bacia 2 após o corte do eucalipto. . . . . . . . . . . . . 60

Figura 24 - Pontos de coleta de solo na bacia do Ribeirão da Onça. . . . . . . . . . 61

Figura 25 - Mapa potenciométrico para a bacia do Ribeirão da Onça. . . . . . . . . . 62

Figura 26 - Localização dos pontos de estudo, do trabalho de Arantes, Marcussi e Chaudhry (2006), na Bacia do Ribeirão da Onça. . . . . . . . . . . . . 63 
Figura 27 - Tipos de usos e ocupação do solo encontrados na bacia do Ribeirão da Onça. . . . . . . . . . . . . . . . . . 64

Figura 28 - Mapa de uso do solo da BRO para 2017. . . . . . . . . . . . . . . 65

Figura 29 - Estação meteorológica instalada na fazenda Monte Alegre . . . . . . . 66

Figura 30 - Principais dimensões do tipo de calha usada no trabalho. (A) perfil; (B) planta. . . . . . . . . . . . . . . . . . 6 67

Figura 31 - Estrutura de suporte para a instalação da calha Parshall. . . . . . . . . 68

Figura 32 - Caixa de ferro utilizada para suspender a calha Parshall. . . . . . . . . 69

Figura 33 - Instalação das calhas Parshall. . . . . . . . . . . . . . . . . . . . 69

Figura $34-A D C P$ SonTek ${ }^{\circledR} I Q$, utilizado no estudo. . . . . . . . . . . . . . . . . . 70

Figura 35 - A) Esquema da seção de medição; B) Foto da seção de medição de vazão. 70

Figura 36 - Desenho da posição da estaca para monitoramento manual e do linígrafo para monitoramento automático no vertedor triangular. . . . . . . . 71

Figura 37 - Instalação do vertedor triangular. . . . . . . . . . . . . . . . . . 72

Figura 38 - ADCP na entrada da calha Parshall, fixado em uma folha galvanizada. 72

Figura 39 - Arduino Pro mini . . . . . . . . . . . . . . . . . . . . . . . . . 74

Figura 40 - Sensor de medição de distância ultrassônico HC-SR04. . . . . . . . . . 75

Figura 41 - Especificações do HC - SR04 . . . . . . . . . . . . . . . . . 75

Figura 42 - Fluxograma linear de funcionamento do sistema de medição de nível elaborado. . . . . . . . . . . . . . . . . . . 75

Figura 43 - Desenho do circuito impresso na placa controladora do medidor de nível. 76

Figura 44 - Tubo de PVC usado na calibração do sensor de nível. . . . . . . . . . . 76

Figura 45 - Esquema da ligação em série do multímetro com o data logger. . . . . . 77

Figura 46 - Data logger e placa solar instalados em campo. . . . . . . . . . . . . . 77

Figura 47 - Estrutura para sustentar o sensor acima da calha. . . . . . . . . . . . 78

Figura 48 - Exemplo da separação do escoamento de base pelo método dos mínimos locais. . . . . . . . . . . . . . . . . . . . 8 81

Figura 49 - Desenho esquemático da contribuição do aquífero para o Ribeirão. . . . 82

Figura 50 - Esquema da seção do leito do Ribeirão da Onça. . . . . . . . . . . . . . 83

Figura 51 - Equipamento para levantamento do gradiente de temperatura no leito do Ribeirão. . . . . . . . . . . . . . . . . . . . . . . . . . . . . . . . . 84

Figura 52 - Trabalho sendo realizado no Ribeirão da Onça. . . . . . . . . . . . . . 84

Figura 53 - Variação da pressão absoluta e da pressão atmosférica nas calhas Parshall. 85

Figura 54 - Variação da pressão absoluta, normalizada, nas calhas Parshall, e da pressão atmosférica. . . . . . . . . . . . . . . . . . 86

Figura 55 - Variação nos níveis d'água medidos nas calhas Parshall 1 e 2. . . . . . 87

Figura 56 - Resultado (Equação e coeficiente de determinação - $R^{2}$ ) da calibração

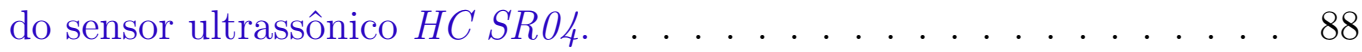

Figura 57 - Pinos oxidados do sensor HC - SR04 . . . . . . . . . . . . 88 
Figura 58 - Comparação das medições realizadas pelo transdutor de pressão (DIVER) e pelo sensor HC - SR04.

Figura 59 - Gráfico da regressão e coeficiente de determinação - $R^{2}$ entre os dados do vertedor e os dados da calha Parshall 1. . . . . . . . . . . . . . . . . 91

Figura 60 - Gráfico da regressão e coeficiente de determinação - $R^{2}$ entre os dados do vertedor e os dados da calha 2. . . . . . . . . . . . . . . . . . 91

Figura 61 - Hidrograma do escoamento superficial para a sub-bacia 1. . . . . . . . 92

Figura 62 - Hidrograma do escoamento superficial para a sub-bacia 2. . . . . . . . 92

Figura 63 - Hidrograma do escoamento superficial para a sub-bacia 3. . . . . . . . 93

Figura 64 - Hidrograma do escoamento superficial e escoamento de base para a sub-bacia 1. . . . . . . . . . . . . . . . . . . . 994

Figura 65 - Hidrograma do escoamento superficial e escoamento de base para a sub-bacia 2. . . . . . . . . . . . . . . . . . . . . . . . . 94 94

Figura 66 - Hidrograma do escoamento superficial e escoamento de base para a sub-bacia 3. . . . . . . . . . . . . . . . . 95

Figura 67 - Contribuição superficial do escoamento de base, diário, na sub-bacia 2, situada na área de estudo. . . . . . . . . . . . . . . . . . . . . . . 96

Figura 68 - Contribuição linear do escoamento de base, diário, na sub-bacia 2, situada na área de estudo. . . . . . . . . . . . . . . . . . . . . . 96

Figura 69 - Ajuste da vazão observada na calha 1 e dos modelos quadrático (Boussinesq) e exponencial (Maillet). . . . . . . . . . . . . . . . . . . . 98

Figura 70 - Ajuste da vazão observada na calha 2 e dos modelos quadrático (Boussinesq) e exponencial (Maillet). . . . . . . . . . . . . . . . . . . . . 98

Figura 71 - Ajuste da vazão observada no ADCP e dos modelos quadrático (Boussinesq) e exponencial (Maillet).

Figura 72 - Variação da temperatura da água do aquífero (poço 16) e do ribeirão da Onça (linígrafo) no período de 2011 a 2017. . . . . . . . . . . . . . . 100

Figura 73 - Gradiente de temperatura no leito do ribeirão da Onça para o trecho entre as calhas $($ sub-bacia 2). . . . . . . . . . . . . . 100

Figura 74 - Escoamento subsuperficial ao longo do trecho entre as calhas Parshall. 101

Figura 75 - Cascalho encontrado na base do ribeirão da Onça. . . . . . . . . . . . . 102

Figura 76 - Logger de temperatura fixado por meio de uma vara de bambu na base arenosa do ribeirão da Onça. . . . . . . . . . . . . . . . . . . . . . . . 102

Figura 77 - Boxplot das temperaturas observadas em campo nos 4 canais. . . . . . 103

Figura 78 - Instalação da calha Parshall 1. . . . . . . . . . . . . . . . . . . . . . . . 119

Figura 79 - Instalação da calha Parshall 2. . . . . . . . . . . . . . . . . . . . . 120

Figura 80 - Impressão do circuito na placa condutora (a)-(e). Datalogger instalado

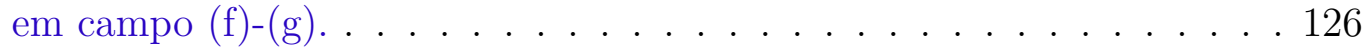





\section{Lista de tabelas}

Tabela 1 - Coeficientes e expoentes para calhas Parshall . . . . . . . . . . . 38

Tabela 2 - Algumas publicações em foram encontrados valores do coeficiente de

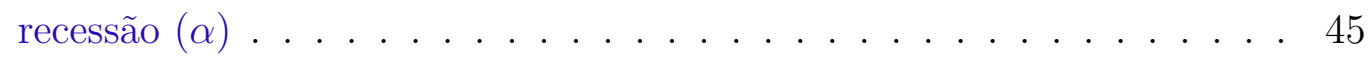

Tabela 3 - Trabalhos acadêmicos sobre a interação rio aquífero utilizando a temperatura como traçador. . . . . . . . . . . . . . . . 52

Tabela 4 - Principais características do modelo UNO R3 . . . . . . . . . 53

Tabela 5 - Área e comprimento das três sub-bacias na área de estudo. . . . . . . . 59

Tabela 6 - Valores de rendimento específico para a bacia do Ribeirão da Onça . . 62

Tabela 7 - Taxa de surgimento em $m m \cdot d^{-1}$ para as três seções de estudo . . . . . 63

Tabela 8 - Porcentagem do uso do solo, para as 3 de seções de monitoramento (Calha 1, Calha 2 e ADCP) para 2017 . . . . . . . . . . . 65

Tabela 9 - Variáveis meteorológicas monitoradas na fazenda Monte Alegre . . . . 67

Tabela 10 - Componentes do data logger . . . . . . . . . . . . . 75

Tabela 11 - Indicadores estatísticos aplicados ao data logger . . . . . . . . . . . . 79

Tabela 12 - Indicadores estatísticos para as pressões absolutas registradas pelo transdutor de pressão nas calhas e para a pressão atmosférica registrada pela estação meteorológica Monte Alegre (EMMA) . . . . . . . . . . . 86

Tabela 13 - Indicadores estatísticos para os dados brutos e corrigidos das calhas 1 e 287

Tabela 14 - Valores dos indicadores estatísticos de operação do sensor HC - SR04 . 90

Tabela 15 - Dados estatísticos do escoamento superficial, expresso em unidade de vazão, para cada sub-bacia . . . . . . . . . . . . . . . 93

Tabela 16 - Contribuição de base para as sub-bacias 1 e 2 e 3 . . . . . . . . . 95

Tabela 17 - Valores dos coeficientes de recessão $(\alpha)$ calculados pelos métodos de Boussinesq e Maillet para cada sub-bacia. . . . . . . . . . . . . . 97 



\section{Lista de abreviaturas e siglas}

$\begin{array}{ll}\text { ADCP } & \text { Perfilador hidroacústico } \\ \text { BFI } & \text { Índice de escoamento de base } \\ \text { BRO } & \text { Bacia do Ribeirão da Onça } \\ \text { CRHEA } & \text { Centro de Recursos Hídricos e Ecologia Aplicada } \\ \text { DTS } & \text { Equipamento para coleta de temperatura distribuída } \\ \text { EMMA } & \text { Estação Meteorológica Monte Alegre } \\ \text { GPS } & \text { Sistema de posicionamento global } \\ \text { HYSEP } & \text { Software de computador para separação e análise para escoamento de } \\ & \text { base } \\ \text { IDE } & \text { Ambiente de programação } \\ \text { LOESS } & \text { Regressão polinomial local ponderada } \\ \text { MDE } & \text { Modelo Digital de Elevação } \\ \text { PCB } & \text { Placa de circuito impresso } \\ \text { SAG } & \text { Sistema Aquífero Guarani } \\ \text { WTF } & \text { Variação do nível do lençol freático }\end{array}$





\section{Lista de símbolos}

$H \quad$ Espessura da camada saturada do aquífero

K Condutividade hidráulica do aquífero

$Q_{b} \quad$ Vazão de base

$Q_{r t} \quad$ Vazão total resultante de cada área

$S_{y} \quad$ Rendimento específico

$V_{b} \quad$ Volume total do escoamento de base 



\section{Sumário}

INTRODUÇÃo $\ldots \ldots \ldots \ldots \ldots \ldots \ldots \ldots$

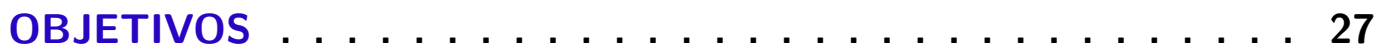

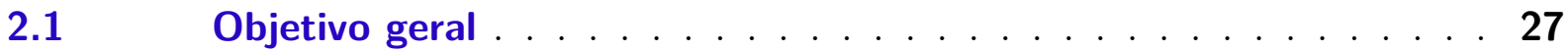

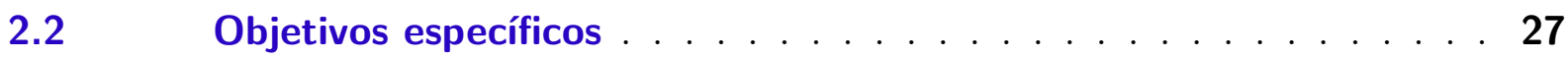

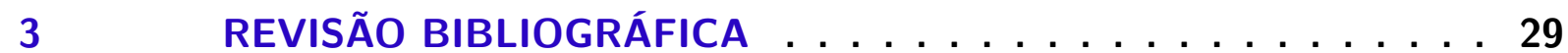

$3.1 \quad$ Ciclo hidrológico $\ldots \ldots \ldots \ldots \ldots$

$3.1 .1 \quad$ Balanço hídrico . . . . . . . . . . . . . . . . . 30

3.1.2 Balanço de massa (hídrico) de um rio . . . . . . . . . . . . . 30

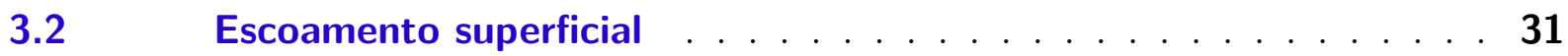

3.2.1 Quantificação do escoamento superficial . . . . . . . . . . . . . . . 32

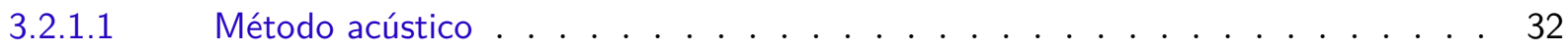

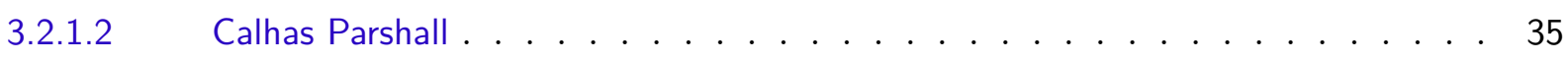

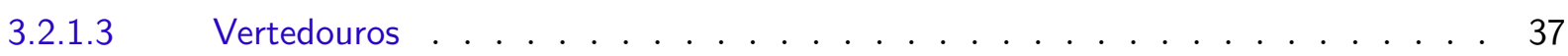

$3.3 \quad$ Escoamento de base . . . . . . . . . . . . . . . . . 39

3.3.1 Recessão do escoamento de base . . . . . . . . . . . . . . . . . . 42

3.3.2 Métodos de separação do escoamento de base . . . . . . . . . . . . . 45

3.4 Uso da temperatura da água do aquífero como traçador . . . . . . . 48

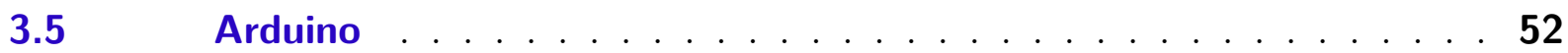

$3.5 .1 \quad$ Circuito Impresso $\ldots \ldots \ldots \ldots \ldots \ldots \ldots$

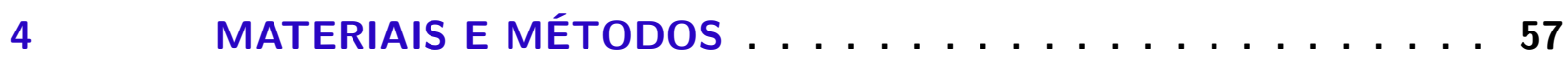

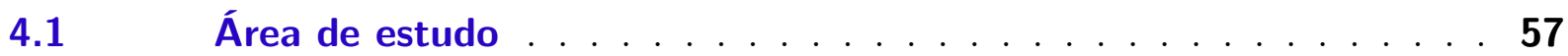

4.1.1 Bacia Hidrográfica do Ribeirão da Onça . . . . . . . . . . . . . 58

$4.1 .2 \quad$ Clima . . . . . . . . . . . . . . . . . . . 61

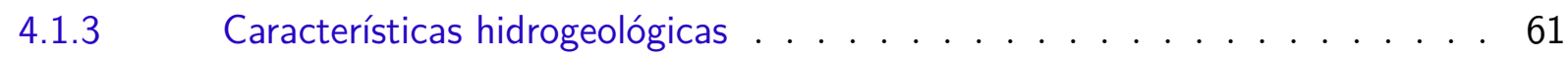

$4.1 .4 \quad$ Uso e ocupação do solo . . . . . . . . . . . . . . . . . . 63

$4.2 \quad$ Período do estudo e coleta dos dados meteorológicos . . . . . . 65

$4.3 \quad$ Instalação dos equipamentos . . . . . . . . . . . . . 67

4.3.1 Calhas Parshall nas sub-bacias 1 (montante) e 2 (jusante) . . . . . . . 67

4.3.2 ADCP na sub-bacia 3 (Seção de medição de vazão da BRO) . . . . . . . . 69

4.3.3 Instalação do vertedor triangular na sub-bacia $2 \ldots \ldots \ldots$

4.4 Validação das medições das calhas Parshall . . . . . . . . . 72

4.5 Monitoramento da vazão do Ribeirão da Onça . . . . . . . . . . 73

4.5.1 Coleta dos dados de níveis d'água nas calhas e no vertedor . . . . . . . . 73 
4.5.1.1 Data logger usando Arduino . . . . . . . . . . . . . . . . . . 74

4.5.1.2 Estatísticas de precisão do HC - SR04 . . . . . . . . . . . . . . . . 79

4.5.2 Cálculo das vazões das sub-bacias . . . . . . . . . . . . . . . . . . . 79

$4.6 \quad$ Análise da interação rio aquífero . . . . . . . . . . . . . . . 80

4.6.1 Identificação dos pontos de interação rio - aquífero . . . . . . . . . . . . 83

5 RESUltAdOS E disCuSSÃO . . . . . . . . . . . . . 85

$5.1 \quad$ Análise do escoamento superficial . . . . . . . . . . . 85

5.1.1 Variação da pressão atmosférica (barométrica) e filtragem - passa baixa . . 85

5.1 .2 Performance do Arduino . . . . . . . . . . . . . . . . . . 87

5.1.3 Preenchimento de falhas de dados do vertedor triangular . . . . . . . . . 90

5.1.4 Vazão do ribeirão na área de estudo . . . . . . . . . . . . . . . . . . . 92

5.2 Variação do escoamento de base entre as áreas de contribuição . . 94

5.2.1 Escoamento de base . . . . . . . . . . . . . . . . . . 94

5.2.2 Coeficiente de recessão . . . . . . . . . . . . . . . . . . . . . 97

5.3 Temperatura como traçador . . . . . . . . . . . . . . . 99

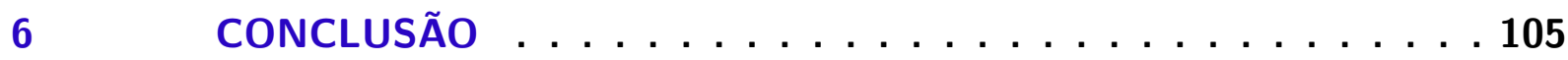

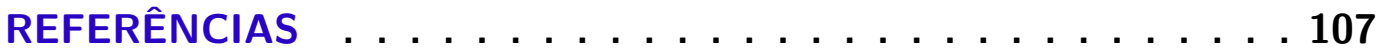

APÊNDICES

APÊNDICE A - IMAGENS DA INSTALAÇÃO DAS CALHAS PARSHALL119

APÊNDICE B - CÓDIGO DO ARDUINO . . . . . . . . . . . 121

APÊNDICE C - IMAGENS DA IMPRESSÃO DO CIRCUITO NA

PLACA CONDUTORA . . . . . . . . . . . 125

ANEXOS

ANEXO A - DATASHEET DO ARDUINO PRO MINI . . . . . . 129 


\section{INTRODUÇÃO}

O escoamento superficial é o componente do ciclo hidrológico caracterizado pelo escoamento da água na superfície do solo. Apesar de apresentar importância singular, não deve ser considerado isolado do escoamento subterrâneo, já que se interagem entre si em diferentes usos do solo e características hidrogeológicas do aquífero (WINTER et al., 1999; SOPHOCLEOUS, 2002).

Isso implica que problemas como deficit hídrico, em sistemas de abastecimento dependentes de águas superficiais, podem estar relacionados com a interação destas fontes com as águas subterrâneas (MILLER et al., 2016). Outro problema que é largamente encontrado é a dificuldade da conservação da qualidade das águas superficiais, que também pode levar à alteração qualidade das águas subterrâneas (TREESE; MEIXNER; HOGAN, 2009).

Além disso, existe a implicação nos processos biológicos que ocorrem no fundo e nas zonas ripárias dos rios, lagos, wetlands e corpos hídricos superficiais em geral. A relação direta dessas áreas com o tipo de interação predominante pode ser justificada pelas transformações químicas e físicas que a água sofre ao se comunicar com o aquífero na zona hiporreica e também pela regularização hídrica que ocorre através dessas interações e permitem a conservação da fauna e da flora nesses ambientes (CARDENAS, 2009; MCCALLUM; ANDERSEN; ACWORTH, 2014).

Outro fator que também têm sido abordado na literatura é a regulação da temperaura das águas superficiais por meio da interação entre o rio e o aquífero. Em regiões de estações bem definidas e de clima temperado, a temperatura da água do aquífero tende a ser menor que das águas superficiais, sendo que em regiões de clima tropical o contrário ocorre (STONESTROM; CONSTANTZ, 2003).

Essa diferença na temperatura destas duas fontes hídricas pode influenciar na comunidade de espécies aquáticas, como algas, macro invertebrados e micro invertebrados. Algumas espécies de insetos e peixes por exemplo dependem de faixas de temperatura ideais para se reproduzirem, e portanto pontos de aquecimento ou resfriamento no fundo destes ambientes aquáticos superficiais (DALLAS, 2008).

Com base no exposto, diversos pesquisadores mudaram o foco de suas pesquisas a partir dos anos 1960 para melhor compreender os mecanismos de troca entre um rio e um aquífero (WINTER, 1995). 
Algumas técnicas podem ser aplicadas para avaliar as relações entre as águas superficiais e as subterrâneas, como: o emprego de traçadores para a estimativa do escoamento de base (BLUMSTOCK et al., 2015), uso de infiltrômetros para medir a taxa de contribuição do aquífero (ARANTES; MARCUSSI; CHAUDHRY, 2006; VERAS et al., 2016), análises do escoamento de base e também do índice de recessão (período sem chuva) (THOMAS; VOGEL; FAMIGLIETTI, 2015) e medidas de temperatura da base do rio (LEE et al., 2013). Todas essas técnicas apresentam vantagens e desvantagens, sendo aconselhável utilizar no mínimo duas para se obter com mais clareza a dimensão da interação avaliada.

Com base no crescente avanço de pesquisas acerca do tema interação rio - aquífero e na necessidade de compreender melhor esse processo, este estudo visa contribuir para a comunidade científica através de uma análise da interação entre um rio efluente e um aquífero livre, situados em uma bacia hidrográfica de uso predominantemente agrícola. 


\section{OBJETIVOS}

\subsection{Objetivo geral}

Analisar a interação entre o rio e o aquífero na bacia hidrográfica por meio do balanço de massa do rio e da utilização do gradiente de temperatura entre a água do aquífero e do rio como traçador.

\subsection{Objetivos específicos}

1. Monitorar o escoamento superficial da área de estudo;

2. Estimar o escoamento de base, a partir do escoamento superficial;

3. Calcular o coeficiente de recessão para cada área de contribuição;

4. Estimar a profundidade média da camada saturada no aquífero livre e a transmissividade da área de estudo;

5. Coletar dados de temperatura do leito do rio, em uma área de contribuição, para identificação dos possíveis locais de interação do aquífero e o rio. 



\section{REVISÃO BIBLIOGRÁFICA}

\subsection{Ciclo hidrológico}

Ciclo hidrológico de uma bacia hidrográfica é um conjunto de processos físicos, alimentados pela energia solar, que transferem a água para diferentes estágios na atmosfera. Este ciclo pode ser considerado fechado se analisado globalmente e com alguns subciclos se observado em escala regional (NARASIMHAN, 2009; COLLISCHONN; DORNELLES, 2015).

Na Figura 1 é apresentado um esquema que descreve os principais processos neste processo, como a : (1) precipitação, (2) escoamento superficial, (3) evapotranspiração (evaporação + transpiração das plantas) e a (4) infiltração.

Figura 1 - Desenho esquemático do ciclo hidrológico.

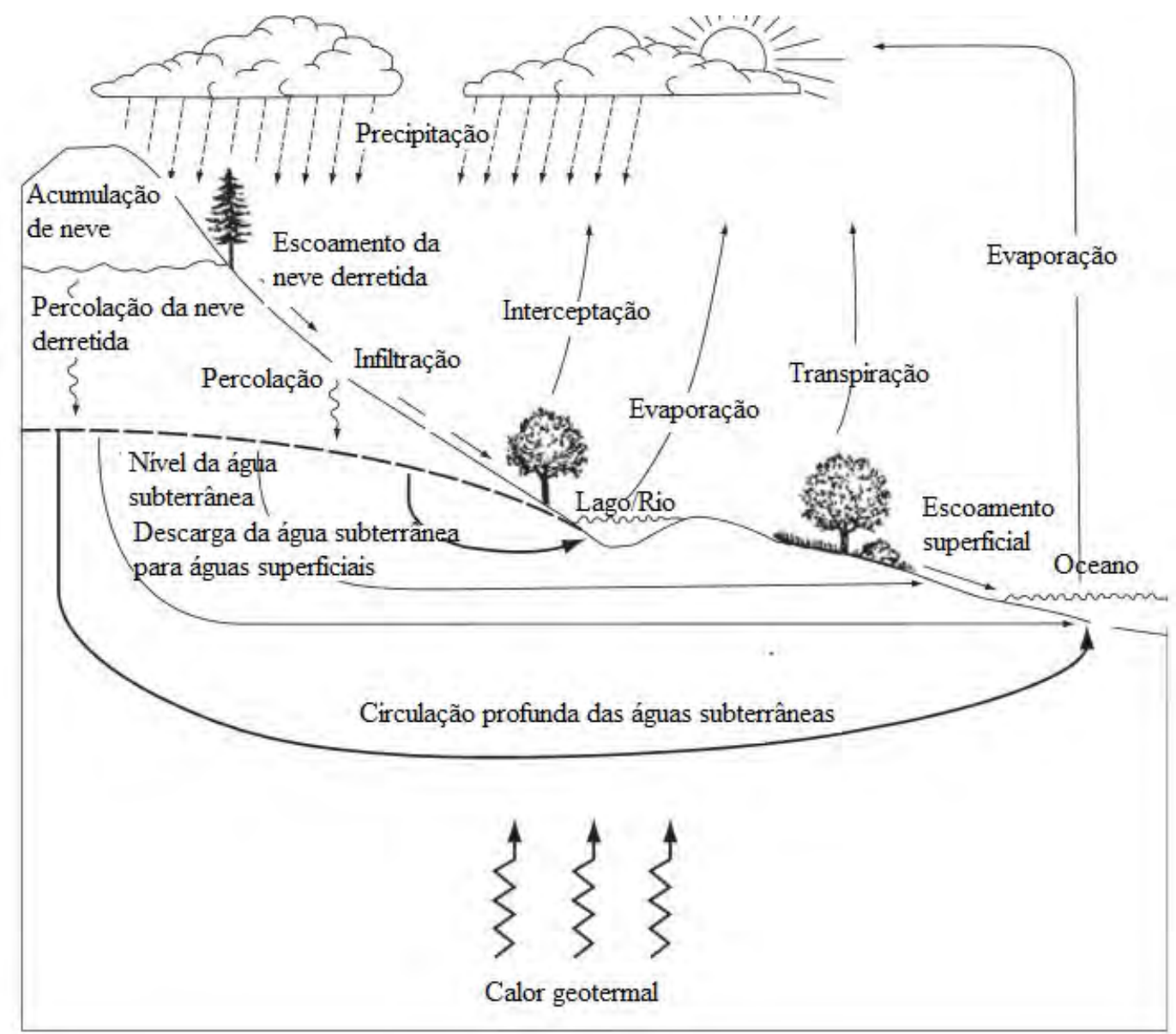

Fonte: Adaptado de Narasimhan (2009). 


\subsubsection{Balanço hídrico}

Como o ciclo hidrológico pode ser considerado um processo fechado, um simples equacionamento pode ser proposto para fazer o balanço de entrada e saída de água na bacia (balanço hídrico). Sendo assim, a Equação 3.1 mostra uma formulação para o balanço hídrico em uma bacia hidrográfica (EAGLESON, 1978).

$$
P_{a}=E T_{a}+R s_{a}+R g_{a}
$$

Em que $P_{a}$ é a precipitação total anual, $E T_{a}$ é a evapotranspiração total anual, $R s_{a}$ o escoamento superficial direto total anual e $R g_{a}$ o escoamento subterrâneo total anual na bacia.

Discretizando a Equação 3.1, outro volume de controle pode ser desenvolvido para uma bacia hidrográfica, o qual é mostrado na Figura 2. Nesta situação a Equação 3.2 pode ser utilizada para representar seu balanço hídrico. Segundo o trabalho desenvolvido por Wendland, Gomes e Troeger (2015), em que foi proposto um volume de controle do aquífero, essa variação do armazenamento pode estar relacionada com a recarga profunda do aquífero.

$$
P_{t}=E T_{t}+E l t+E d t+\Delta s
$$

Em que $P_{t}$ é a precipitação total, $E T_{t}$ a evapotranspiração total, Elt o escoamento lateral total, $E d t$ o escoamento direto total e $\Delta s$ a variação do armazenamento.

A partir da Equação 3.2 percebe-se que o escoamento superficial é a soma do componente rápido do escoamento (Runoff) e do escoamento lateral, ou a contribuição do aquífero para o rio. Assim, é possível determinar por exemplo a quantidade de água que infiltrou e passou a contribuir para o rio e a variação do armazenamento, a partir do monitoramento da precipitação, do cálculo da estimativa da evapotranspiração e do monitoramento do escoamento superficial direto.

\subsubsection{Balanço de massa (hídrico) de um rio}

A partir do modelo de balanço hídrico proposto por Lerner, D.N.;Issar, A.S.;Simmers (1992), foi desenvolvida no trabalho de Mccallum, Andersen e Acworth (2014) uma equação de balanço de massa de um rio (Equação 3.3).

$$
Q_{u}+Q_{i}+Q_{f}=Q_{d}+Q_{o}+E_{a}+\frac{\Delta S}{\Delta t}
$$

Em que $Q_{u}$ é o escoamento de montante, $Q_{i}$ é o escoamento de tributários, $Q_{f}$ é a contribuição do aquífero, $Q_{d}$ é o escoamento de jusante, $Q_{o}$ é o escoamento relacionado à 
Figura 2 - Volume de controle para uma bacia hidrográfica.

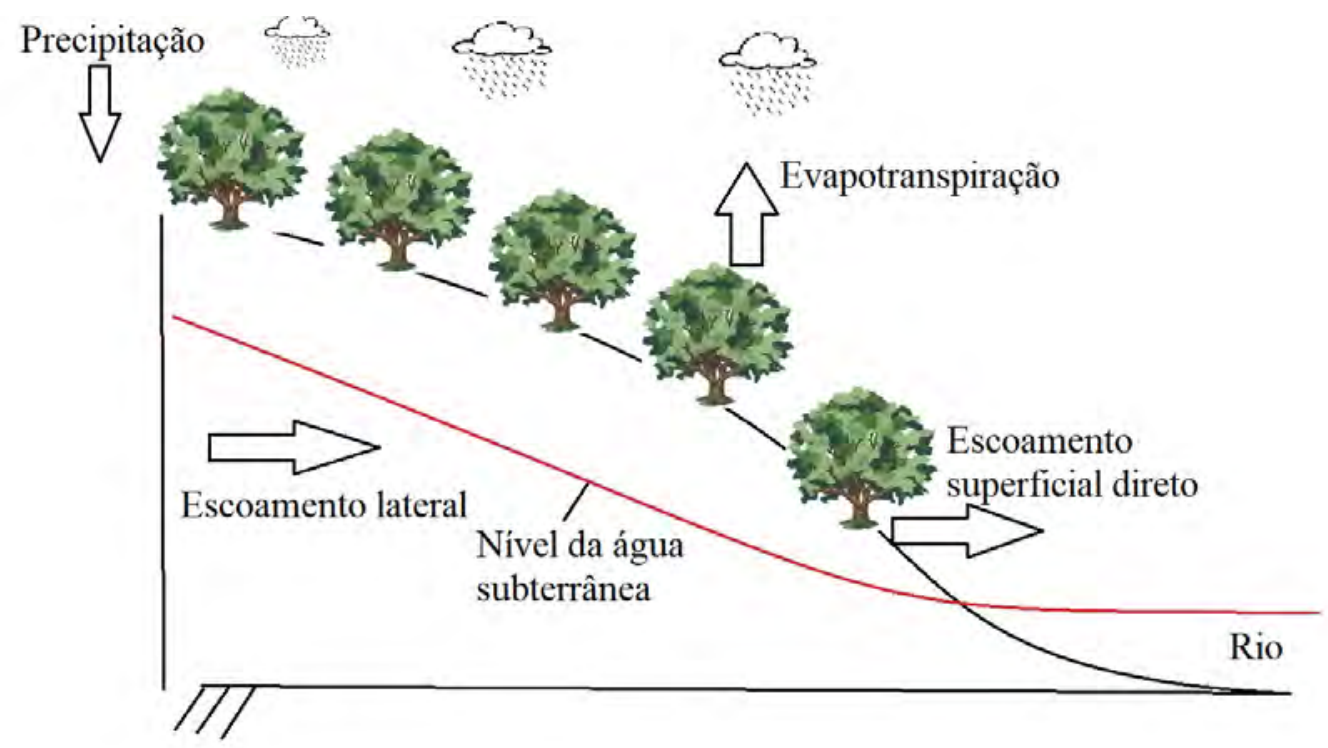

Fonte: Elaborado pelo autor.

efluências, $E_{a}$ é a evaporação do rio e $\frac{\Delta S}{\Delta t}$ é a variação de armazenamento do canal. Todos os componentes do balanço de massa do rio têm a seguinte dimensão $\left(L^{3} \cdot T^{-1}\right)$.

Para longos períodos de tempo e em rios onde possuem grandes taxas de escoamento, o $\frac{\Delta S}{\Delta t}$ e o $E_{a}$ podem ser desconsiderados, simplificando a equação para :

$$
Q_{u}+Q_{i}+Q_{f}=Q_{d}+Q_{o}
$$

\subsection{Escoamento superficial}

O escoamento superficial pode ser definido como a quantidade de água presente no ciclo hidrológico, que escoa sobre a superficíe do solo. Em uma bacia hidrográfica, esse escoamento pode ser representado por um gráfico de descarga em função do tempo, o qual é denominado de hidrograma, como pode ser visto na Figura 3 (CHOW; MAIDMENT; MAYS, 1988; LINSLEY; KOHLER; PAULHUS, 1949).

Ao observar a Figura 3, é possível observar o ponto "A", que é o ponto de inflexão da curva do hidrograma, em razão de um evento de chuva, "B"o pico da vazão ou vazão máxima do hidrograma, onde ocorre a máxima vazão para o evento, "C"o ponto de inicial de inflexão descendente, que representa o início da queda da vazão em razão de períodos sem chuva e "D"o ponto final da inflexão descendente, representando o início do processo.

O hidrogama do escoamento superficial de uma bacia é composto por dois tipos de 
Figura 3 - Forma e características gerais de um hidrogama.

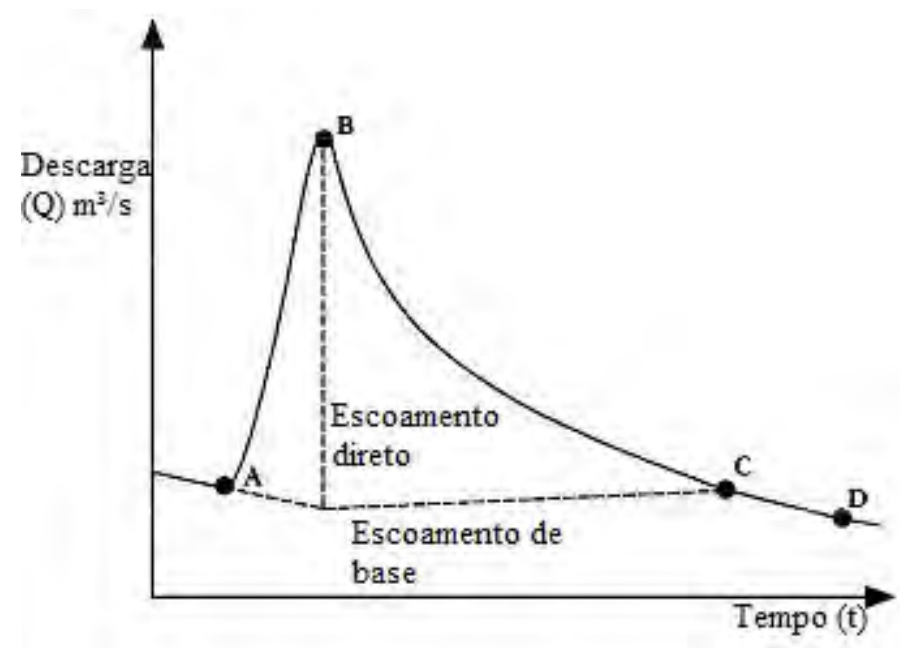

Fonte: Adaptado de Linsley, Kohler e Paulhus (1949).

escoamento principais: (1) escoamento superficial direto ou rápido, que segundo Sophocleous (2002) é a parcela originada da chuva que não infiltra no solo e segue em direção ao rio e (2) o escoamento de base ou escoamento lento, o qual Hall (1968), Griffiths e Clausen (1997), Smakhtin (2001) definem como a contribuição de outras fontes como: aquífero, wetlands, lagos e derretimento de neve, para o escoamento do rio.

\subsubsection{Quantificação do escoamento superficial}

Diversos métodos são apresentados na literatura para o monitoramento de vazão, e são classificados em estruturais ou não-estruturais (PAIVA; PAIVA, 2001).

Métodos não estruturais como o método acústico e estruturais como vertedouro e seções de controle (e.g.calhas Parshall), podem ser encontrados no estudo desenvolvido por Maldonado (2009).

\subsubsection{Método acústico}

Esse método foi desenvolvido para medir velocidades em correntes marítimas, sendo possível medir velocidades a grandes profundidades (MALDONADO, 2009).

O princípio de funcionamento deste método é oriundo do efeito Doppler, descoberto por Christian Johann em 1842. Esse efeito pode ser descrito de forma prática quando há uma diferença de um sinal (som) emitido por um objeto em movimento em um meio propagador e o sinal recebido por um observador estático. Ribeiro (1999) descreve a relação matemática que representa a velocidade do meio propagador, conforme a Equação 3.5: 


$$
V=\frac{\Delta f * C_{t}}{2 f_{o} \cos \theta}
$$

Em que, $V$ é a velocidade do meio propagador, $\Delta f$ é a diferença entre a frequência transmitida e a recebida, $f_{o}$ é a frequência de transmissão, $\theta$ é o ângulo do cristal transmissor e receptor com relação à direção de propagação do fluido e $C_{t}$ é a velocidade do som no transdutor. A Figura 4 apresenta um esquema com o ângulo $\theta$.

Figura 4 - Componente de velocidade medido por um perfilador acústico.

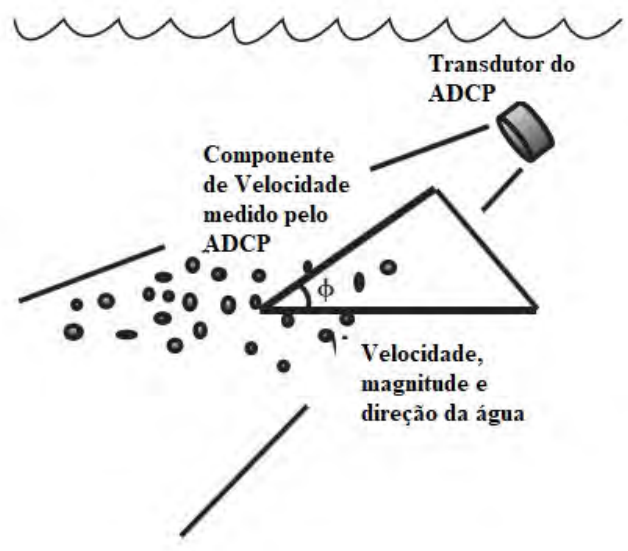

Fonte: Adaptado de Simpson (2001).

O ADCP (acoustic Doppler current profilers), equipamento que utiliza este método, possui porcelanas piezoelétricas que emitem ondas acústicas de altas frequências, sob o nível d'água na direção do leito do escoamento. Esse equipamento tem sido utilizado na literatura para medir velocidades em ambientes oceânicos e em rios (STACEY; MONISMITH; BURAU, 1999; CHRISTENSEN; HERRICK, 1982).

Para medir velocidades nas três componentes dimensionais, um típico ADCP transmite e recebe sinais por meio de três transdutores distribuídos em uma configuração conhecida com Janus, sendo posicionados horizontalmente em torno de um círculo a cada $120^{\circ}$, conforme a Figura 5. O dispositivo começa a receber o eco vindo de diferentes tempos de atraso de sucessivos volumes ao longo do feixe para determinar quanto do sinal transmitido pelo equipamento foi desviado e assim determinar a velocidade do meio propagador. Geralmente um quarto transdutor é empregado no equipamento para identificar e corrigir erros de processamento e não homogeneidade do escoamento. Um exemplo deste processo pode ser observado na Figura 6

Estes equipamentos podem possuir frequências pré-estabelecidas de 300 a 5000 $\mathrm{KHz}$, sendo que quanto maior a frequência, maior será a capacidade de medir a velocidade em pequenas profundidades (MALDONADO, 2009). 
Figura 5 - Desenho de um ADCP.

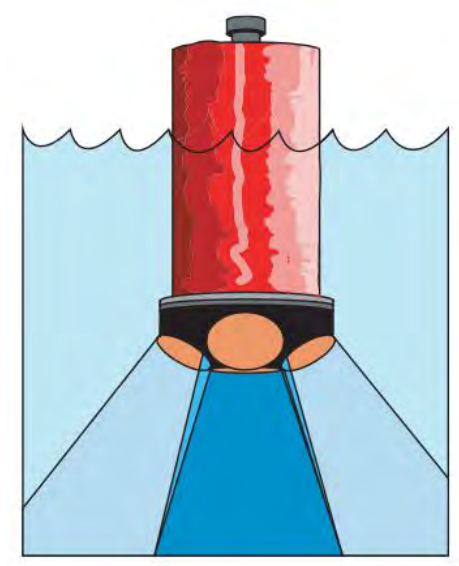

Fonte: Simpson (2001).

Figura 6 - Propagação dos feixes de um ADCP.

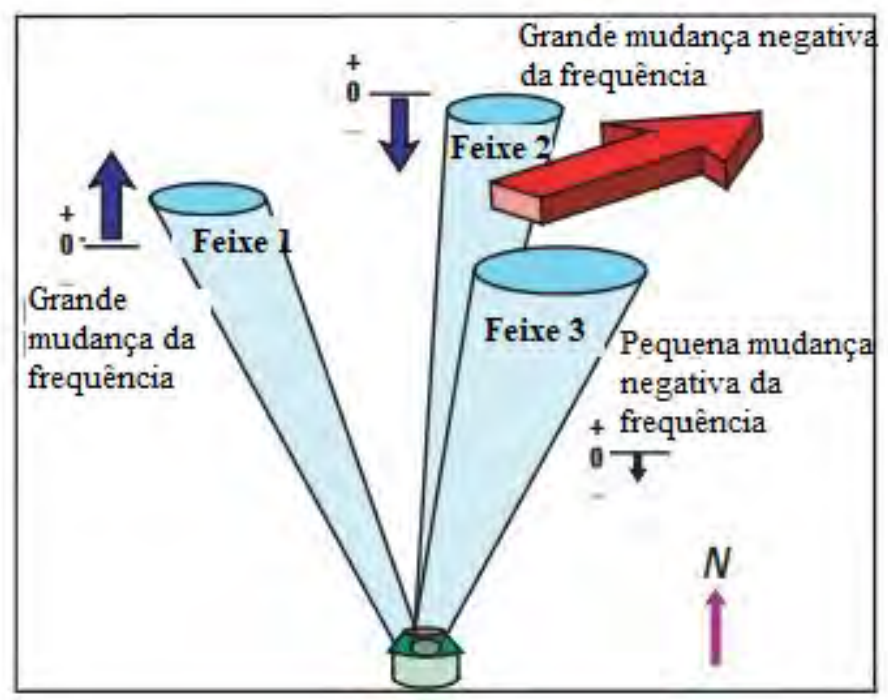

Fonte: Adaptado de Simpson (2001).

Para estimar a vazão do rio, o ADCP precisa ser movimentado, geralmente por meio de um barco, de margem a margem, processo conhecido como travessia. A velocidade de deslocamento do equipamento é calculada por meio de um Sistema de Posicionamento Global Diferencial (DGPS), em que o GPS transmite em tempo real (a cada segundo), por meio de satélites, a posição do equipamento (SIMPSON, 2001). 


\subsubsection{Calhas Parshall}

A calha Parshall é uma estrutura hidráulica que provoca a alteração do regime de escoamento da água (de subcrítico para supercrítico) e permite que a velocidade crítica de escoamento seja calculada em função da altura da lâmina de água de montante. Sendo assim, elas se baseiam no princípio da conservação da energia (CHOW, 1959).

Segundo Parshall (1950) a calha Parshall consiste em uma seção convergente, a garganta e uma seção divergente, podendo operar em duas condições distintas de escoamento (livre e submerso). No escoamento livre a vazão é depedente apenas da alura da lâmina de água da seção de estrangulamento (garganta) e da profundidade da lâmina à montante. Já no escoamento submerso a vazão depende também da altura da lâmina na seção de estrangulamento, uma vez que o volume à jusante da calha influencia no escoamento de montante. Nesse caso, a relação entre $H_{b}$ e $H_{a}$, que representa o escoamento submerso, é, geralmente, maior ou igual a 0,6, sendo que esta razão limite de transição para a submergência varia de acordo com a largura da garganta da calha (SKOGERBOE et al., 1966).

Para calcular a vazão nesta condição Skogerboe et al. (1967) descreveu a Equação 3.6 baseada no balanço de momento do volume de controle de montante e de jusante da calha Parshall.

$$
Q(c f s)=\frac{c_{1}\left(H_{a}-H_{b}\right)^{n_{1}}}{\left[-\left(\log \frac{H_{b}}{H_{a}}+c_{2}\right)\right]^{n_{2}}}
$$

Em que, Q (cfs) é a vazão em pés cúbicos por segundo, $c_{1}, c_{2}, n_{1}$ e $n_{2}$, constantes adimensionais, em função da dimensão da garganta da calha, $H_{a}$ a profundidade, em pés, do nível de água na seção convergente da calha e $H_{b}$, a profundidade, em pés, do nível de água na garganta da calha.

Na Figura 7 é possível ver, o ${ }^{1}$ ponto que R.L. Parshall definiu para a medição do nível de água à montante (cerca de $2 / 3$ de $\mathrm{C}$ ).

As equações a seguir mostram a dedução da Equação 3.18 que representam a vazão na calha Parshall:

$$
\begin{gathered}
E=y+\frac{q^{2}}{2 q y^{2}} \\
q=\frac{Q}{b}
\end{gathered}
$$

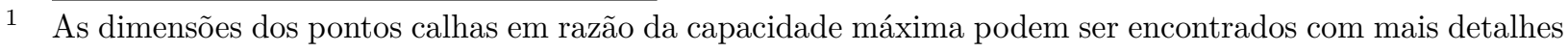
na pág. 15 do trabalho de Skogerboe et al. (1967). 
Figura 7 - Calha Parshall para medição de vazão.
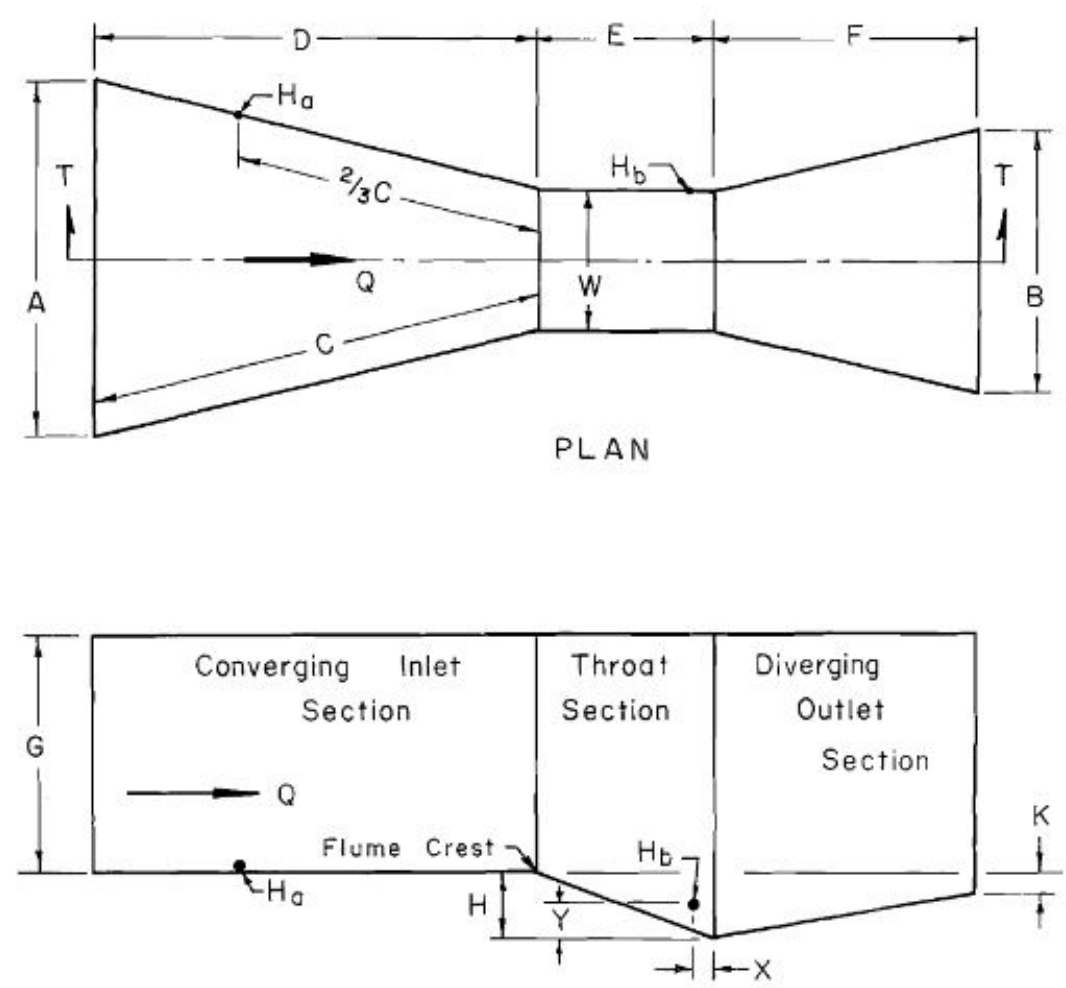

Fonte: Skogerboe et al. (1967).

$$
E_{1}+\triangle z=E_{2}+\triangle z
$$

Na Equação 3.9 E1 é a energia específica na posição de montante e E2 é a energia especifica no início da garganta da calha.

$$
\begin{gathered}
E c=\frac{3}{2} y c \\
y 1+\frac{\left(\frac{Q}{b 1}\right)^{2}}{\left(2 g y_{1}^{2}\right)}=\frac{3}{2} y c
\end{gathered}
$$

Reorganizando a Equação 3.11, temos que:

$$
\frac{2}{3}\left(y 1+\frac{\left(\frac{Q}{b 1}\right)^{2}}{\left(2 g y_{1}^{2}\right)}\right)=y c
$$

Sabendo-se que $\mathrm{Q}=$ vyb e $\mathrm{v}_{\mathrm{c}}=\sqrt{\left(g y_{c}\right)}$ na profundidade crítica, pode-se então usar estas relações para solucionar a vazão Q: 


$$
\begin{gathered}
Q=b_{2} \sqrt{g}\left(\frac{2}{3}\left(y_{1}+\frac{\left(\frac{Q}{b 1}\right)^{2}}{2 g y_{1}^{2}}\right)\right)^{\frac{3}{2}} \\
\frac{\left(\frac{Q}{b_{1}}\right)^{2}}{2 g y_{1}^{2}}=\frac{v^{2}}{2 g} \\
E_{1}=y_{1}+\frac{v 2}{2 g}
\end{gathered}
$$

Uma vez que $y_{1} \gg \frac{v^{2}}{2 g}$ pode-se então supor que:

$$
Q \approx b_{2} \sqrt{g}\left(\frac{2}{3} y_{1}\right)^{\frac{3}{2}}
$$

A Q em $\left(\mathrm{m}^{3} / \mathrm{s}\right)$ pode ser expressa pela Equação 3.17 abaixo.

$$
\begin{gathered}
Q \approx 1,704\left(b_{2}\right) y_{1}^{\frac{3}{2}} \\
Q=c H_{a}^{n_{1}}
\end{gathered}
$$

No trabalho de Skogerboe et al. (1967) é apresentada uma tabela com os valores de coeficiente e expoentes, calibrados em laboratório, para a Equação 3.18, como pode ser visto na Tabela 1. Estes valores utilizados na Equação 3.18, com $H_{a}$ dado em pés (fts) determinam a vazão em pés cúbicos por segundo $(c f s)$.

\subsubsection{Vertedouros}

Vertedouros ou vertedores, podem ser definidos como orifícios de grandes dimensões sem a aresta superior que são instalados perpendicularmente à direção do fluxo da água. Esse obstáculo é o responsável por elevar o nível da lâmina até o ponto de descarga (crista), sendo que a altura da elevação é proporcional à energia contida no escoamento. Os tipos mais utilizados de vertedores são os retangulares e os triangulares de parede fina (PORTO, 2006).

Para os vertedores a dedução do funcionamento é similar ao das calhas, já que se baseiam no princípio da conservação da energia. Desta forma, a equação de Bernoulli pode ser escrita para um ponto em montante e outro para a crista do vertedor Equação 3.19. A Figura 8 mostra uma situação de descarga por um vertedor.

$$
\begin{gathered}
h_{t}=h+\frac{v_{u}^{2}}{2 g}=C h_{t}+h_{l}+\frac{v_{v}^{2}}{2 g} \\
V_{v}=\sqrt{2 g} \sqrt{h_{t}(1-C)-h_{l}}
\end{gathered}
$$


Tabela 1 - Coeficientes e expoentes para calhas Parshall

\begin{tabular}{|c|c|c|c|c|c|c|}
\hline $\mathbf{W}$ & $\mathrm{C}$ & C1 & $\mathrm{C} 2$ & n1 & $\mathrm{n} 2$ & St \\
\hline 1" & 0.338 & 0.299 & 0.0044 & 1.55 & 1 & 0.56 \\
\hline $2^{\prime \prime}$ & 0.676 & 0.612 & 0.0044 & 1.55 & 1 & 0.61 \\
\hline $3^{\prime \prime}$ & 0.992 & 0.915 & 0.0044 & 1.55 & 1 & 0.64 \\
\hline 6" & 2.06 & 1.66 & 0.0044 & 1.58 & 1.08 & 0.55 \\
\hline 9" & 3.07 & 2.51 & 0.0044 & 1.53 & 1.06 & 0.63 \\
\hline $12^{\prime \prime}$ & 4 & 3.11 & 0.0044 & 1.52 & 1.08 & 0.62 \\
\hline $18^{\prime \prime}$ & 6 & 4.42 & 0.0044 & 1.54 & 1.115 & 0.64 \\
\hline $24 "$ & 8 & 5.94 & 0.0044 & 1.55 & 1.14 & 0.66 \\
\hline 30" & 10 & 7.22 & 0.0044 & 1.555 & 1.15 & 0.67 \\
\hline $3^{\prime}$ & 12 & 8.6 & 0.0044 & 1.56 & 1.16 & 0.68 \\
\hline $4^{\prime}$ & 16 & 11.1 & 0.0044 & 1.57 & 1.185 & 0.7 \\
\hline 5 & 20 & 13.55 & 0.0044 & 1.58 & 1.205 & 0.72 \\
\hline 6 & 24 & 15.85 & 0.0044 & 1.59 & 1.23 & 0.74 \\
\hline $7^{\prime}$ & 28 & 18.15 & 0.0044 & 1.6 & 1.25 & 0.76 \\
\hline $8^{\prime}$ & 32 & 20.4 & 0.0044 & 1.6 & 1.26 & 0.78 \\
\hline $10^{\prime}$ & 40.13 & 24.79 & 0.0044 & 1.59 & 1.275 & 0.8 \\
\hline 12 & 47.5 & 29.34 & 0.0044 & 1.59 & 1.275 & 0.8 \\
\hline 15 & 58.56 & 36.17 & 0.0044 & 1.59 & 1.275 & 0.8 \\
\hline $20^{\prime}$ & 77 & 47.56 & 0.0044 & 1.59 & 1.275 & 0.8 \\
\hline 25 & 95.44 & 58.95 & 0.0044 & 1.59 & 1.275 & 0.8 \\
\hline $30^{\prime}$ & 113.88 & 70.34 & 0.0044 & 1.59 & 1.275 & 0.8 \\
\hline $40^{\prime}$ & 150.75 & 93.11 & 0.0044 & 1.59 & 1.275 & 0.8 \\
\hline $50 '$ & 187.63 & 115.85 & 0.0044 & 1.59 & 1.275 & 0.8 \\
\hline
\end{tabular}

Fonte: Skogerboe et al. (1967).

$$
V_{v} \approx C^{\prime} \sqrt{2 g h_{t}}
$$

Pela lei da continuidade $Q=A_{v} V_{v}$.

$$
\begin{gathered}
Q=C_{c} A C^{\prime} \sqrt{2 g h_{t}} \\
Q=C_{d} A \sqrt{h_{t}}
\end{gathered}
$$

Na Equação $3.23 C_{d}$ é o coeficiente de descarga e a a área. Analisando a Figura 9 Porto (2006) descreve a Equação 3.23 como sendo igual a Equação 3.24 para o vertedor triangular. Um tipo de vertedor triangular é o que apresenta um $\alpha$ de abertura de $90^{\circ}$, sendo classificado como modelo Thomson com altura dada em $m$ e descarga dada pela Equação $3.25 \mathrm{em} \mathrm{m}^{3} / \mathrm{s}$.

$$
Q=\frac{8}{15} C_{d} \sqrt{2 g \tan (\alpha / 2) h^{\frac{5}{2}}}
$$


Figura 8 - Linha de energia em um vertedor.

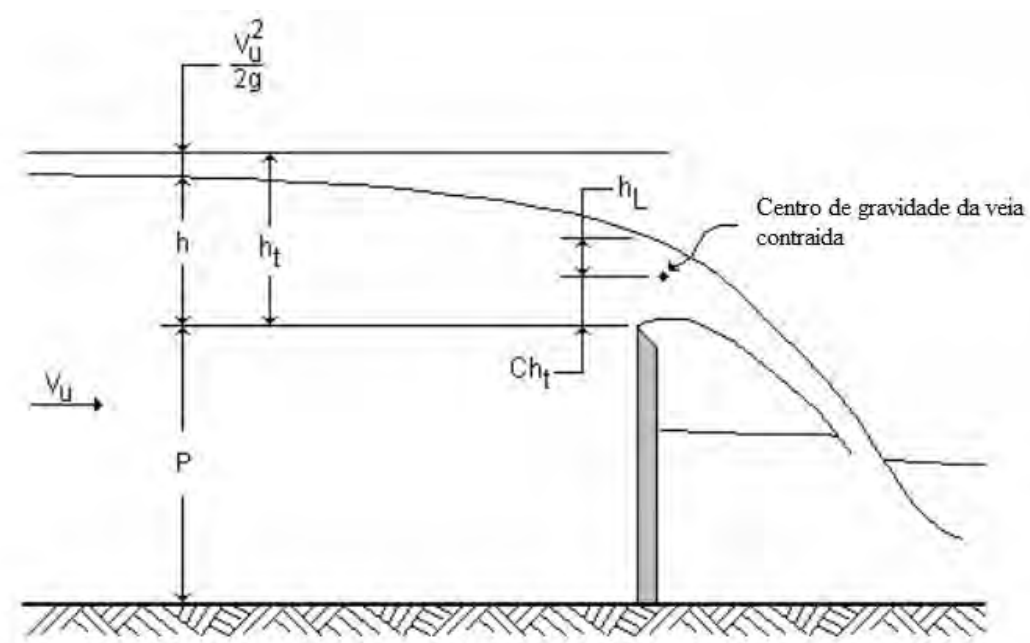

Fonte: Elaborado pelo autor.

Figura 9 - Vista frontal de um vertedor triangular.

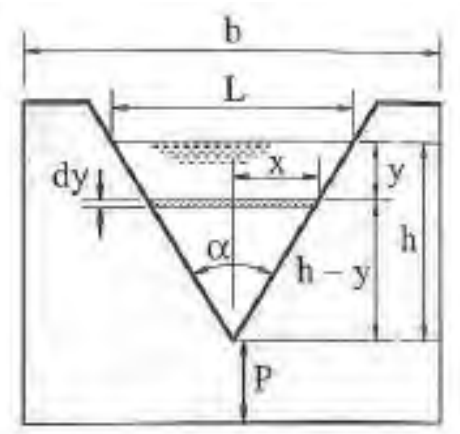

Fonte: Porto (2006).

$$
Q=1,40 h^{\frac{5}{2}}
$$

\subsection{Escoamento de base}

Escoamento de base é a porção do fluxo que é oriunda do escoamento da água subterrânea e de fontes de reserva (seção 3.2). Esta parcela d'água é a responsável por manter o escoamento superficial ativo durante períodos secos (sem chuva), em rios perenes. Isso ocorre em razão da conexão hidráulica entre as águas subterrâneas e as águas superficiais em um processo conhecido como interação rio - aquífero, na zona hiporreica (situada centímetros abaixo da base do rio) (WINTER et al., 1999). A Figura 10 apresenta 
um exemplo dos quatro principais tipos de interação rio - aquífero.

Figura 10 - Exemplo de caraterística de interação em um rio influente (A), em um rio efluente (B) e em um rio hidraulicamente desconectado (C). Há outro tipo de interação que acontece em eventos chuvosos no qual o nível de água do rio fica maior que o do aquífero e permite um armazenamento marginal (D).

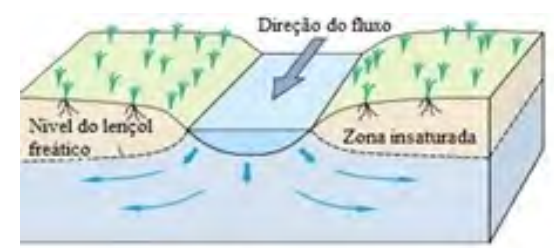

(A)

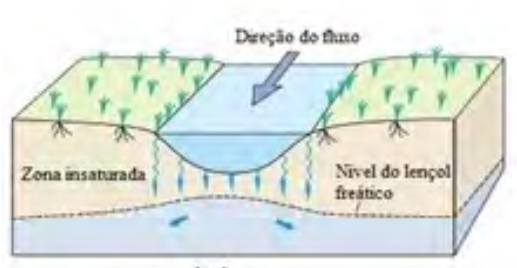

(C)

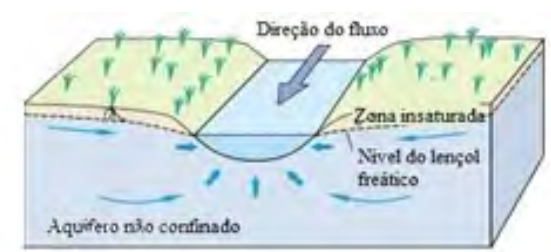

(B)

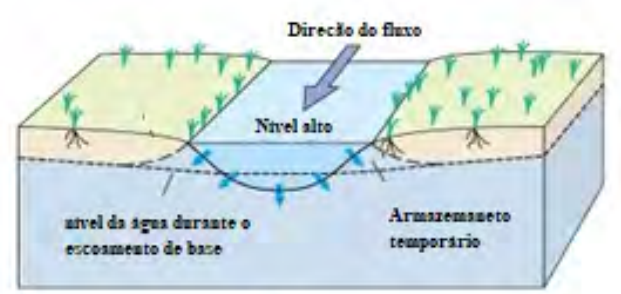

(D)

Fonte: Modificado de Winter et al. (1999).

Na Figura 10 é possível perceber que em alguns rios (efluente), o aquífero contribui para o escoamento superficial, parcela conhecida como escoamento de base e em outros o rio (influente) contribui para o aquífero. Há também um caso que pode ocorrer logo após períodos de chuva, em que o nível d'água do rio fica relativamente maior que a do aquífero proporcionando uma inversão do sentido de fluxo e criando armazenamentos marginais. Beven (1989) define estes armazenamentos marginais, denominados de escoamento subsuperficial ou interflúvio, como a quantidade de água que flui do rio para a margem em resposta a um grande evento chuvoso. A Figura 74 apresenta o escoamento subsuperficial em um hidrograma gerado de um rio.

As direções em que o aquífero interage com o rio foram classificada por Larkin e Sharp (1992), as quais podem ser: componente de fluxo dominado (underflow-component dominated) em que o escoamento da água subterrânea ocorre paralelamente ao rio e na mesma direção, ou componente de escoamento de base dominado (baseflow component dominated), em que esse escoamento ocorre perpendicularmente ao rio. Há também a situação em que o sistema é misto, isto é, quando escoa tanto paralelamente, quanto perpendicularmente.

A interação entre o rio e o aquífero ocorre devido a diferentes fatores como o gradiente hidráulico no aquífero, a condutividade hidráulica e a condição de precipitação 
Figura 11 - Componentes de um hidrograma de um rio.

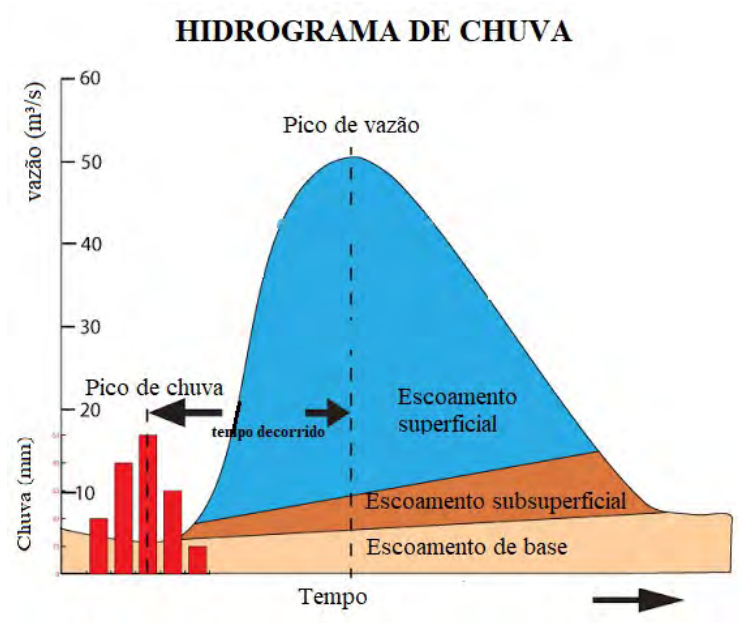

Fonte: Elaborado pelo autor.

(como agente de recarga dos aquíferos) (SOPHOCLEOUS, 2002). Sendo assim é possível a partir de uma análise do escoamento de base, estimar o valor das variáveis que controlam a descarga do aquífero no rio.

O mecanismo que controla a descarga do aquífero no rio é baseado na lei de Darcy. Com isso a descarga pode ser quantificada pelo produto entre o coeficiente de drenagem do fundo do rio (i.e. relação da condutividade hidráulica, na base do rio, com a espessura do aquífero), e o gradiente hidráulico entre o rio e o nível d'água no aquífero como mostra a Equação 3.26 (RUSHTON; TOMLINSON, 1979).

$$
q=k \Delta h
$$

$\mathrm{Na}$ qual q é o escoamento entre o rio e o aquífero, k é o coeficiente de drenagem do fundo do rio e $\Delta h$ é a diferença de carga hidráulica entre o rio e o aquífero.

Outra relação, também proposta por Rushton e Tomlinson (1979), melhora a representação dessa descarga, como mostra a Equação 3.2\%, em que é feita a combinação entre a expressão linear, apresentada na Equação 3.26, e uma expressão não linear. Nessa equação, $k_{1}, k_{2}$ e $k_{3}$ são constantes.

$$
q=k_{1} \Delta h+k_{2}\left[\exp \left(k_{3} \Delta h\right)\right]
$$

Esse método foi aplicado por Wendland, Barreto e Gomes (2007) na bacia do Ribeirão da Onça, situada em uma zona de afloramento do Sistema Aquífero Guarani (SAG), o qual encontrou os valores $0.0143,2.26$ e -8.2819 para $k_{1}, k_{2}$ e $k_{3}$ respectivamente. 


\subsubsection{Recessão do escoamento de base}

A caracterização hidrogeológica do aquífero pode ser realizada a partir da análise da forma da recessão do escoamento de base (caracterizado no período de estiagem). Dewandel et al. (2003) apresentaram uma revisão dos métodos disponíveis na literatura para análise da recessão de hidrogramas. Dois dos métodos são os mais utilizados, sendo um deles proposto por Boussinesq (1877) e Maillet (1905), formulação exponencial, (Equação 3.28; Figura Figura 12 (a)) e o outro de Boussinesq (1903), com formulação quadrática, (Equação 3.29; Figura Figura 12(b)).

Figura 12 - Modelos conceituais de aquíferos.

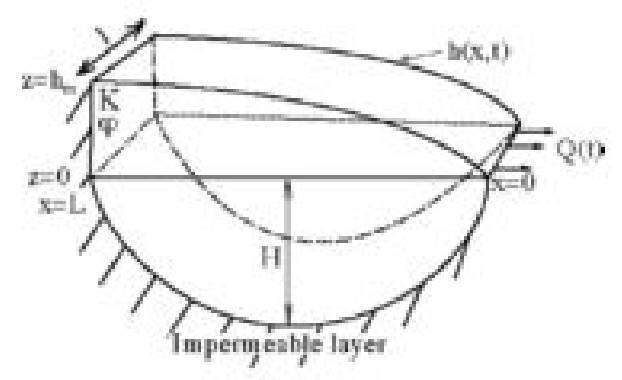

(a) Proposto por Boussinesq (1877). Fonte: Modificado de Dewandel et al. (2003).

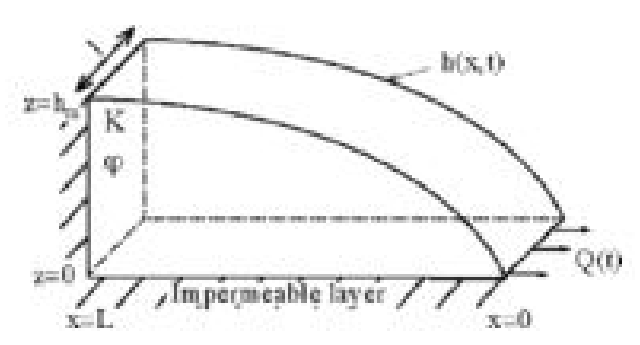

(b) Proposto por Boussinesq (1903). Fonte: Modificado de Dewandel et al. (2003).

$$
\begin{gathered}
Q_{t}=Q_{0} e^{-\alpha t} \\
Q_{t}=\frac{Q_{0}}{(1+\alpha t)^{2}}
\end{gathered}
$$

Em que $Q_{t}$ é a vazão no tempo t, $Q_{0}$ é a vazão no início da recessão, $\alpha$ é o coeficiente de recessão e t é o tempo em dias desde o início da recessão.

A formulação exponencial ajusta melhor as recessões em que a componente de escoamento vertical é mais importante enquanto que na quadrática a horizontal é mais importante que a componente vertical, o que permite avaliar o tipo de anisotropia do aquífero (DEWANDEL et al., 2003).

O coeficiente de recessão pode ser calculado utilizando uma correlação linear, na qual são plotados dados de vazão, no período de estiagem (decrescente), de um dia (Qn) em função da vazão em um intervalo de t dias antes (Qn-t). As curvas geradas tendem a uma reta de recessão à medida que a vazão diminui. Feito isso, calcula-se a constante de recessão k (coeficiente linear da correlação), conforme a Equação 3.30 (LANGBEIN, 1938).

$$
k={\frac{Q_{n}}{Q_{n-t}}}^{\frac{1}{t}}
$$


Sabendo pela (Equação 3.28) que:

$$
Q_{t}=Q_{0} k^{t}
$$

E que:

$$
k=e^{-a}
$$

Pode-se então calcular o $\alpha$ pela Equação 3.33.

$$
\alpha=\frac{-\log k}{0,4343}
$$

O coeficiente de recessão é uma função da condutividade hidráulica $K\left(m\right.$.dia $\left.{ }^{-1}\right)$, da espessura da camada saturada do aquífero $b(\mathrm{~m})$, do rendimento específico $S_{y}$ e da distância da drenagem do divisor de água $L(\mathrm{~m})$, como mostra a Equação 3.34 (BOUSSINESQ, 1877).

$$
\alpha=\frac{\pi^{2} K b}{4 S_{y} L^{2}}
$$

Outra formulação para o coeficiente de recessão foi proposta por Boussinesq (1903), como pode ser visto na Equação 3.35, obtida pelo ajuste quadrático (Equação 3.29).

$$
\alpha=\frac{1,115 K b}{S_{y} L^{2}}
$$

Além dessas propriedades do aquífero, apresentadas na Equação 3.34, outras também podem ser determinadas pelo coeficiente de recessão, como a transmissividade $T$ e a difusidade D (COSTA; ALMEIDA; BACELLAR, 2010). A Equação 3.36 apresenta o cálculo dessas duas variáveis $(T$ e $D)$.

$$
D=\frac{T}{S_{y}}=\frac{4 L^{2} \alpha}{\pi^{2}}
$$

Em que, $T$ é a transmissividade do aquífero $\left(m^{2} \cdot d i a^{-1}\right)$ e $D$ é a difusidade $\left(m^{2} \cdot d i a^{-1}\right)$.

O escoamento de base também pode ser utilizado como um indicador da recarga do aquífero (RORABAUGH, 1964; RUTLEDGE, 1997; HEALY, 2010). Apesar do escoamento de base ser um indicador de recarga, assumindo que toda a água que alcança o lençol freático descarrega para o aquífero, alguns autores, concluíram que as estimativas de recarga utilizando esse método tende a subestimar a recarga quando comparados com 
outros métodos como a WTF (variação do lençol freático) (MAU; WINTER, 1997; LUCAS, 2013). Essa diferença das estimativas de recarga pode ser justificada pela água utilizada na evapotranspiração da zona ripária e na recarga de aquíferos mais profundos (RUTLEDGE; DANIEL, 1994; MAU; WINTER, 1997).

O escoamento de base também pode ser empregado no índice de escoamento de base (BFI - Base Flow Index). Esse índice é um valor adimensional calculado a partir da razão entre o volume total de escoamento de base, escoado no rio, e o volume total de água escoado no rio (SMAKHTIN, 2001).

A seguir são descritos alguns estudos que estimaram o coeficiente de recessão $\alpha$ em aquíferos com diferentes características:

- Em uma bacia de uso agrícola da cidade de Mabegondo (Nordeste da Espanha), Rodriguez Suarez et al. (2014) desenvolveram um estudo dos efeitos, no escoamento superficial, devido ao florestamento por Eucalyptos globulus. Para isso, um modelo hidrológico Hydrologiska Byråns Vattenbalansavdelning (HBV), foi utilizado para calibrar a simulação do escoamento para a área com o cultivo de eucalipto, e em seguida, simular o escoamento superficial para o cenário anterior ao florestamento. Foi necessário calcular alguns parâmetros para o modelo, dentre eles o $\alpha$ que foi de 0,034 $\mathrm{dia}^{-1}$ e também a constante de recessão $k$, igual a $0,81 \mathrm{dia}^{-1}$.

- Schmidt et al. (2014) caracterizaram e modelaram o escoamento em condutos de aquíferos cársticos, na nascente Auja (vale do rio Jordão - Israel). O aquífero em que foi realizado o estudo começou a ser formado no período cretáceo e possui cerca de $800 m$ de profundidade de carbonato. Além disso a nascente, descrita no estudo, é perene, com escoamento médio de $0,3 \mathrm{~m}^{3} \mathrm{~s}^{-1}$. O valor de $\alpha$ foi de $0,004 \mathrm{dia}^{-1}$ para a matriz fraturada.

- Outro estudo também foi realizado em um aquífero cárstico no Sudeste da China. Nesse estudo, Fu, Chen e Wang (2016) separaram alguns eventos de precipitação e observaram as curvas de recessão, nas quais foram encontrados valores de 0,0158 a $0,151 h^{-1}$ para o coeficiente de recessão.

- Lyon et al. (2015) utilizaram um modelo hidrológico para descrever as variações estacionárias e regionais do escoamento de rios em toda a bacia de drenagem do mar Báltico. Utilizando os dados de vazão observados na área de estudo, foi possível calibrar os parâmetros do modelo, entre eles o coeficiente de recessão do escoamento de base, que ficaram compreendidos no intervalo de $1,9 x 10^{-3}$ a $8,7 x 10^{-3} \mathrm{dia}^{-1}$.

- No Brasil, Costa, Almeida e Bacellar (2010), usando a análise do escoamento de base, caracterizaram a hidrogeologia de nove micro bacias, localizadas no Quadrilátero Ferrífero (Estado de Minas Gerais), e estruturadas em rochas ígneas e metamórficas. 
Para estimar a transmissividade e a difusividade das áreas foi necessário calcular o $\alpha$, o qual apresentou valores entre $3,34 x 10^{-3}$ a $4,1 x 1.4^{-2} \mathrm{dia}^{-1}$.

- Também no Brasil, Ledesma (2016) realizou um estudo, no qual avaliou as relações do escoamento de base com as características hidrogeológicas no rio Gravataí (Estado do Rio Grande do Sul), localizado em um aquífero fraturado confinado. Para uma sub-bacia (Passo de Canoas) da área de estudo, o valor de $\alpha$, calculado por meio do Software ${ }^{2}$ Recession of groundwater discharge (RECESS), foi de 0,0285 dia $^{-1}$ e de 0,0134 $\mathrm{dia}^{-1}$ para o método de Maillet e 0,0099 $\mathrm{dia}^{-1}$ para o método proposto por Boussinesq (1903).

A Tabela 2 apresenta um resumo dos valores do coeficiente de recessão encontrados nos trabalhos supracitados.

Tabela 2 - Algumas publicações em foram encontrados valores do coeficiente de recessão $(\alpha)$

\begin{tabular}{ccc}
\hline Autor & Local & $\alpha$ \\
\hline Rodriguez Suarez et al. (2014) & Nordeste da Espanha & 0,034 \\
Schmidt et al. (2014) & Nascente Auja , rio Jordão & (Israel) \\
Lyon et al. (2015) & Bacia de drenagem do mar & 0,004 \\
Fu, Chen e Wang (2016) & Báltico & $0,0019-0,0087$ \\
& Sudeste da China & $0,0158-0,151$ \\
Costa, Almeida e Bacellar (2010) & Quadrliátero Ferrífero & \\
& Estado de Minas Gerais & $0,00334-0,014$ \\
Ledesma (2016) & (Brasil) & \\
& Gravataí, Estado do Rio & 0,0134 \\
\hline
\end{tabular}

Fonte: Elaborado pelo autor.

\subsubsection{Métodos de separação do escoamento de base}

Existem alguns métodos para separar o escoamento de base do escoamento total (Hidrograma) do rio. Esses métodos podem ser manuais, por meio de separação gráfica, ou analíticos, utilizando equações empíricas para identificar o tipo de escoamento, ou químicos, com o uso de traçadores.

Segundo Chow, Maidment e Mays (1988) há três métodos manuais (Figura 13) para separação do escoamento direto e do escoamento de base, sendo eles:

2 Disponível em: <https://water.usgs.gov/ogw/recess/>. 
- Método da linha reta (a): representa o traçado de uma linha horizontal a partir do ponto que apresenta o início do escoamento rápido até a intersecção com a curva de decaimento;

- Método da base fixa (b): esse método assume que o escoamento rápido ou direto termina em um tempo fixo $\mathrm{N}$ após o pico do hidrograma. A curva de recessão antecedente (escoamento de base antes do início do escoamento superficial direto, ou escoamento rápido) é extrapolada até a linha vertical perpendicular ao pico. Em seguida, uma linha reta é usada para conectar esta extrapolação até o ponto da curva de recessão correspondente ao final do escoamento rápido;

- Método da inclinação variável (c): a curva de recessão antecedente é extrapolada à frente do pico, e a curva de recessão, após a ocorrência do escoamento direto, é extrapolada para trás, até o ponto de inflexão. Após isso conectam-se os pontos por um linha reta.

Figura 13 - Métodos manuais de separação do escoamento de base do escoamento superficial: (a) método da linha reta, (b) método da base fixa, (c) método da inclinação variável.

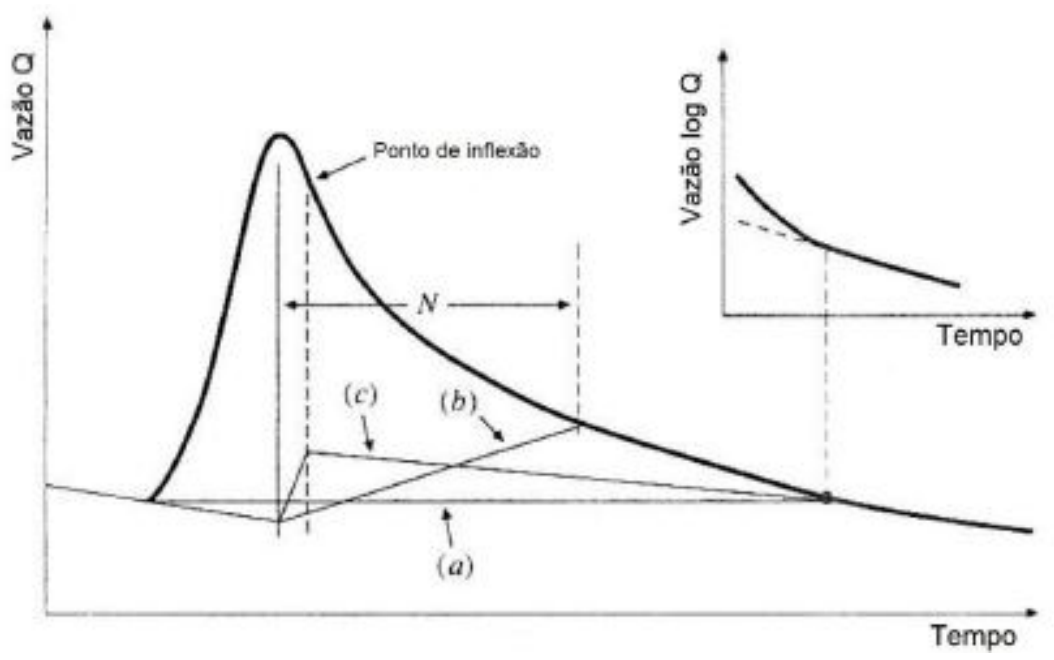

Fonte: Modificado de Chow, Maidment e Mays (1988).

Para calcular o tempo fixo N proposto no método da base fixa, Linsley, Kohler e Paulhus (1949) formularam uma equação empírica, como mostra a Equação 3.37, na qual $\mathrm{N}$ é o tempo decorrido entre o pico do hidrograma e o término do escoamento rápido, e A é a área da bacia em $\mathrm{km}^{2}$. O método da base fixa, que utiliza o tempo fixo $\mathrm{N}$, pode ser encontrado no ${ }^{3}$ Software HYSEP, desenvolvido por Sloto e Crouse (1996). 


$$
N=0,83 A^{0,2}
$$

Os métodos analíticos são mais eficazes na aplicação das técnicas de separação porque eliminam o grau de subjetividade dos métodos manuais. No trabalho de Lyne e Hollick (1979) foi proposto um filtro digital recursivo para realizar essa separação, como pode ser visto na Equação 3.38, em que $Q_{i}^{\text {filt }}$ é o escoamento rápido filtrado em um instante i, $\beta$ é o parâmetro do filtro e $Q_{i}$ é a vazão total no instante i. De acordo com Nathan e McMahon (1990), o melhor ajuste do parâmetro $\beta$ assumiu o valor de 0,925.

$$
Q_{i}^{f i l t}=\beta Q_{i-1}^{f i l t}+\frac{(1+\beta)\left(Q_{i}-Q_{i-1}\right)}{2}
$$

O escoamento de base no instante i é calculado pela subtração entre $Q_{i}^{f i l t}$ e $Q_{i}$, sendo que Nathan e McMahon (1990) recomendam que a equação seja aplicada em triplicata para se obter resultados mais confiáveis.

Eckhardt (2005) propôs uma adaptação nesse filtro digital, como pode ser visto na Equação 3.39. Nessa equação, $b_{t}$ é o escoamento de base no instante $t, b_{t-1}$ o escoamento de base no instante t-1 e $k$ a constante da recessão do escoamento de base em $d i i^{-1}$.

$$
b_{t}=\frac{\left(1-B F I_{\max }\right) k b_{t-1}+(1-k) B F I_{\max } Q_{t}}{1-k B F I_{\max }}
$$

Para rios perenes em aquíferos porosos, o valor recomendado para $B F I_{\text {max }}$ é de 0,8 enquanto que para rios efêmeros em aquíferos porosos é de 0,5. Esses valores podem ser calibrados para diferentes situações em conjunto com traçadores químicos (ECKHARDT, 2005).

O valor de $k$ pode ser encontrado por meio de uma regressão linear entre o escoamento total do ribeirão no instante t com o escoamento total do ribeirão no instante t+1 como mostra a Figura 14 (ECKHARDT, 2008).

Os filtros recursivos digitais citados acima, podem ser encontrados no ${ }^{4}$ Software Web - based Hydrograph Analysis Tool (WHAT).

Há ainda o método químico para estimar a contribuição de base em um rio, que utiliza traçadores isotópicos químicos. A identificação do escoamento de base em um hidrograma se dá pelo balanço de massa dos isótopos em cada componente do hidrograma, sendo que o escoamento rápido, ou direto, apresenta uma idade menor e, portanto, menor decaimento da massa original de isótopos do que o do escoamento de base (RAO et al., 2015; GARCÍA, 2016).

4 Está disponível no seguinte endereço eletrônico: < https://engineering.purdue.edu/mapserve/WHAT/> 
Figura 14 - Regressão linear da constante $\alpha$.

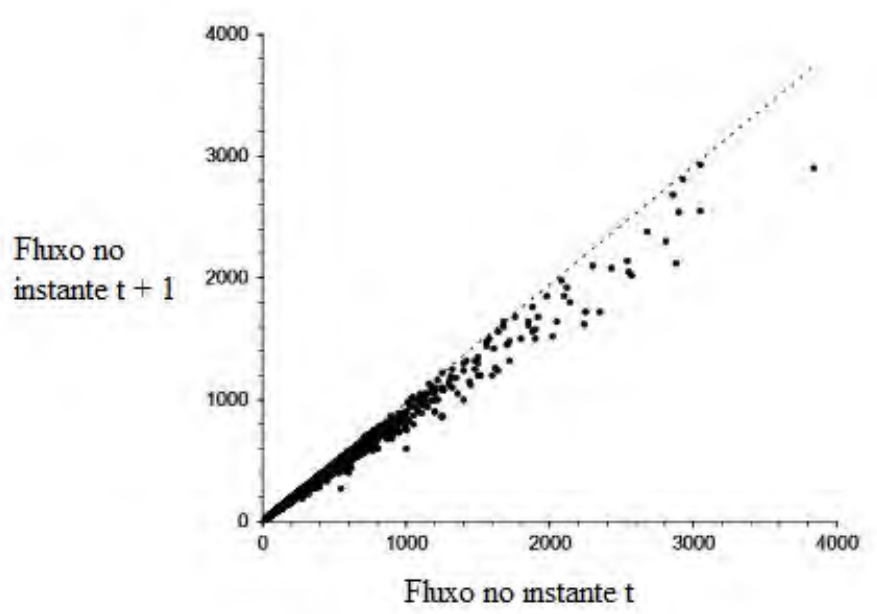

Fonte: Adaptado de Eckhardt (2008).

\subsection{Uso da temperatura da água do aquífero como traçador}

O calor contido na água do aquífero é um traçador que pode ser usado para identificar pontos de ganho e perda entre a água superficial e o aquífero (LAPHAM, 1989; ANDERSON, 2005; CONSTANTZ, 2008; BECK; GARVEN; STEGENA, 2013). Em algumas situações, a variação sazonal da temperatura das águas superficiais pode ser abrupta o suficiente para distingui-la da água contida no aquífero, uma vez que a variação dessa última é mais suave.

Estudos sobre esse traçador começaram a ser desenvolvidos no começo dos anos 90 com Bouyoucos (1915), o qual analisou o transporte de calor através de sedimentos e outros materiais porosos. Anos depois outros hidrogeologistas, Rorabaugh (1954), e Stallman (1965), começaram a explorar a possibilidade de utilizar medidas de temperatura para estimar a taxa de transporte de água entre a superfície e maiores profundidades.

O princípio dessa técnica consiste na transferência de calor entre dois meios com temperaturas diferentes. Essa transferência ocorre por dois processos físicos: a convecção (transferência de calor em fluídos por movimento ascendente e descendente) e a advecção (transferência de calor em fluídos por movimento horizontal).

A simplicidade das medições da temperatura torna esse método economicamente mais viável e prático, comparado com os traçadores químicos, já que a temperatura é um traçador natural e demanda apenas coletas em campo com termômetros ao invés de análises laboratoriais (STONESTROM; CONSTANTZ, 2003; ANDERSON, 2005; LOWRY et al., 2007). 
Com a diferença de calor (representada pela diferença de temperatura) entre as águas subterrâneas (aquíferos) e as superficiais (rios) é possível estimar a intensidade da interação, o sentido de fluxo d'água e algumas características do meio poroso do aquífero, (condutividade hidráulica, por exemplo). Para isso é necessário coletar dados de variação de nível de água no rio e em piezômetros próximos ao rio, e também informações de temperatura na base do rio e nos piezômetros próximos ao rio.

Um exemplo do uso desse traçador pode ser observado na Figura 15, em que se apresenta duas situações de interação rio-aquífero, uma em que o rio é efluente Figura $15 \mathrm{~A}$ e outra em que é influente Figura 15B. Em rios onde há a contribuição do aquífero, a temperatura da zona hiporreica sofre uma variação diária de temperatura menor que a da água do rio, o que representa uma forte relação de ganho. Como a água superficial está mais exposta à radiação solar e à variação da temperatura do ar, durante o dia sua amplitude da variação térmica é maior que da água do aquífero. Por outro lado, em rios que contribuem para o aquífero, a temperatura da zona hiporreica e da água superficial apresentam amplitudes similares, ou seja, praticamente variam da mesma forma.

Figura 15 - Exemplo de caraterística de variação da temperatura em um rio efluente (A) e em um rio influente (B).
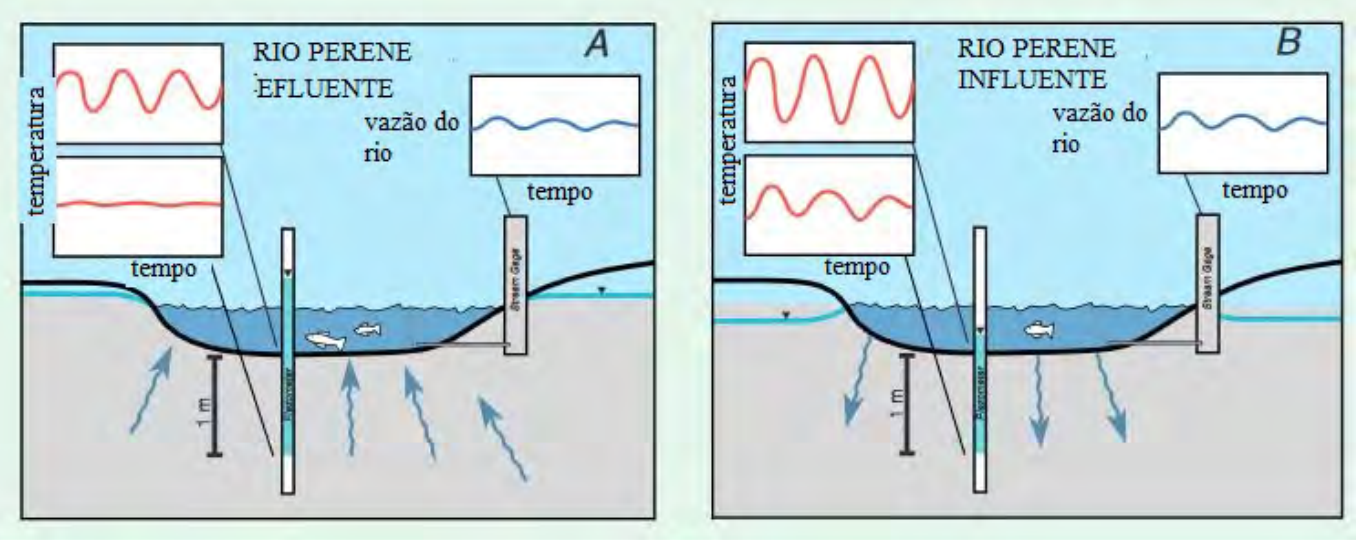

Fonte: Modificado de Stonestrom e Constantz (2003).

Diferentes estudos são encontrados na literatura utilizando essa ferramenta como um indicador das características da interação entre o rio e o aquífero, como o de Bartolino (2002), que comparou informações de temperatura e nível d'água nos piezômetros com os da base do rio Grande, no Novo México. Além desse, outros trabalhos foram desenvolvidos para diferentes finalidades como: identificar e quantificar a infiltração de água subterrânea Briggs et al. (2012), Swanson e Cardenas (2010), traçar os padrões de fluxo de água subterrânea Fanelli e Lautz (2008), Bastola e Peterson (2016), estimar a condutividade hidráulica da base do rio Su et al. (2004). 
A Figura 16 apresenta um exemplo de variação de temperatura da zona hiporreica e do rio, em campo, apresentado no trabalho de Bastola e Peterson (2016).

Figura 16 - Variação da temperatura do rio em diferentes estações do ano.
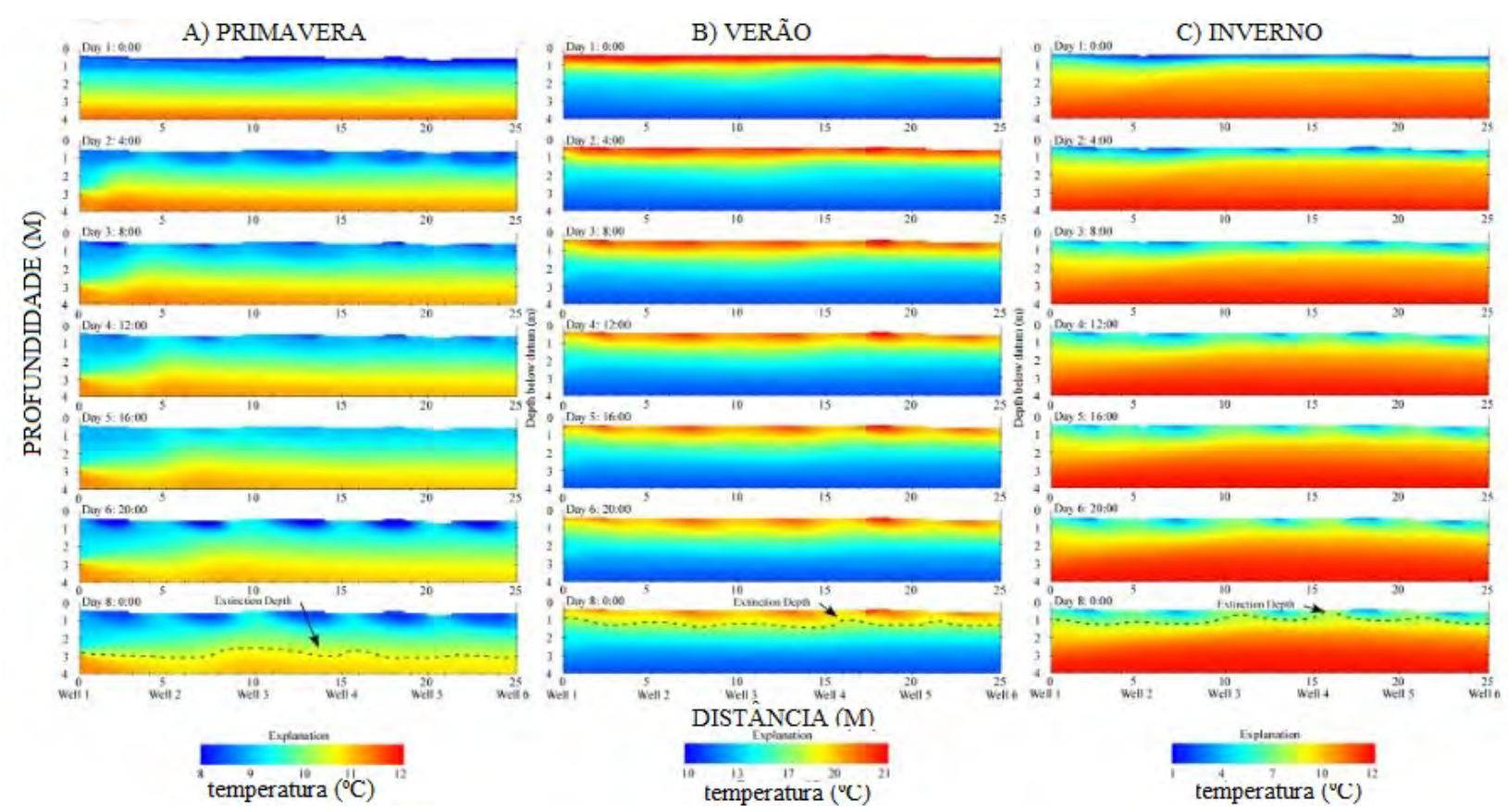

Fonte: Modificado de Bastola e Peterson (2016).

Na Figura 16 é possível perceber que no verão a temperatura na superfície é maior que em contas mais profundas. Isso pode apontar a existência da contribuição do aquífero para o rio. Já no inverno, a temperatura do ar é menor que a da água do aquífero, porém há ocorrência de temperaturas mais elevadas a partir de uma profundidade de $\sim 2 m$, indicando que as condições de interação permanecem praticamente similares, caracterizando um rio rio efluente.

A coleta de dados de temperatura da base do rio pode ser realizada por meio de sensores de temperatura,instalados no fundo do rio, conectados a loggers, ou por meio de um equipamento conhecido como DTS (Distributed Temperature Sensing), que permite um melhor monitoramento espacial e temporal. A Figura 17 apresenta um DTS sendo utilizado em campo.

O DTS se baseia na dispersão da luz por meio de um cabo de fibra ótica para determinar a temperatura. A luz laser é transmitida através da fibra e variações ao longo da fibra causam alterações na retrodispersão, provocando diferenças no comprimento de onda e na intensidade do laser. A luz transmitida, por sua vez, viaja pela fibra com altos comprimentos de onda (Stokes) e baixos (anti-Stokes), sendo que apenas esse último sofre interferência devido à variação da temperatura. Desta forma, por meio da taxa entre os 
Figura 17 - Distributed Temperature Sensor (DTS) sendo utilizado no ribeirão da Onça.

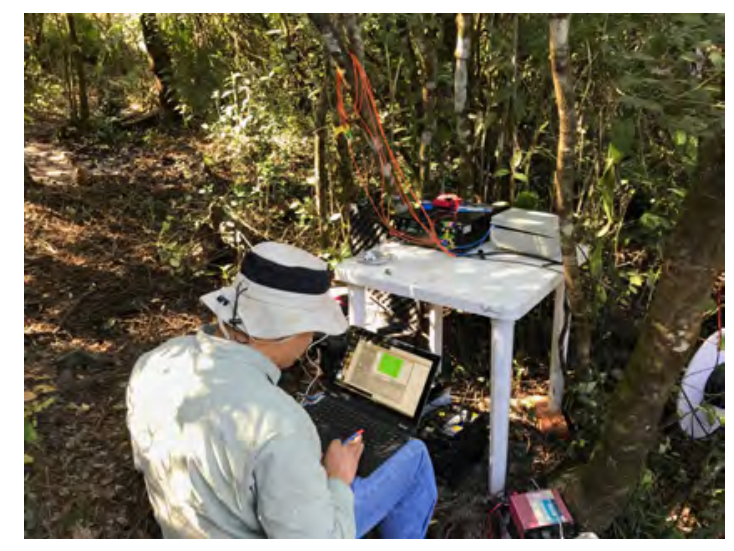

Fonte: Elaborado pelo autor.

Stokes e os anti-Stokes é possível calcular a temperatura para uma determinada seção da fibra (SELKER et al., 2006).

Este equipamento é capaz de registrar a temperatura a cada $1 m$ de comprimento da fibra com uma frequência de 15 - 20s. Essa é uma de suas vantagens, já que, como pode ser conectado a uma fibra colocada ao longo do fundo do rio, permite o monitoramento contínuo e instantâneo ao longo da extensão da fibra (LOWRY et al., 2007).

A seguir, são apresentadas com mais detalhes algumas pesquisas feitas adotando a temperatura como traçador natural:

- Na bacia de Allequash (Província de Wisconsin) Lowry et al. (2007) identificaram a variabilidade espacial em uma wetland usando um DTS. Os autores verificaram que durante o mês de Setembro/2006 a temperatura da água do aquífero fica de 5 a 16 ○mais fria que a água do corpo hídrico. Também foi verificado que existem limitações quanto ao uso do DTS e que para a sua área de estudo não houve mudança espacial das zonas de interação entre o rio e o aquífero.

- No aquífero de Motril-Salobreña (Espanha), realizado por Duque, Calvache e Engesgaard (2010), um modelo de fluxo no software VS2DHI, com dados de entrada do gradiente de temperatura entre o rio Guadalfeo e o aquífero, detectou a relação de influência do rio, com contribuição de cerca até $18 \%$ durante períodos com maiores valores de escoamento.

- Na bacia de Haean (Nordeste de Seoul - Korea) Lee et al. (2013), identificara usando parâmetros físicos e dados de variação de temperatura, que o rio recebe e cede contribuição para o aquífero, de acordo com a variação do nível do lençol freático determinada pelo uso agrícola. 
- Xie et al. (2016) realizaram um estudo na bacia do rio Heihe (Nordeste da China), que apresenta característica de influência e efluência. Os autores utilizaram diferentes métodos para estimar a interação entre o rio e o aquífero. Por meio de análise de incertezas, ficou comprovado que o uso da temperatura como traçador não funciona bem em grandes rios. Neste caso, o randon-222 (traçador químico) apresentou melhor desempenho.

- Nos Estados Unidos, bacia Kickapoo (Illinois), recentemente foi feito um estudo sobre o efeito da sazonalidade (verão e inverno) nos tipos de interação entre o rio e o aquífero. Bastola e Peterson (2016) verificaram que no verão, o rio contribui para o aquífero. Além disso, também foi construído um modelo termal da base do rio com o VS2DHI, para simular as temperaturas verticais da base do rio, monitoradas em campo.

A Tabela 3 apresenta um resumo das produções citadas, sobre o uso da temperatura como traçador para identificar interações entre rios e aquíferos.

Tabela 3 - Trabalhos acadêmicos sobre a interação rio aquífero utilizando a temperatura como traçador.

\begin{tabular}{|c|c|c|c|c|}
\hline Autor & Local & $\begin{array}{c}\Delta T \\
\text { rio } \\
\left({ }^{\circ} \mathrm{C}\right) \\
\end{array}$ & $\begin{array}{c}\Delta T \\
\text { aquífero } \\
\left({ }^{\circ} \mathrm{C}\right)\end{array}$ & $\begin{array}{l}\text { Tipo de } \\
\text { interação }\end{array}$ \\
\hline Lowry et al. (2007) & $\begin{array}{l}\text { Northern Highlands } \\
\text { (Allequash creek) } \\
\text { Província de Wisconsin }\end{array}$ & 17,6 & 6 a 7 & Rio misto \\
\hline $\begin{array}{l}\text { Duque, Calvache e } \\
\text { Engesgaard (2010) }\end{array}$ & $\begin{array}{c}\text { Motril - Salabrenã } \\
\text { (Sudeste da Espanha) }\end{array}$ & $\begin{array}{c}10 \mathrm{a} \\
25\end{array}$ & 17 a 18 & $\begin{array}{l}\text { Rio } \\
\text { influente }\end{array}$ \\
\hline Xie et al. (2016) & Bacia do rio Heise & 10,6 & 14 & $*$ \\
\hline Lee et al. (2013) & $\begin{array}{c}\text { Bacia Haean (Nordeste } \\
\text { de Seoul - Korea) }\end{array}$ & 9 & 15,2 & $*$ \\
\hline $\begin{array}{c}\text { Bastola e Peterson } \\
\qquad(2016)\end{array}$ & $\begin{array}{c}\text { Bacia do Kickapoo } \\
\text { (centro rural de Illinois) }\end{array}$ & 8 & 11 & $*$ \\
\hline
\end{tabular}

Fonte: Elaborado pelo autor.

\subsection{Arduino}

${ }^{5}$ Arduino ${ }^{\circledR}$ é uma ferramenta opensource usualmente difundida entre programadores, que permite analisar e comandar sensores de resposta a estímulos ambientais (Arduino, 2017). Apresenta uma plataforma física baseada em uma placa micro controladora, em

5 Mais informações acesse <https://www.arduino.cc/> 
conjunto com um ambiente de programação (IDE) em linguaguem $\mathrm{C}++$ para a criação dos códigos (Sketch) que serão executados na memória do micro controlador contido na placa (Arduino, 2017).

Existem diversos modelos de placas Arduino disponíveis no mercado, cada qual com características singulares, convenientes para diferentes usos. O modelo UNO R3, apresentado na Figura 18 é o mais difundido em razão da simplicidade do manejo de suas componentes elétricas (alimentação/ portas de entrada e saída) e pelo padrão aceito em quase todas as expansões (SHIELDS) presentes para a tecnologia. Essas expansões permitem conectar o microcontrolador com diversos sensores (FERDOUSH; LI, 2014).

Figura 18 - Arduino Uno

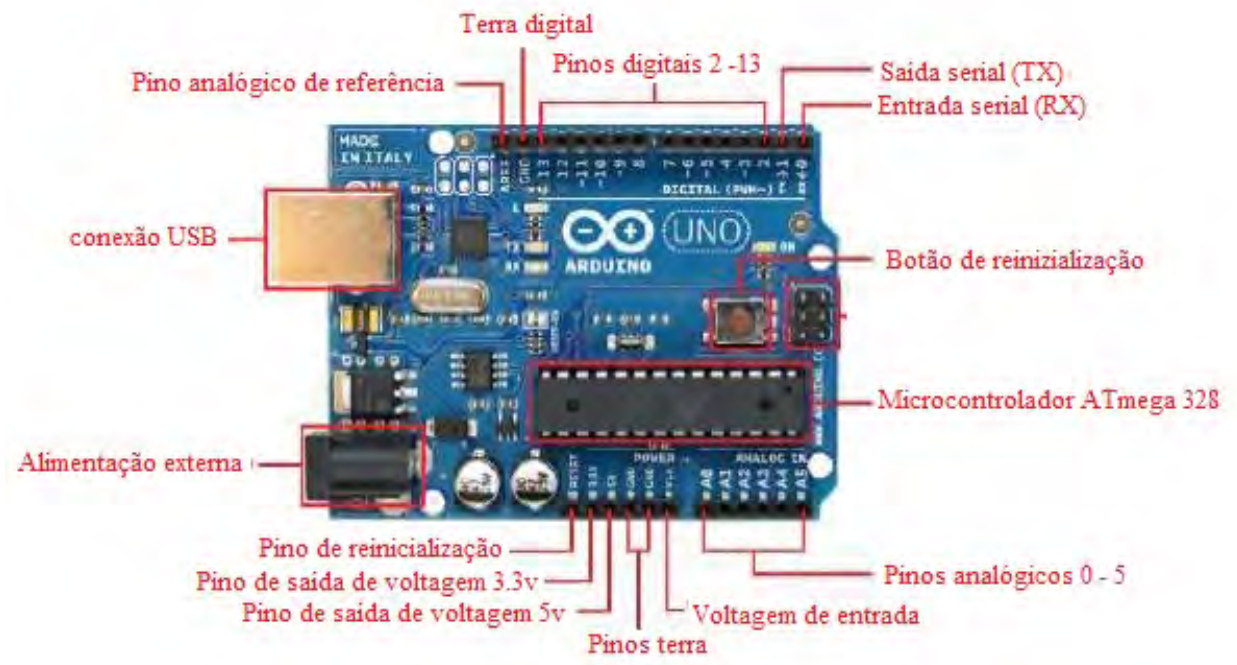

Fonte: Elaborado pelo autor.

A Tabela 4 apresenta, em resumo, as principais características dessa placa. O Atmega328, que equipa essa placa, opera em 32 bits e controla um relógio com velocidade de $16 \mathrm{MHz}$. Além disso, a placa utiliza uma interface USB que pode ser conectado a um computador via cabo USB.

Tabela 4 - Principais características do modelo UNO R3

\begin{tabular}{cc}
\hline \multicolumn{2}{c}{ Características } \\
\hline Portas digitais & 14 \\
Portas analógicas & 6 \\
Alimentação & $6-15 \mathrm{v}$ \\
Tensão de operação & 3 e $5 \mathrm{v}$ \\
Microprocessador & Atmega328 \\
\hline
\end{tabular}

Fonte: Elaborado pelo autor. 
Diversos trabalhos têm sido desenvolvidos utilizando essa ferramenta,o que revela seu potencial como: a utilização em conjunto com a Internet para ambientes de monitoramento, Ferdoush e Li (2014), automatização de infiltômetros, Fatehnia et al. (2016) e controle na produção de micro-algas, Wishkerman e Wishkerman (2017). Além desses, outros estudos, para a aquisição de estímulos ambientais, foram desenvolvidos, como:

- SILVA SOUZA et al. (2017), desenvolveram um sistema de alerta de enchentes, para regiões críticas. Por meio de um sensor de medição de distância ultrassônico (HCSR04), conectado a um microcontrolador, similar ao Arduíno, e um sistema de telemetria, era possível, em situações de emergência, disparar um alarme para comunicar o risco à população e enviar uma mensagem, via sms, para as autoridades competentes. Neste trabalho foi observado a possibilidade da utilização um sistema de baixo custo e uma discrepância entre a precisão descrita no Datasheet do sensor e o observado nos testes.

- Jordão et al. (2017), criaram um sistema de monitoramento de temperatura, para leiras de compostagem, utilizando sensores de temperatura (DS18B20) conectados a uma placa de Arduíno UNO e a uma SHIELD de armazenamento de dados. A precisão do sistema de monitoramento, ficou compreendida entre 1 a $1,9{ }^{\circ} \mathrm{C}$ e foi capaz de suportar temperaturas maiores que $70{ }^{\circ} \mathrm{C}$.

- Um pluviômetro semiautomático do tipo Hellmann foi desenvolvido por Manrínquez, Espinosa e Vega (2016), que utilizaram o Arduíno para controlar coletar as informações de níveis d'água no pluviômetro e armazenar as informações em um módulo SD Card. O sistema apresentou uma precisão de $90 \%$ e, segundo os autores, apresentou baixo custo e pode ser utilizado em ambientes domésticos e inclusive profissionais

O Arduino pode ser conectado a outros componentes e sensores por meio de uma placa de prototipagem (protoboard) ou por uma placa de circuito impresso, visto com mais detalhes na subseção 3.5.1. Esse último, segundo Khandpur (2005), é mais usual devido a algumas vantagens em relação à protoboard, como:

1. O tamanho da montagem é reduzido, reduzindo também seu peso;

2. As partes locais são fixas o que simplifica a identificação e a manutenção do equipamento eletrônico;

3. As chances de erro na conexão do circuito são minimizadas;

4. Oferece alto nível de repetibilidade e uniformidade das características elétricas de cada montagem. 


\subsubsection{Circuito Impresso}

O circuito impresso ou PCB (Printed Circuit Board) é considerado um dos elementos mais essenciais na eletrônica, já que são utilizados em quase todos os produtos eletrônicos. Ele foi inicialmente concebido em 1903 pelo inventor alemâo Albert Hanson que descreveu folhas laminadas para uma placa laminadora em múltiplas camadas. A partir dele outros pesquisadores iniciaram seus estudos em razão dessa técnica, como Thomas Edison que experimentou métodos químicos para galvanização de condutores em um papel de linho em 1904 (HARPER, 2004).

As PCB's são compostas por uma placa isolante, que geralmente é o fenolite, com uma superfície condutora, geralmente fabricada com cobre. Existe ainda as que são compostas por mais de 2 camadas condutoras, conhecidas como multilayers ou multicamadas (HARPER, 2004).

Existem vários métodos para fabricar circuitos impressos, porém todos eles começam basicamente com os seguintes passos:

1. Fabricação assistida por computador (FAC)

2. Panelização

3. Padrões de cobre

Na fabricação assistida por computador, um software é utilizado para realizar o desenho das trilhas e o posicionamento delas em favor dos componentes eletrônicos que irão compor o circuito. Esse processo permite o arranjo do circuito e a verificação dos possíveis erros no arranjo, como trilhas que se cruzam.

Após produzir o desenho e finalizar o seu arranjo, é necessário panelizar, que consiste em imprimir vários arranjos em uma placa grande para produzir o maior número possível de circuito por vez.

O último processo da fabricação é o acabamento final dado à placa. Nesse processo, são separados os circuitos panelizados, cada um com uma impressão, feita com uma tinta resistiva (Silk Screen), do circuito desenhado na FAC. O cobre que não é utilizado no Silk Screen é raspado para dar origem às trilhas que serão utilizadas na condução da corrente elétrica pelo circuito.

Para remover o cobre excedente são utilizados diferentes processos tais como : a exposição à luz ultravioleta, fresadoras, e corrosão química com persulfato de amônia ou cloreto férrico. 



\section{MATERIAIS E MÉTODOS}

\section{1 Área de estudo}

A área de estudo encontra-se em uma área de afloramento do SAG (Sistema Aquífero Guarani), que é um aquífero transfronteiriço, com áreas em quatro países da América do Sul , como: Argentina (225.500 km²), Brasil (839.800 km²), Paraguai ( 71.700 $\mathrm{km}^{2}$ ) e Uruguai $\left(58.500 \mathrm{~km}^{2}\right.$ ), como pode ser visto na Figura 19 (ARAÚJO; FRANÇA; POTTER, 1999).

Figura 19 - Distribuição do Sistema Aquífero Guarani pela América do Sul.

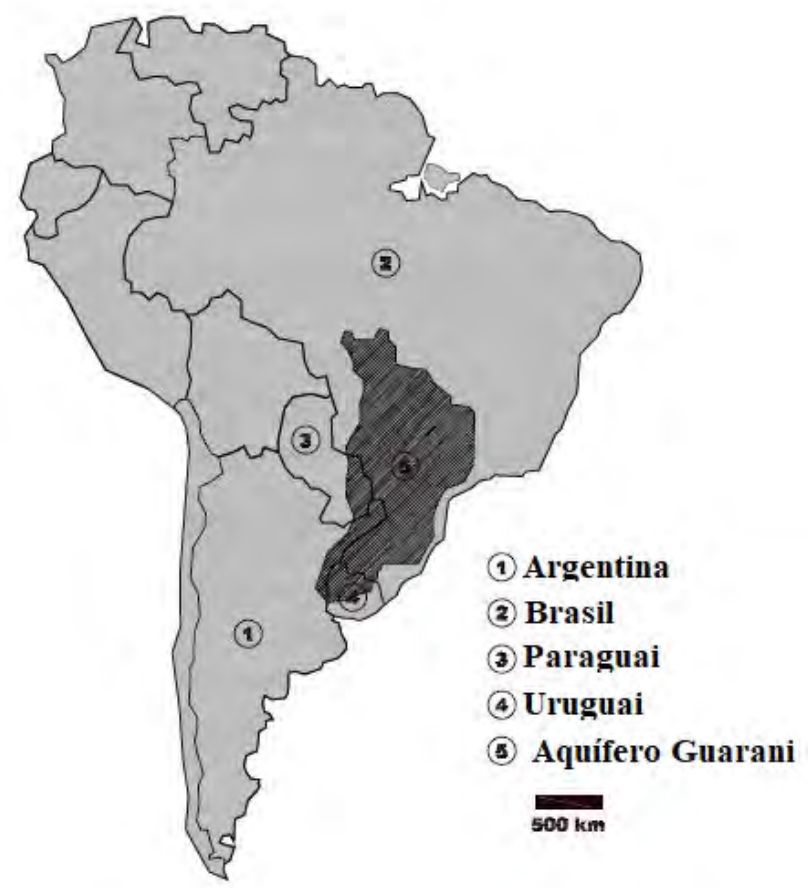

Fonte: Modificado de Wendland, Rabelo e Roehrig (2004).

No Brasil o $S A G$ possui uma área de cerca de $839.800 \mathrm{~km}^{2}$ distribuída nos estados do Mato Grosso do Sul $\left(213.200 \mathrm{~km}^{2}\right)$, Rio Grande do Sul $\left(157.600 \mathrm{~km}^{2}\right)$, São Paulo $(155.800$ $\mathrm{km}^{2}$ ), Paraná $\left(131.300 \mathrm{~km}^{2}\right)$, Goiás $\left(55.000 \mathrm{~km}^{2}\right.$ ), Minas Gerais $\left(51.300 \mathrm{~km}^{2}\right)$, Santa Catarina $\left(49.200 \mathrm{~km}^{2}\right)$ e Mato Grosso $\left(26.400 \mathrm{~km}^{2}\right.$ ) (ARAÚJO; FRANÇA; POTTER, 1999).

A espessura do aquífero varia entre $600 \mathrm{~m}$ e $800 \mathrm{~m}$, sendo menor que estes valores nas áreas de afloramentos, e as isotermas do aquífero geralmente seguem um gradiente de $29{ }^{\circ} \mathrm{C} . \mathrm{km}^{-1}$, sendo que na porção Oeste do estado de São Paulo a temperatura da 
água chega a $50{ }^{\circ} \mathrm{C}$, e na porção Leste a temperatura fica em torno de $25{ }^{\circ} \mathrm{C}$ (ARAÚJO; FRANÇA; POTTER, 1999).

\subsubsection{Bacia Hidrográfica do Ribeirão da Onça}

O local de estudo está situado na Bacia Hidrográfica do Ribeirão da Onça (BRO), a qual está situada no município de Brotas, na porção Centro - Leste do Estado de São Paulo entre os paralelos $22^{\circ} 10^{\prime}$ e $22^{\circ} 15^{\prime}$ de latitude Sul e os meridianos $47^{\circ} 55^{\prime}$ e $48^{\circ} 00^{\prime}$ de longitude Oeste. A bacia contem, aproximadamente, 6500 ha $\left(65 \mathrm{~km}^{2}\right)$ de área e está totalmente situada em uma área de afloramento do Sistema Aquífero Guarani (SAG), como pode ser visto na Figura 20

Figura 20 - Mapa de localização da BRO.

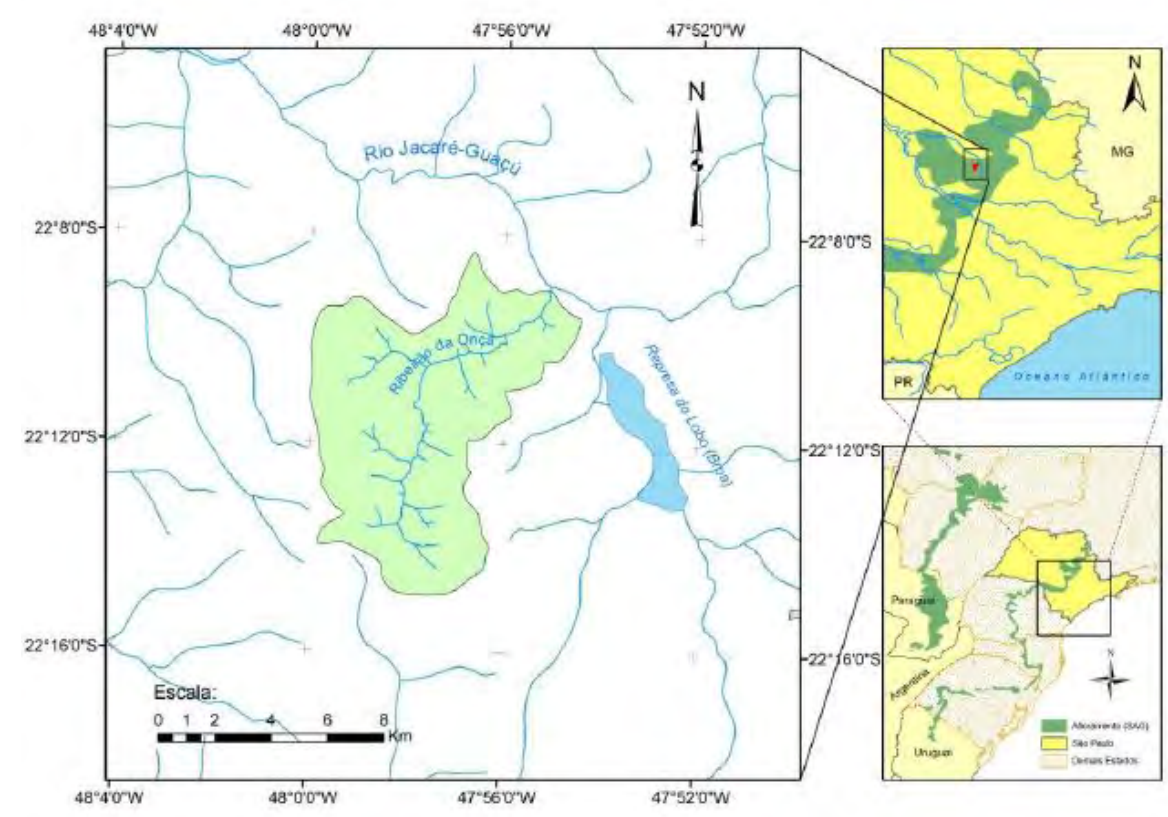

Fonte: Mattos (2015).

Nesse trabalho foram utilizados dados de quatro pontos de monitoramento de vazão distribuídos na bacia (2 calhas Parshall, 1 ADCP e 1 Vertedor triangular). Na Figura 21 são apresentadas as localizações desses pontos e as respectivas sub-bacias em que estão localizadas. Essas sub-bacias foram geradas por meio de um Modelo Digital de Elevação (MDE) do SRTM ( Shutlle Radar Topography Mission) com resolução espacial de 30m de 23/09/2014. Nas sub-bacias 1 e 2 foram instaladas calhas Parshall, já na 3 foi usado um perfilador hidroacústico $(\mathrm{ADCP})$ para medir a vazão do ribeirão. Ainda na sub-bacia 2 foi instalado um vertedor triangular para medir a vazão do afluente representado na Figura 21. 
Figura 21 - Pontos de monitoramento na área de estudo na BRO

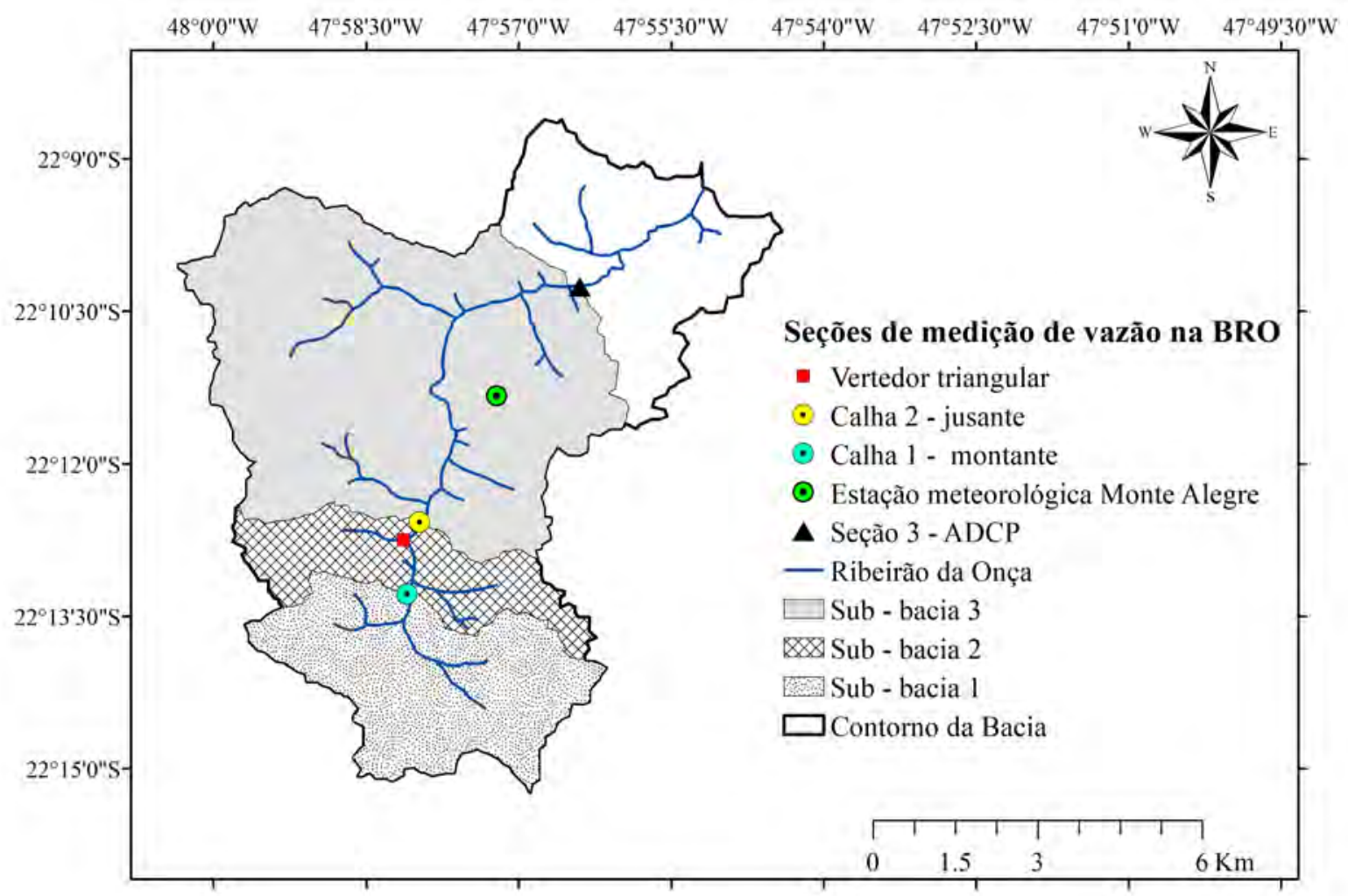

Fonte: Elaborado pelo autor.

É possível perceber que existem dois afluentes principais ao ribeirão da Onça na sub-bacia 2, no entanto apenas um deles foi monitorado, pois a lâmina d'água do outro era muito pequena e mais distribuída, semelhante a uma área de várzea. Este afluente forma várias quedas d'água ao longo do curso principal do ribeirão no trecho entre as calhas, como pode ser visto na Figura 22.

A seguir são apresentadas na Tabela 5 as características gerais das sub-bacias monitoradas, apresentadas na Figura 21.

Tabela 5 - Área e comprimento das três sub-bacias na área de estudo.

\begin{tabular}{ccc}
\hline Sub-bacia & Área de drenagem & Extensão do curso d'água principal \\
\hline 1 & $12.88 \mathrm{~km}^{2}$ & $2700 \mathrm{~m}$ \\
2 & $7.16 \mathrm{~km}^{2}$ & $1300 \mathrm{~m}$ \\
3 & $33.5 \mathrm{~km}^{2}$ & $6500 \mathrm{~m}$ \\
\hline
\end{tabular}

Fonte: Elaborado pelo autor. 
Figura 22 - Queda d'água na primeira afluência do ribeirão da Onça, localizado a cerca de 500 metros de distância da calha 1 para a calha 2 .

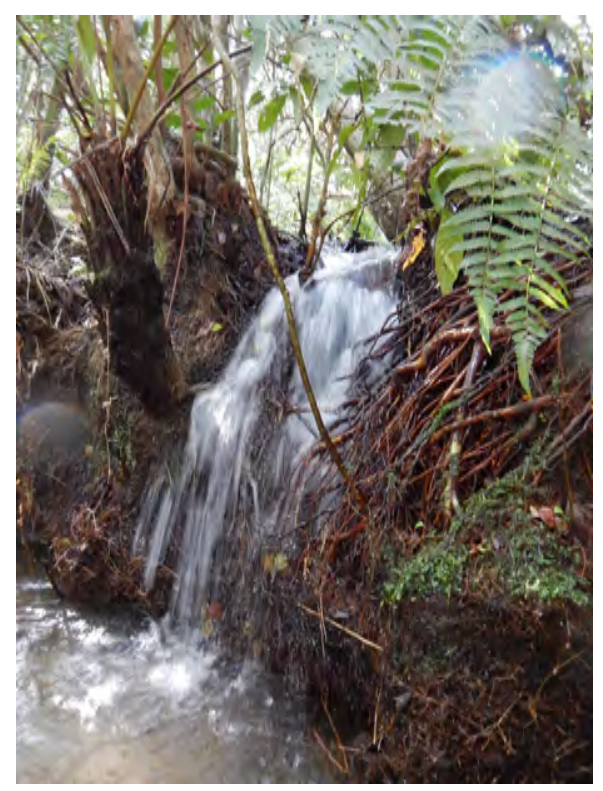

Fonte: Elaborado pelo autor.

A sub-bacia 2 possuía plantação de eucaliptos em praticamente toda sua extensão, no entanto, a plantação foi cortada em Dezembro de 2016 e substituída por novas mudas em Janeiro de 2017. A Figura 23 mostra uma parte da área após o manejo da cultura.

Figura 23 - Vista da sub-bacia 2 após o corte do eucalipto.

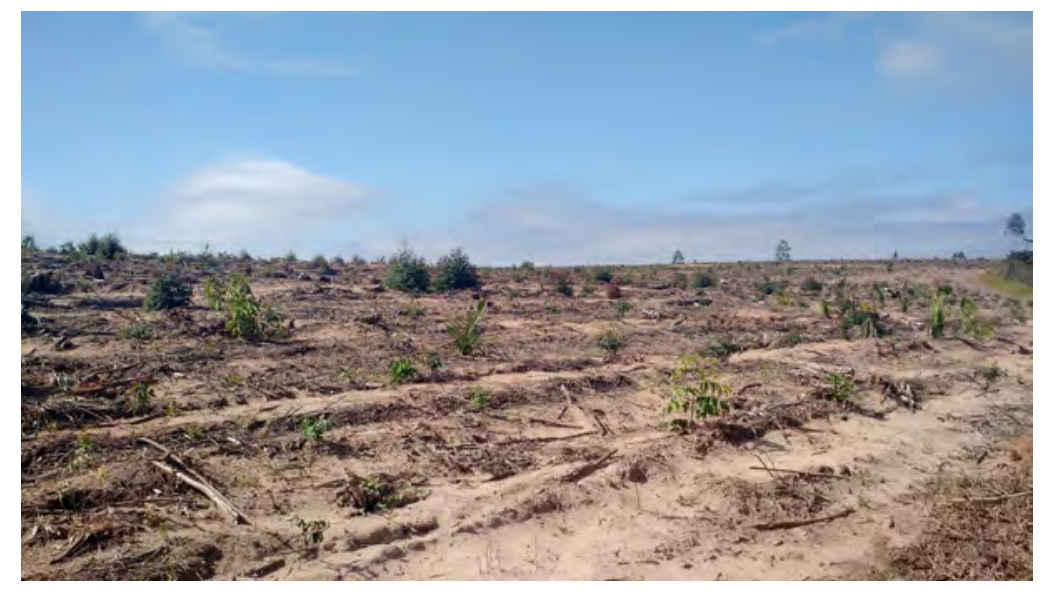

Fonte: Elaborado pelo autor. 


\subsubsection{Clima}

A bacia apresenta clima subtropical úmido com inverno seco e verão chuvoso, $(\mathrm{Ca})$ segundo a classificação de Koppen (OLIVEIRA et al., 2015).

A partir da análise dos dados obtidos na estação climatológica do Centro de Recursos Hídricos e Ecologia Aplicada (CRHEA), verifica-se que as médias diárias de umidade relativa do ar e temperatura foram de $71 \%$ e $21,6{ }^{\circ} \mathrm{C}$, respectivamente, com precipitação média anual de 1486 mm entre 1979 e 2014 (CABRERA et al., 2016).

\subsubsection{Características hidrogeológicas}

Existem dois sistemas de escoamento subterrâneo na BRO, um superior, pouco salinizado, com maior velocidade de circulação e outro, mais profundo, formados pelos arenitos Botucatu e Pirambóia, que representam o Sistema Aquífero Guarani (SAG)(WENDLAND; GOMES; TROEGER, 2015).

O rendimento específico $\left(S_{y}\right)$ foi determinado por Gomes (2008) para diferentes pontos da bacia (Figura 24) e os valores são apresentados na Tabela 6, sendo que a média é de 12,2 \% (WENDLAND; GOMES; TROEGER, 2015).

Figura 24 - Pontos de coleta de solo na bacia do Ribeirão da Onça.

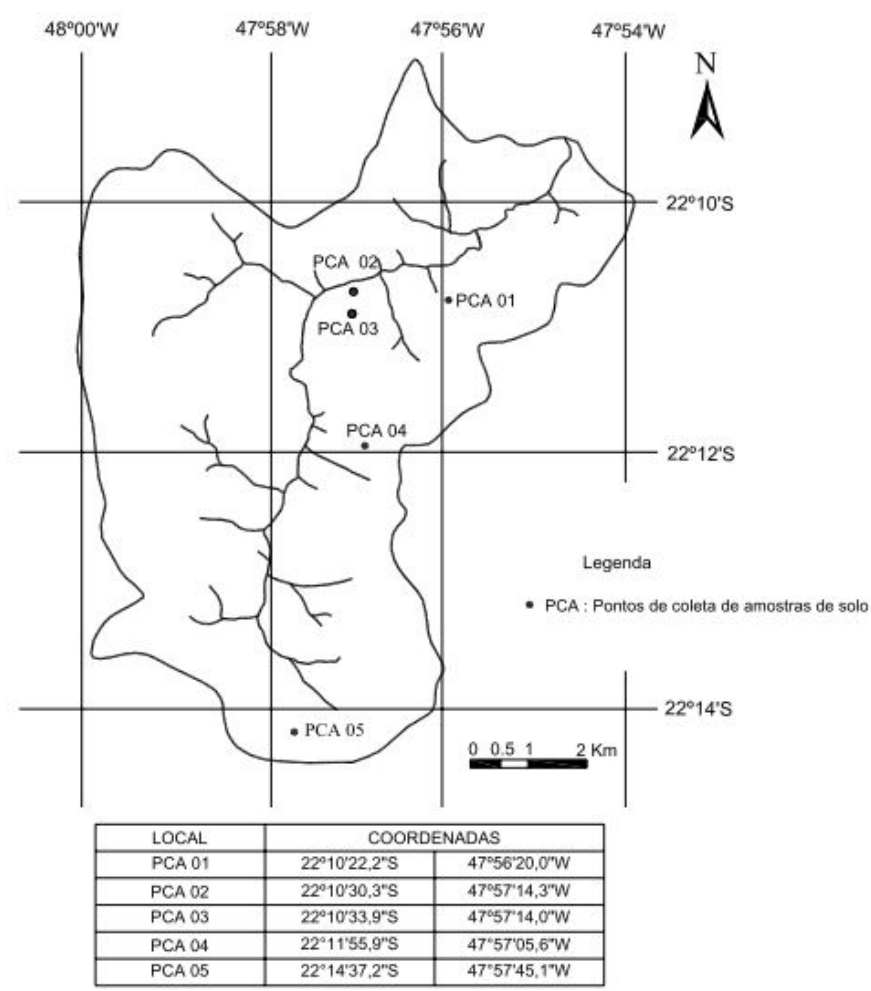

Fonte: Gomes (2008). 
Tabela 6 - Valores de rendimento específico para a bacia do Ribeirão da Onça

\begin{tabular}{|c|c|c|c|c|c|c|c|c|c|}
\hline \multicolumn{10}{|c|}{ Pontos de coleta de amostra do solo (PCA) } \\
\hline \multicolumn{2}{|c|}{ PCA 01} & \multicolumn{2}{|c|}{ PCA 02} & \multicolumn{2}{|c|}{ PCA 03} & \multicolumn{2}{|c|}{ PCA 04} & \multicolumn{2}{|c|}{ PCA 05} \\
\hline Prof. (m) & Sy & Prof. (m) & Sy & Prof. (m) & Sy & Prof .(m) & Sy & Prof. (m) & Sy \\
\hline 13 & 8,7 & 3 & 15,4 & 6,1 & 12,4 & 14,8 & 9,6 & 4,4 & 16,8 \\
\hline 14 & 7,8 & 4 & 15,2 & 7,1 & 12,4 & 16 & 10,4 & 5,4 & 15,7 \\
\hline \multirow[t]{3}{*}{15,8} & 9 & 4,5 & 14,7 & 8,4 & 8,9 & 16,9 & 11,1 & 6 & 15,1 \\
\hline & $*$ & $*$ & $*$ & 9,3 & 10,4 & 18,1 & 12,7 & $*$ & $*$ \\
\hline & $*$ & $*$ & $*$ & $*$ & $*$ & 19,1 & 9 & $*$ & $*$ \\
\hline Média & 8,5 & Média & 15,1 & Média & 11,3 & Média & 10,6 & Média & 15,9 \\
\hline Desvio & 0,6 & Desvio & 0,4 & Desvio & 1,7 & Desvio & 1,4 & Desvio & 0,9 \\
\hline
\end{tabular}

Fonte: Gomes (2008).

No trabalho de Mattos (2015), as condutividades hidráulicas, foram estimadas pelo método do Slug test para os cinco pontos de coleta da Figura 24, apresentando um valor médio de $2,3 \times 10^{-5}$ m.s ${ }^{-1}$.

A média da profundidade da zona saturada do aquífero superior da BRO é de $50 m$ (MELO; CABRERA; WENDLAND, 2017), valor calculado a partir de diferentes profundidades encontradas na BRO. A Figura 25 apresenta a carga hidráulica da zona saturada distribuída pela bacia.

Figura 25 - Mapa potenciométrico para a bacia do Ribeirão da Onça.

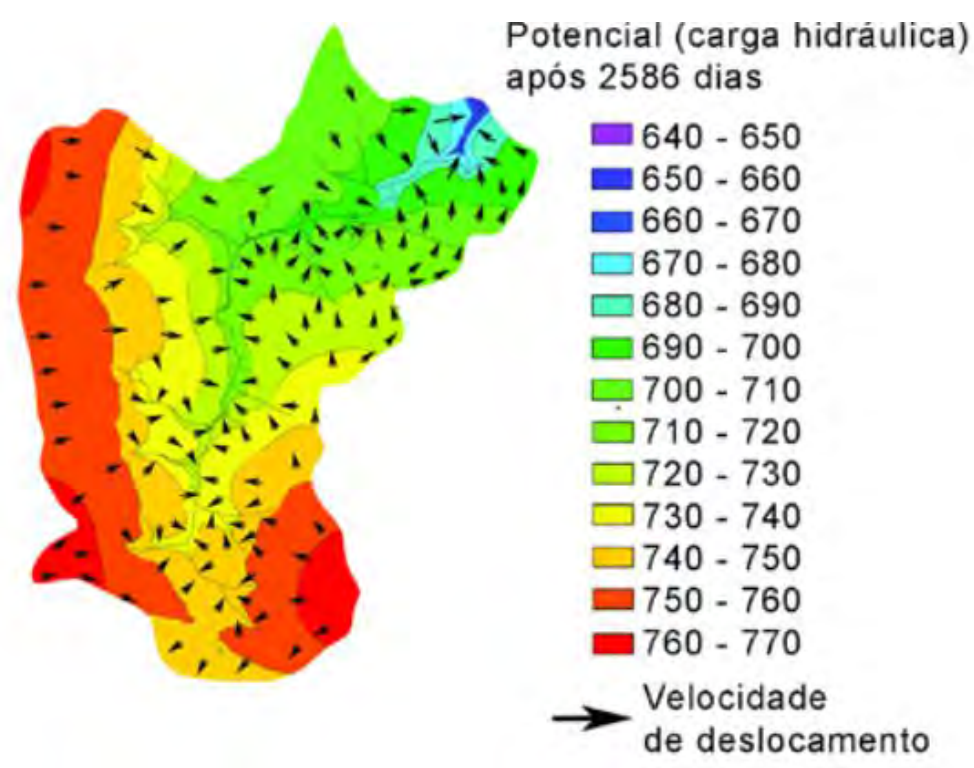

Fonte: Melo, Cabrera e Wendland (2017).

A partir desse mapa, é possível perceber que o rio recebe contribuição do aquífero (rio efluente). Essa contribuição do aquífero para o rio foi verificada no trabalho de Arantes, Marcussi e Chaudhry (2006), em que infiltrômetros e mini piezômetros foram 
empregados para caracterizar o tipo de interação entre o rio e o aquífero na BRO nos pontos apresentados na Figura 26. Os valores médios do surgimento (escoamento da água do aquífero para o rio) na zona de afloramento do aquífero, durante um período de monitoramento de sete meses, são apresentados na Tabela $\%$.

Figura 26 - Localização dos pontos de estudo, do trabalho de Arantes, Marcussi e Chaudhry (2006), na Bacia do Ribeirão da Onça.

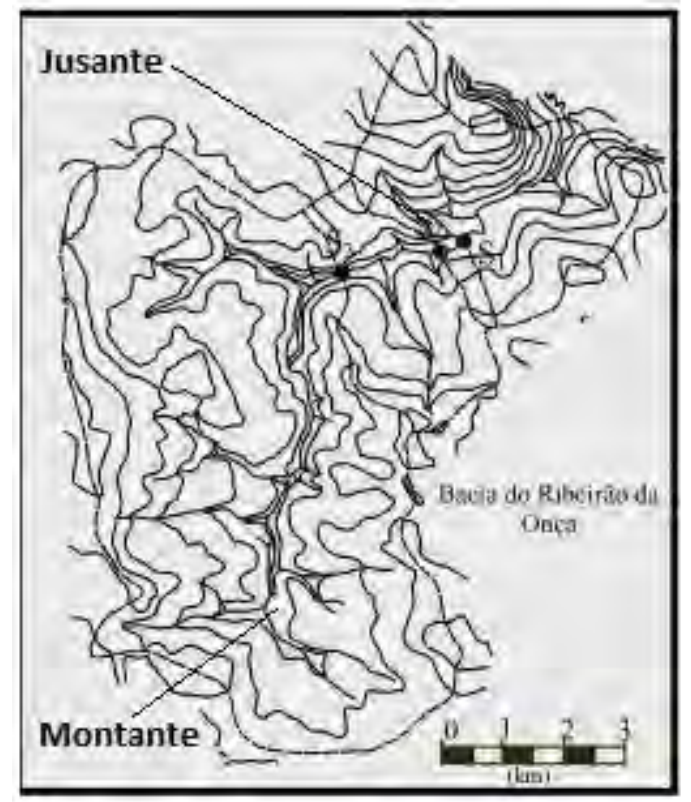

Fonte: Arantes, Marcussi e Chaudhry (2006).

Tabela 7 - Taxa de surgimento em $m m \cdot d^{-1}$ para as três seções de estudo

\begin{tabular}{lrrr}
\hline & Seção 1 & Seção 2 & Seção 3 \\
\hline & \multicolumn{3}{c}{$(\mathrm{mm} /$ dia $)$} \\
\cline { 2 - 4 } Máximo & 285,21 & 670,6 & 901,03 \\
Médio & 175,01 & 290,15 & 556,45 \\
Mínimo & 67,91 & 62,07 & 112,86 \\
\hline
\end{tabular}

Fonte: Arantes, Marcussi e Chaudhry (2006).

Arantes, Marcussi e Chaudhry (2006) observaram que as taxas de surgimento à montante foram superiores aos valores encontrados à jusante da área de estudo na BRO.

\subsubsection{Uso e ocupação do solo}

Os tipos de uso e ocupação do solo podem influenciar no escoamento superficial e nas taxas de recarga do aquífero na BRO. Portanto, para complementar a discussão dos resultados do escoamento superficial nas 3 sub-bacias monitoradas na BRO, foi feito um 
mapa de uso e ocupação do solo da bacia, com os principais tipos de uso e ocupação do solo encontrados, exemplificados na Figura 27, para 2017, como mostra a Figura 28.

Figura 27 - Tipos de usos e ocupação do solo encontrados na bacia do Ribeirão da Onça.

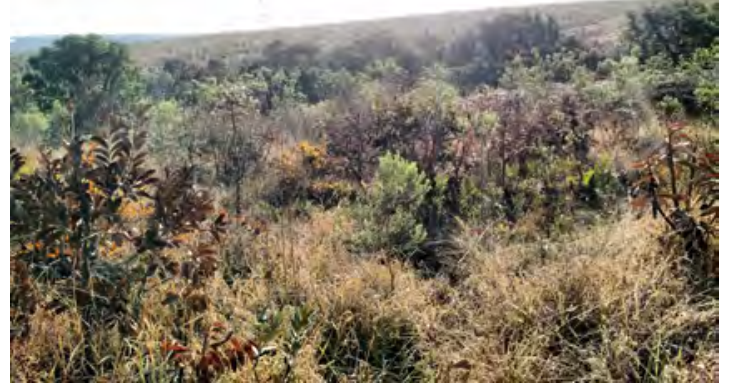

(a) Mata

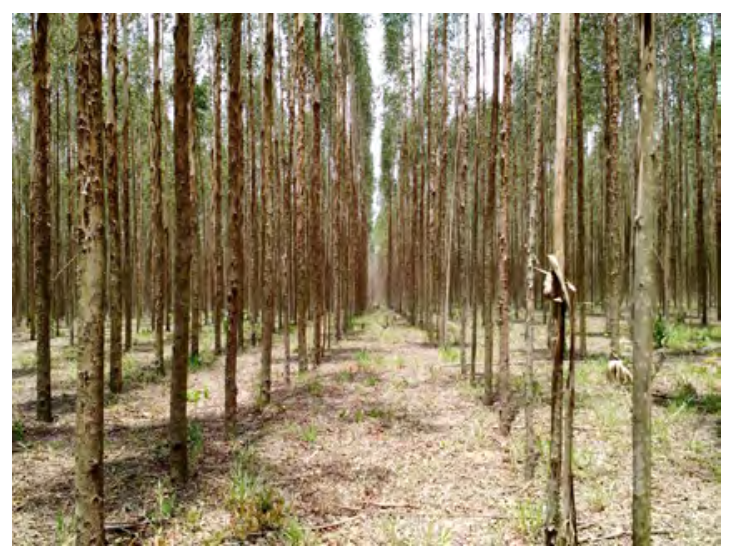

(c) Eucalitpo

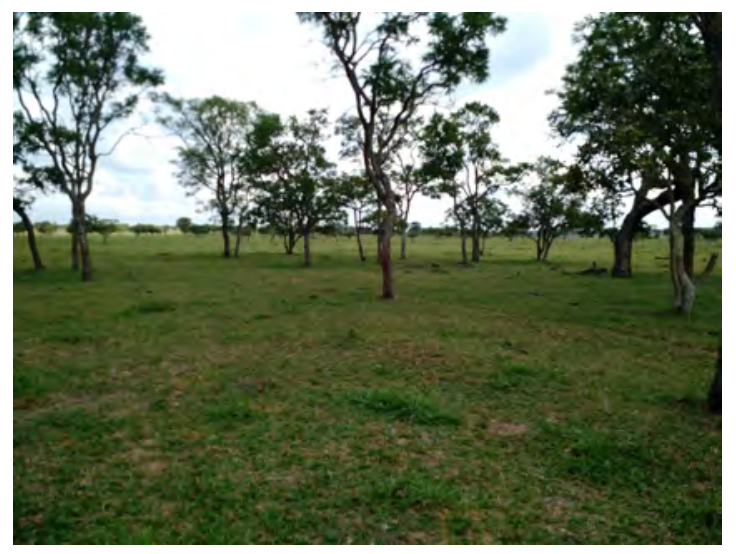

(e) Pasto

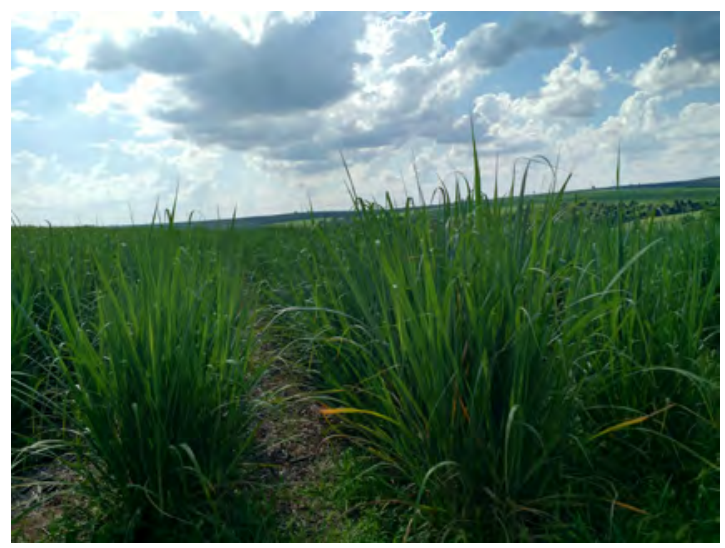

(b) Cana - de - açúcar

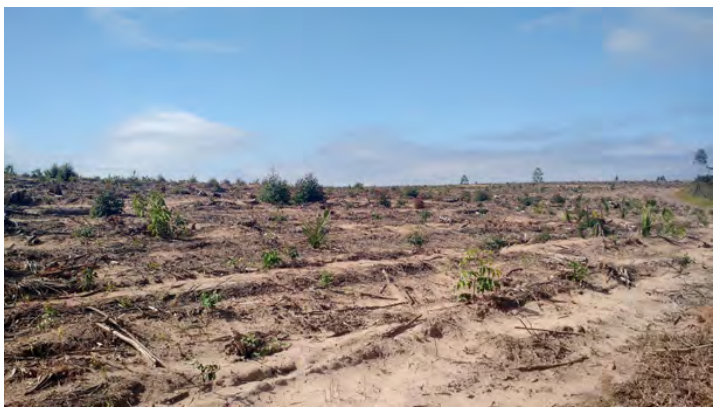

(d) Solo exposto

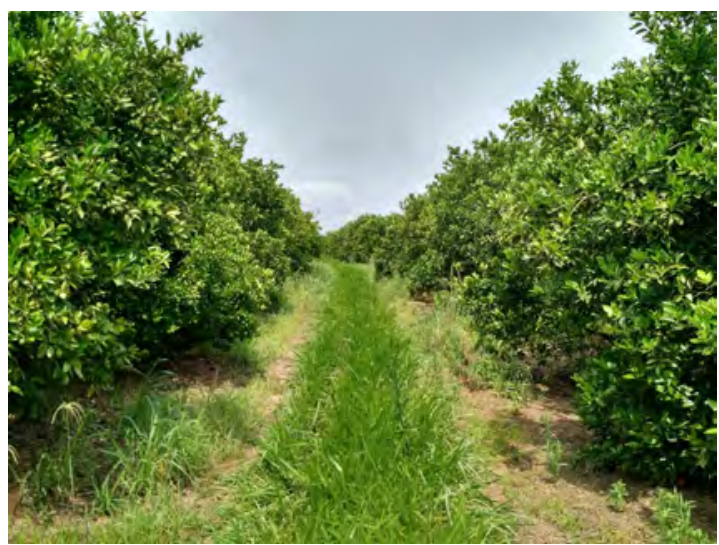

(f) Citros

A porcentagem de cada uso é apresentada na Tabela 8. A partir dessa tabela é possível observar que na sub-bacia 2, existe uma grande parcela de solo exposto, resultante do corte do eucalipto na área, no inicio do estudo (01/2017). 
Figura 28 - Mapa de uso do solo da BRO para 2017.

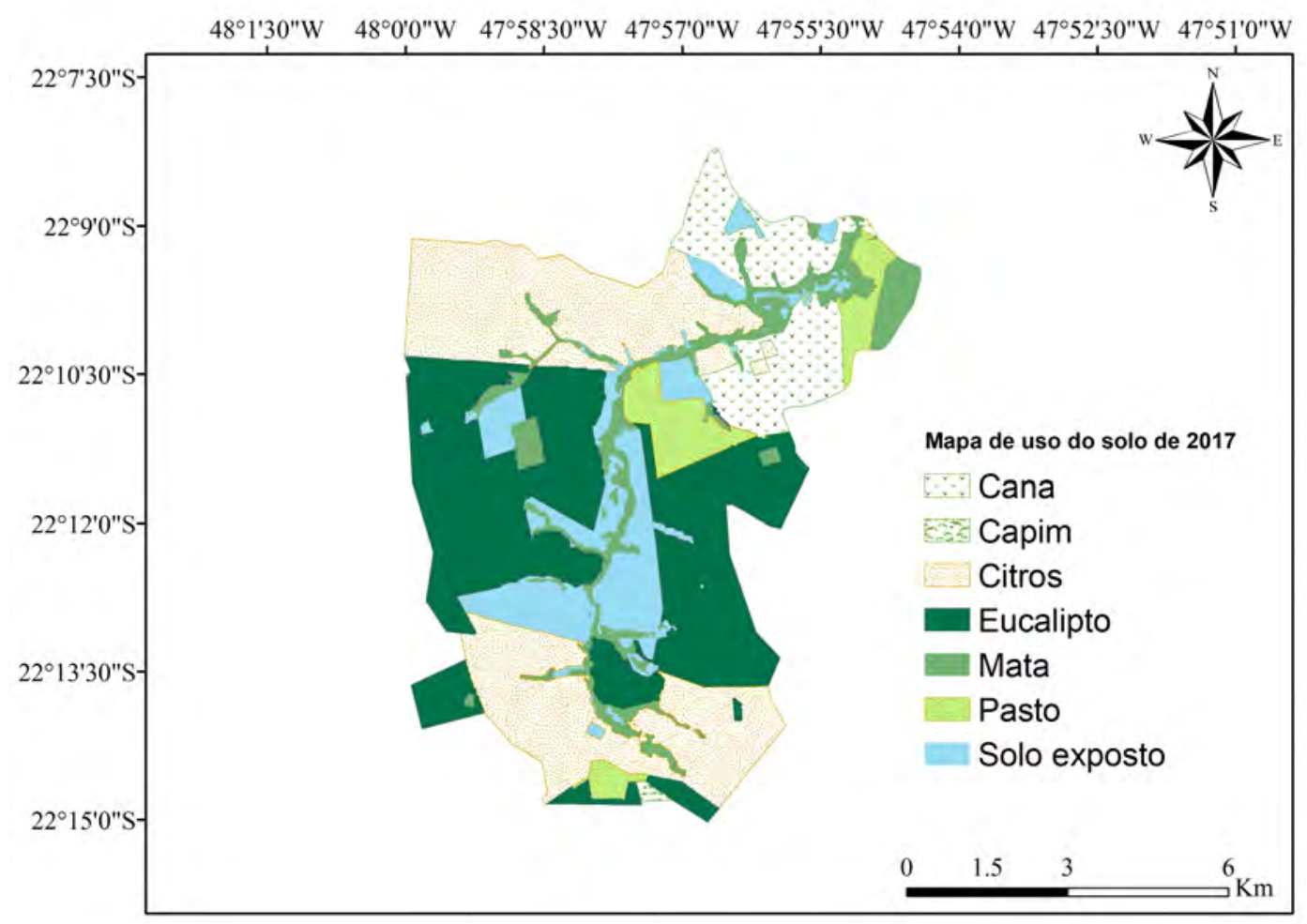

Fonte: Elaborado pelo autor.

Tabela 8 - Porcentagem do uso do solo, para as 3 de seções de monitoramento (Calha 1, Calha 2 e ADCP) para 2017

\begin{tabular}{ccccccc}
\hline Área & $\begin{array}{c}\text { Solo } \\
\text { exposto } \\
(\boldsymbol{\%})\end{array}$ & $\begin{array}{c}\text { Eucalipto } \\
(\boldsymbol{\%})\end{array}$ & Mata (\%) & $\begin{array}{c}\text { Capim } \\
\mathbf{( \% )}\end{array}$ & $\begin{array}{c}\text { Citros } \\
\mathbf{( \% )}\end{array}$ & Cana (\%) \\
\hline 1 & 2,68 & 21,03 & 6,95 & 0,59 & 64,59 & $*$ \\
2 & 41,74 & 44,62 & 6,91 & $*$ & 6,73 & $*$ \\
3 & 13,69 & 42,71 & 8,5 & 6,63 & 24,51 & 3,96 \\
\hline
\end{tabular}

* não possui. Fonte: Elaborado pelo autor.

\subsection{Período do estudo e coleta dos dados meteorológicos}

Para este estudo o período de monitoramento da vazão do Ribeirão da Onça foi de 26/05/2017 a 03/02/2018. Nesse intervalo, foram instaladas 2 calhas Parshall e 1 vertedor triangular. Além de instalá-los, foram coletados dados de níveis d'água tanto nas calhas, quanto no vertedor para calcular as vazões no ribeirão em cada sub-bacia abordada neste trabalho (Figura 21). Na sub-bacia 3, foi utilizado um ADCP para coletar as informações de vazão dessa seção. 
Também foram monitoradas a pressão barométrica (Pbar) e a precipitação em $(\mathrm{mm})$ em uma frequência de registro de $10 \mathrm{~min}$. Para isso foi usada uma estação meteorológica, equipada com um data logger da CAMPBELL SCIENTIFIC ${ }^{\circledR}$, modelo CR1000, localizada na fazenda Monte Alegre (2211'19" S e 4757'12" W - WGS84), como mostra a Figura 29. Essas variáveis foram empregadas, respectivamente, na compensação barométrica (Equação 4.1) e na análise da interação entre o rio e o aquífero nas três sub-bacias (subseção 4.6.1). A Tabela 9 mostra o tipo e a altura dos sensores que foram utilizados para coletar essas variáveis meteorológicas.

Figura 29 - Estação meteorológica instalada na fazenda Monte Alegre

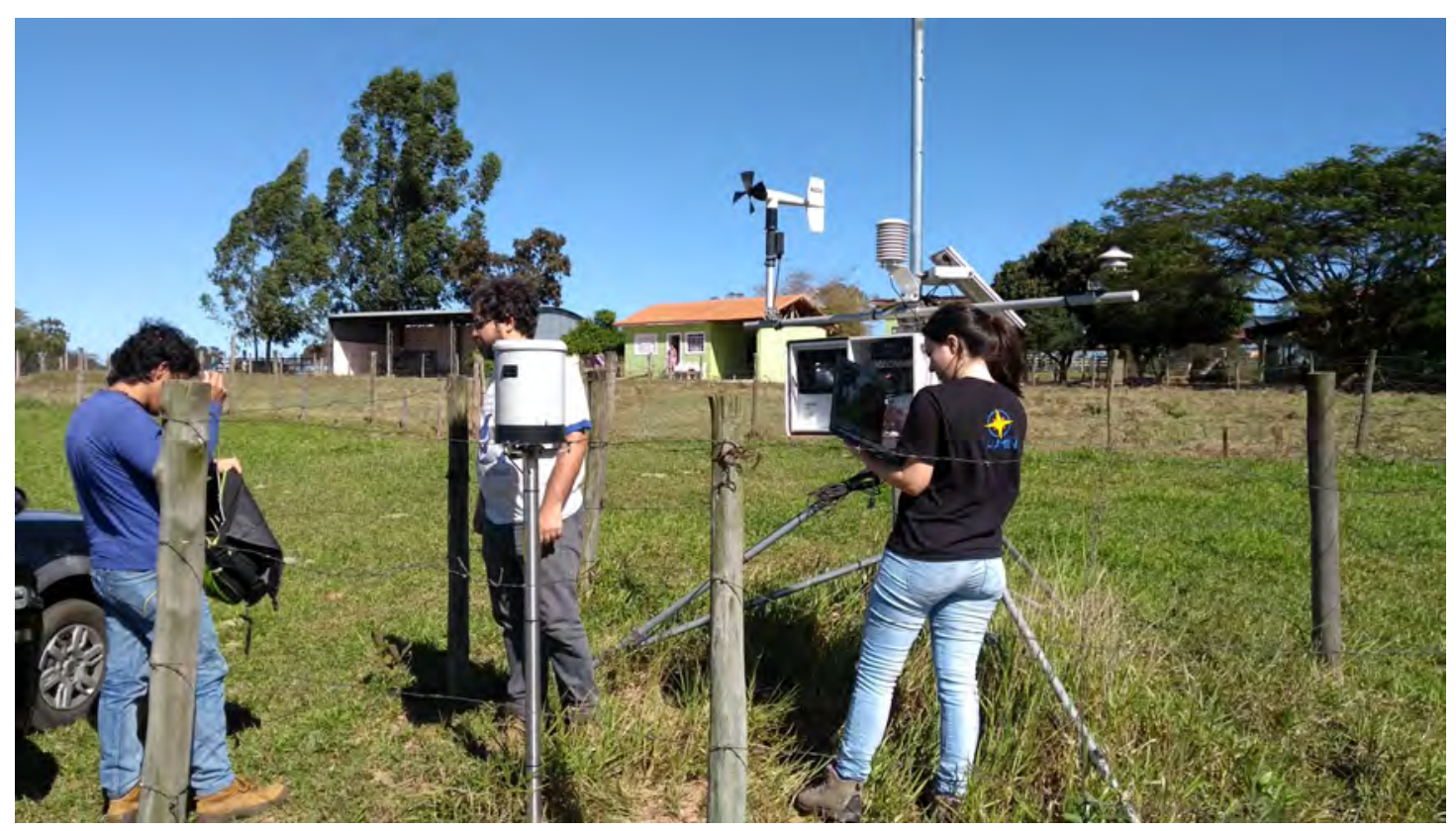

Fonte: Elaborado pelo autor.

Quanto à espacialização dos dados de precipitação, Lucas (2013) comparou os dados diários de precipitação da estação meteorológica da fazenda Monte Alegre com outras duas, também localizadas na bacia, por um período de 6 meses. Com este procedimento, foi possível verificar que a variação dos dados de precipitação entre as estações era pequena, apresentando boa correlação $\left(R^{2}=0,85\right)$ o que levou a concluir que a precipitação na bacia é praticamente homogênea. Além disso, a estação meteorológica da fazenda Monte Alegre possui dados mais atualizados de precipitação, comparados às outras estações, justificando o uso apenas dos dados desta estação. 
Tabela 9 - Variáveis meteorológicas monitoradas na fazenda Monte Alegre

\begin{tabular}{ccc}
\hline Variável monitorada & Sensor & Altura (m) \\
\hline Pressão atmosférica (mbar) & Barômetro CS 106 & 1 \\
Precipitação (mm) & Pluviômetro Hydrological Services TB4 & 1,5 \\
& Tipping Bucket Rain Gauge & \\
\hline
\end{tabular}

Fonte: Elaborado pelo autor.

\subsection{Instalação dos equipamentos}

\subsubsection{Calhas Parshall nas sub-bacias 1 (montante) e 2 (jusante)}

Foram instaladas 2 calhas Parshall com capacidade máxima de $2550 \mathrm{~m}^{3} / \mathrm{h}$, largura da garganta de 18 pol., fabricadas em fibra de vidro. Também foram utilizados poços de estabilização externos, com diâmetro de $250 \mathrm{~mm}$ nas seções convergentes e de estrangulamento de cada calha. A Figura 30 apresenta as principais dimensões da calha utilizada.

Figura 30 - Principais dimensões do tipo de calha usada no trabalho. (A) perfil; (B) planta.
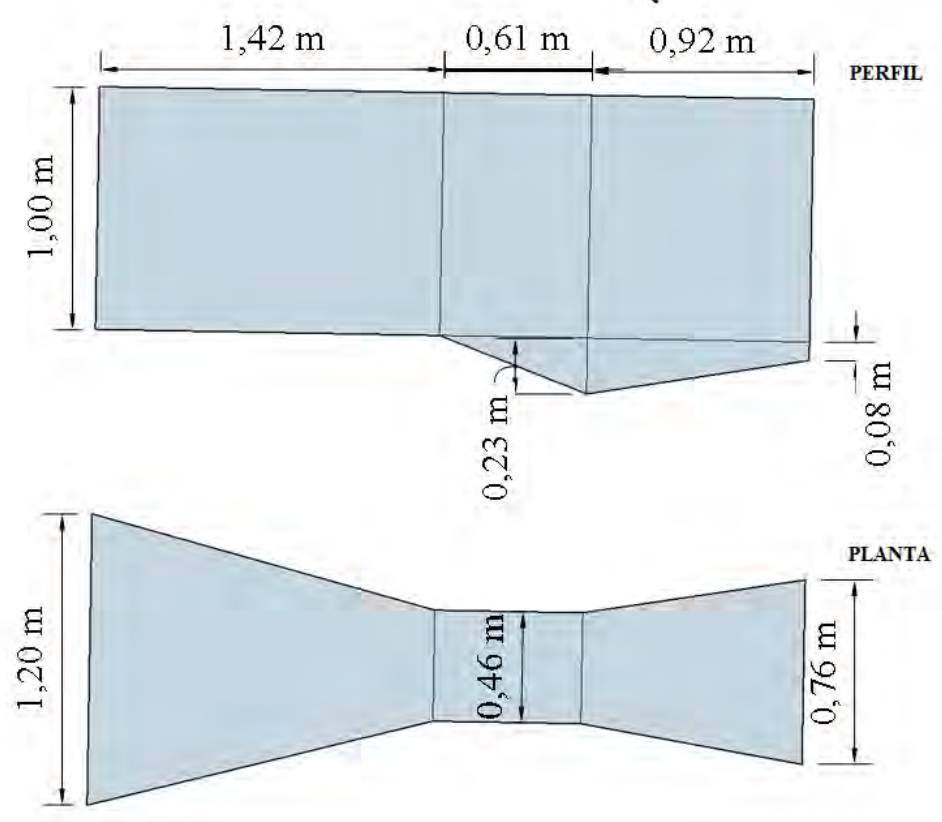

Fonte: Elaborado pelo autor.

As calhas foram instaladas a uma distância de aproximadamente $1300 \mathrm{~m}$ com a intenção de dividir a bacia em 3 áreas distintas, como mostrado na Figura 21. 
Sendo assim, as calhas de montante e jusante foram instaladas nas coordenadas $22^{\circ} 13^{\prime} 16,78^{\prime \prime} \mathrm{S} 47^{\circ} 58^{\prime} 6,15^{\prime \prime} \mathrm{W}$ e $22^{\circ} 12^{\prime} 34,15^{\prime \prime} \mathrm{S} 47^{\circ} 57^{\prime} 58,55^{\prime \prime} \mathrm{W}$ respectivamente.

Para a instalação das calhas Parshall, foi planejada uma estrutura metálica capaz de manter o aparato nivelado transversal e longitudinalmente, além de mantê-lo estável durante os períodos chuvosos. Um desenho tridimensional e uma imagem dessa estrutura sendo instalada em campo são apresentados nas Figura 31 (a) e na Figura 31 (b), respectivamente.

Figura 31 - Estrutura de suporte para a instalação da calha Parshall.

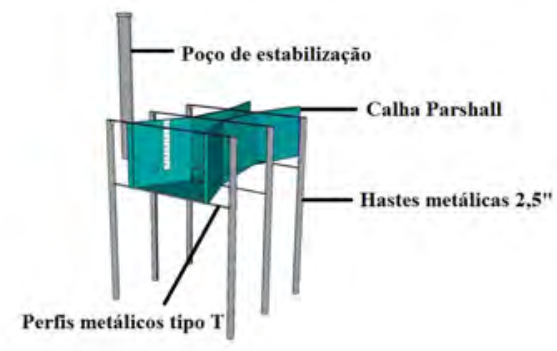

(a) Esquema tridimensional da estrutura de suporte para a instalação da calha Parshall. Fonte: Elaborado pelo autor.

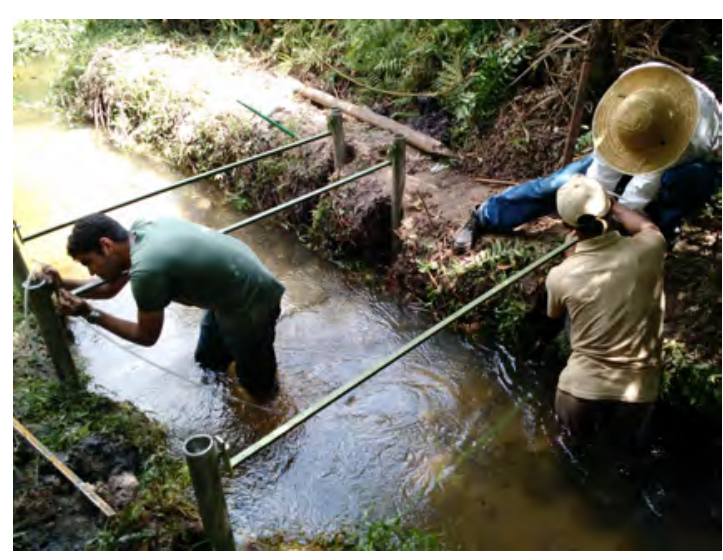

(b) Estrutura de suporte das calhas Parshall sendo instalada em campo. Fonte: Elaborado pelo autor.

A calha 1 foi a primeira a ser instalada em outubro de 2016. No entanto, ela precisou ser elevada posteriormente para que funcionasse em regime de escoamento livre. Para isso, além da estrutura da Figura 31, uma caixa feita com chapa de ferro $\left(1 / 16^{\prime \prime}\right.$ de espessura) foi fabricada para elevar o fundo da calha Parshall. Essa elevação foi proposta, uma vez que Skogerboe et al. (1967) mostraram que, em regime afogado, o nível de jusante tende a influenciar no nível crítico de escoamento a montante. Um desenho mostrando as dimensões da caixa e a sua fabricação, podem ser vistas na Figura 32 (a) e Figura 32 (b), respectivamente.

A calha 2 foi instalada em maio de 2017. A Figura 33 ilustra a instalação da primeira calha Parshall. As fotos da instalação das calhas encontram-se no Apêndice A deste trabalho. 
Figura 32 - Caixa de ferro utilizada para suspender a calha Parshall.

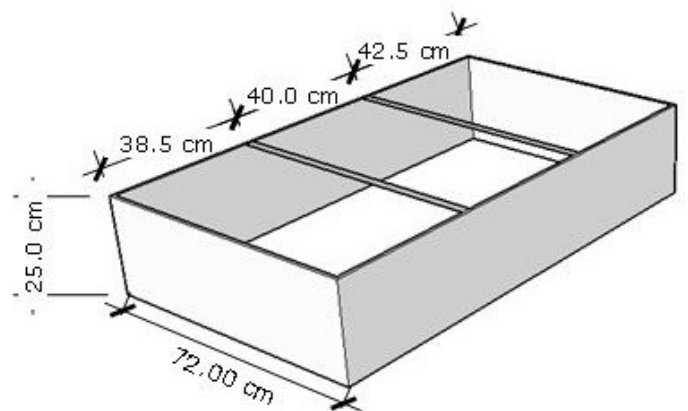

(a) Desenho da caixa de ferro. Fonte: Elaborado pelo autor.

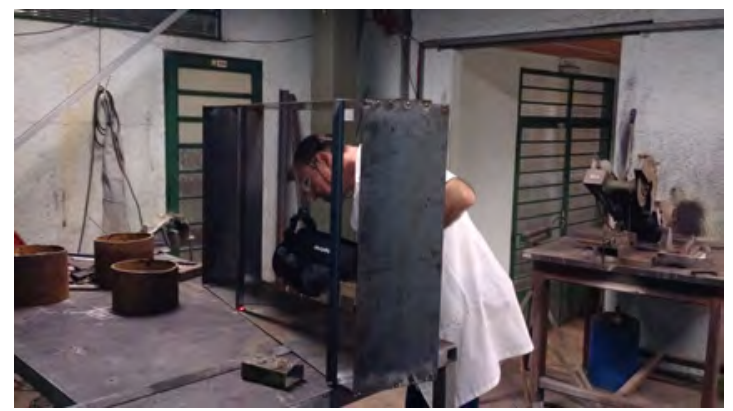

(b) Preparação da caixa de ferro. Fonte: Elaborado pelo autor.

Figura 33 - Instalação das calhas Parshall.

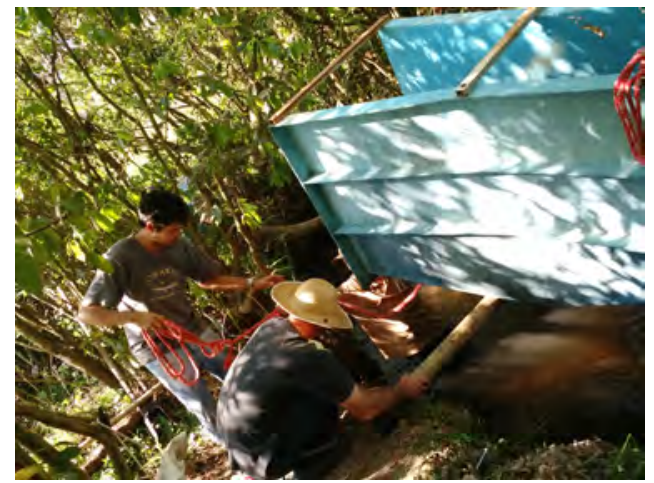

(a) Calha de montante sendo instalada no ribeirão da Onça. Fonte: Elaborado pelo autor.

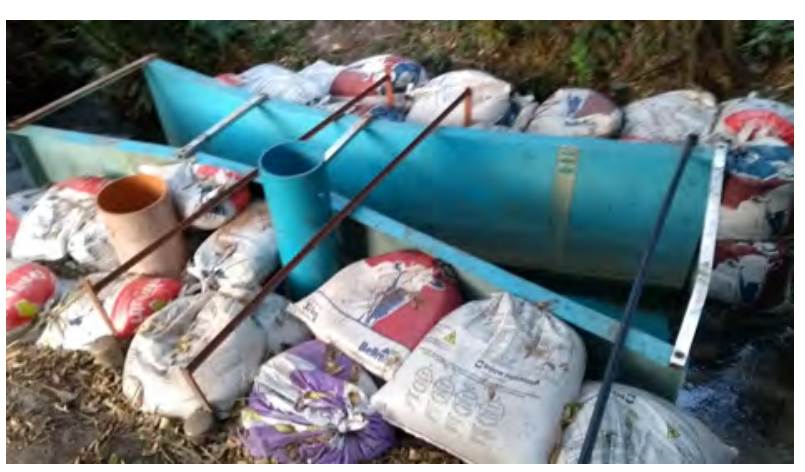

(b) Calha de montante instalada. Fonte: Elaborado pelo autor.

\subsubsection{ADCP na sub-bacia 3 (Seção de medição de vazão da BRO)}

Neste trabalho também foi utilizado um perfilador hidroacústico (ADCP)(SonTek IQ $)^{1}$ da empresa SonTek ${ }^{\circledR}$, com capacidade para medir velocidades de até $+-5 \mathrm{~m} / \mathrm{s}$ em até 10 metros de profundidade, e com uma resolução de 0,0001 m/s. A Figura 34 apresenta o ADCP utilizado no estudo.

Esse ADCP não precisa ser movimentado por uma embarcação, já que deve ser fixado em uma seção com as dimensões definidas. Assim ele é capaz de medir os perfis de velocidade do escoamento e estimar a vazão da seção.

O ADCP já estava operando na seção desde junho de 2015, dentro do bueiro esquerdo da primeira seção de medição de vazão da BRO, que é apresentado na Figura 49. O local deste ponto de monitoramento foi definido no trabalho de Maldonado (2009) e tem sido usado até então para monitorar a vazão do ribeirão da Onça. 
Figura $34-A D C P$ SonTek ${ }^{\circledR} I Q$, utilizado no estudo.

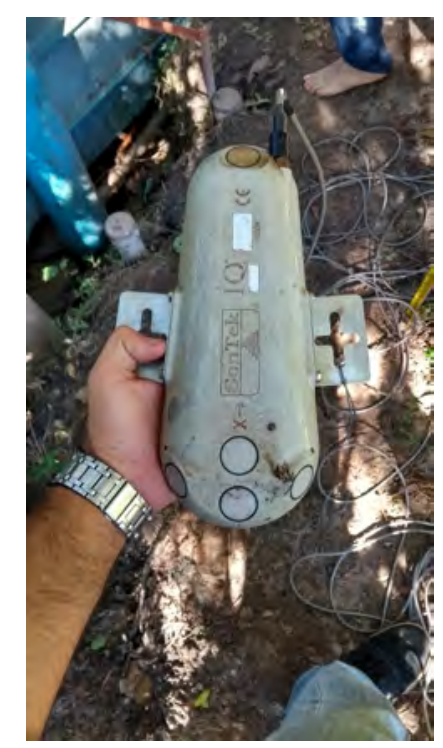

Fonte: Elaborado pelo autor.

Figura 35 - A) Esquema da seção de medição; B) Foto da seção de medição de vazão.
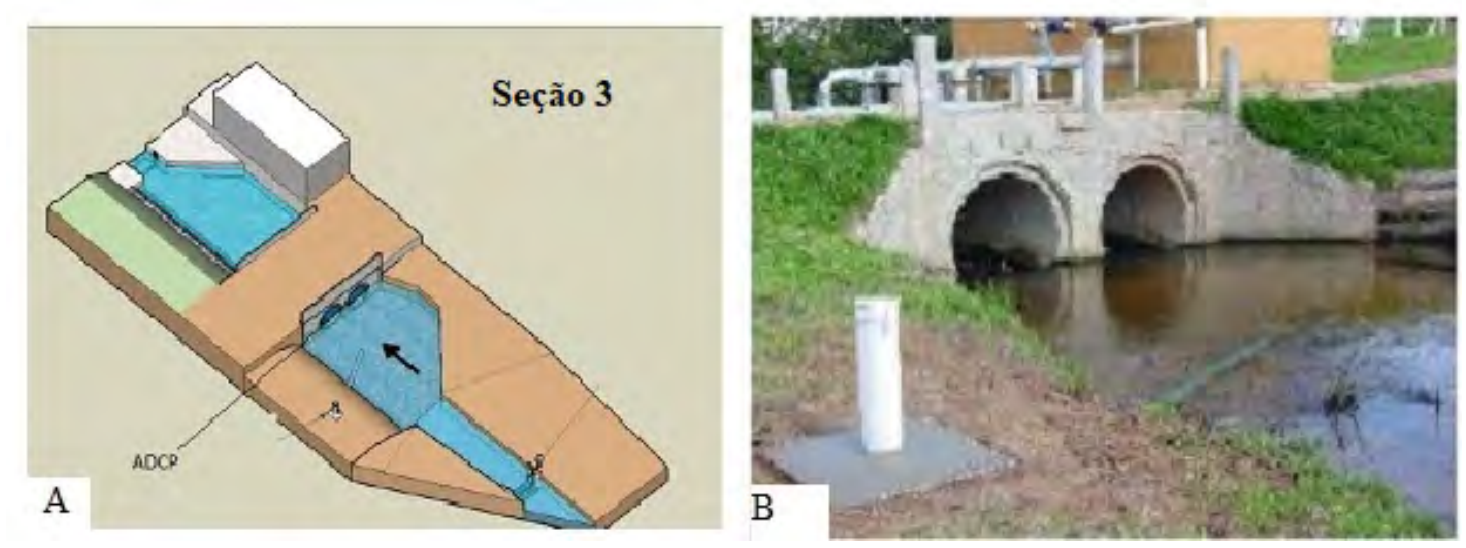

Fonte: Adaptado de Maldonado (2009).

\subsubsection{Instalação do vertedor triangular na sub-bacia 2}

Além das calhas, também foi necessário instalar um vertedor triangular na sub-bacia 2 (Figura 21), nas coordenadas $22^{\circ} 12^{\prime} 44^{\prime \prime} \mathrm{S}$ e $47^{\circ} 58^{\prime} 83^{\prime \prime} \mathrm{W}$, para determinar a vazão de um afluente do Ribeirão da Onça. Esse vertedor foi construído com uma chapa de ferro com $1 / 8^{\prime \prime}$ de espessura e possui capacidade máxima de, aproximadamente, $250 \mathrm{~m}^{3} / \mathrm{h}$.

Com o auxílio de uma marreta e um mourão de eucalipto foi possível perfurar o solo de onde seria realizada a medição e assim descer o vertedor sob a seção de escoamento. Para isso, o mourão foi colocado em cima do vertedor e martelado com a marreta para 
que a base do vertedor pudesse cortar o solo e assim possibilitar a sua descida até que não fosse observado vazamentos pelas laterais e por baixo da chapa do vertedor.

O vertedor foi instalado de forma que sua estrutura ficasse perpendicular ao sentido do fluxo d'água nivelado em suas extremidades por meio de uma mangueira de nível.

Para realizar a medição manual do nível, uma estaca de bambu foi instalada a cerca de $1 \mathrm{~m}$ a montante do vertedor. Para isso, a estaca de bambu foi cortada com altura igual à profundidade do vertedor e depois marcada com a altura total da soleira do vertedor. Dessa forma foi possível colocar o topo da estaca no nível da crista do vertedor como mostra a Figura 36.

Um linígrafo também foi instalado no ponto da estaca, para monitoramento automático do nível d'água. A estrutura do linígrafo consiste em um tubo de PVC de $75 \mathrm{~mm}$ de diâmetro e $2 m$ de altura, com uma extremidade coberta por manta geotêxtil e outra fechada com um cap. Para a medição dos dados dos níveis d'água, um transdutor de pressão foi utilizado.

As Figura 37 (a) e Figura 37 (b) apresentam as dimensões do vertedor e o vertedor em campo, respectivamente.

Figura 36 - Desenho da posição da estaca para monitoramento manual e do linígrafo para monitoramento automático no vertedor triangular.

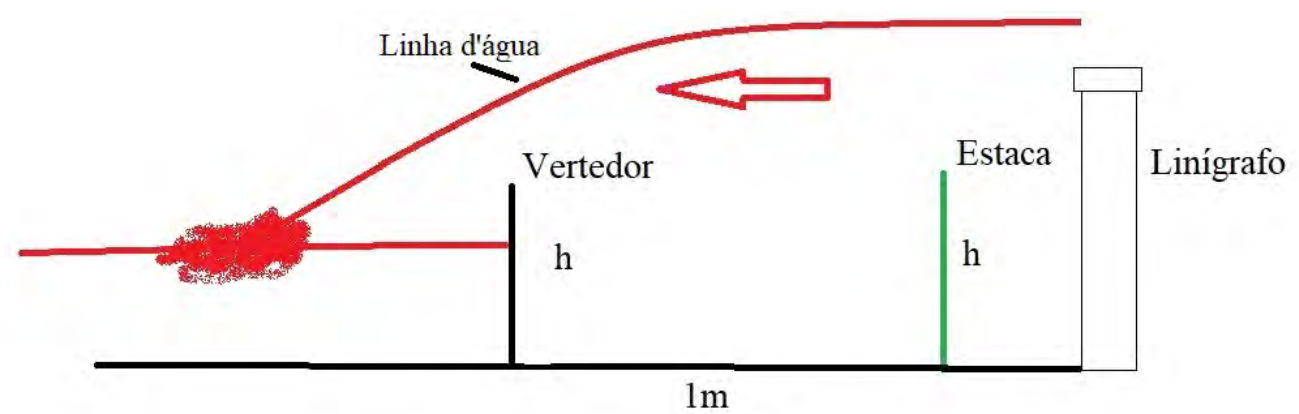

Vista lateral

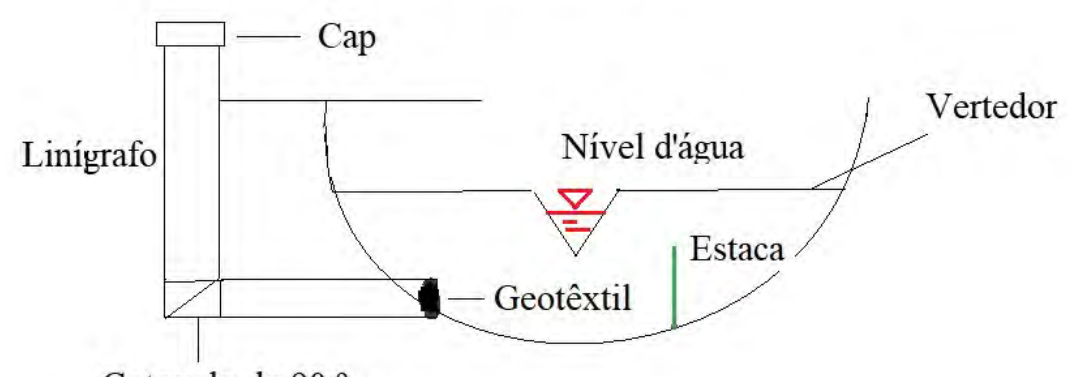

Cotovelo de $90^{\circ}$

Fundo

Fonte: Elaborado pelo autor. 
Figura 37 - Instalação do vertedor triangular.

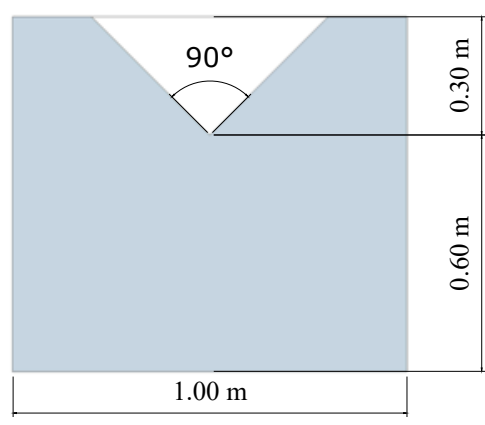

(a) Dimensões do vertedor triangular. Fonte: Elaborado pelo autor.

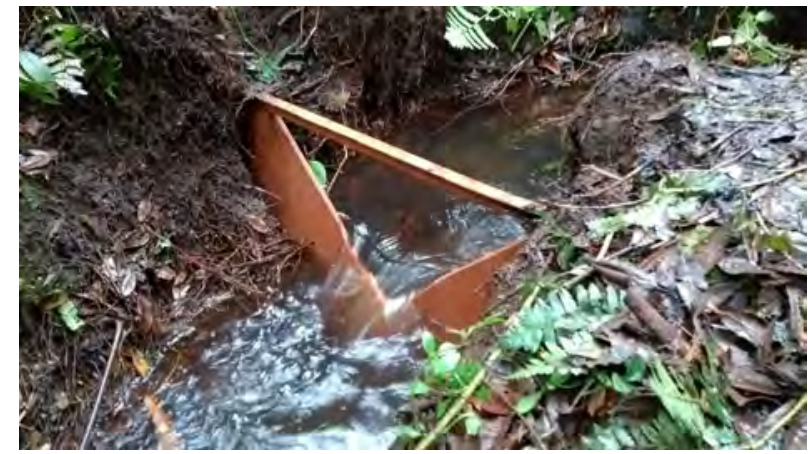

(b) Vertedor instalado em campo. Fonte: Elaborado pelo autor.

\subsection{Validação das medições das calhas Parshall}

Para validar o monitoramento realizado pelas calhas Parshall, foi realizada uma verificação pontual no dia 09/08/2017, utilizando outro ADCP do mesmo modelo que foi usado na sub-bacia 3 (Figura 34).

Para determinar a vazão, primeiro foi necessário definir as dimensões da seção convergente da calha (Figura 30) no software $I Q$ e depois definir a frequência de leitura do equipamento (instantâneo). Feito isso, o equipamento foi fixado na seção convergente da calha, por meio de uma folha galvanizada, e então realizada a leitura. A Figura 38 apresenta uma imagem do ADCP posicionado na entrada da calha Parshall (seção convergente).

Figura 38 - ADCP na entrada da calha Parshall, fixado em uma folha galvanizada.

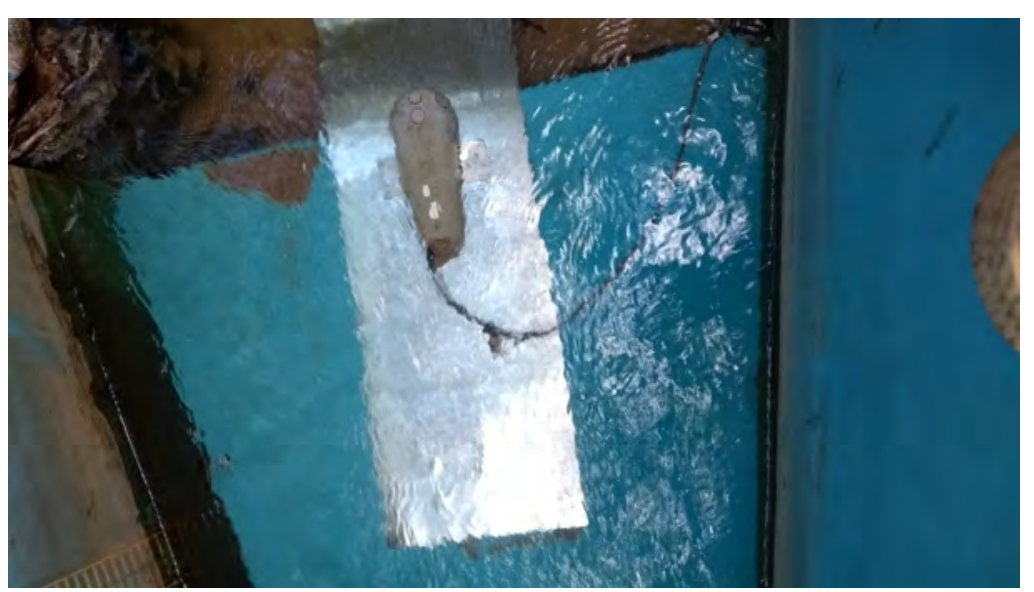

Fonte: Elaborado pelo autor. 


\subsection{Monitoramento da vazão do Ribeirão da Onça}

\subsubsection{Coleta dos dados de níveis d'água nas calhas e no vertedor}

Nos poços de estabilização das calhas e no linígrafo do vertedor foram usados transdutores de pressão ${ }^{2} D_{\text {DVER }}{ }^{\circledR}$ DI501, com precisão máxima de $\pm 2,5 \mathrm{~cm} \mathrm{H}_{2} \mathrm{O}$ e resolução de $0,2 \mathrm{~cm} \mathrm{H}_{2} \mathrm{O}$, segundo o Datasheet do equipamento. A coleta dos dados foi efetuada com uma frequência de 10 min e também de forma manual, com uma régua, a cada 15 dias. Esses transdutores coletaram valores de pressão absoluta em $\mathrm{cm} \mathrm{H}_{2} \mathrm{O}$, ou seja, pressão hidrostática mais a pressão atmosférica. Foi necessário realizar a compensação barométrica, segundo a Equação 4.1 com os dados de pressão atmosférica obtidos na estação meteorológica da fazenda Monte Alegre.

$$
W T=P a b s-P b a r
$$

Sendo WT o nível de água nas Calhas Parshall e no vertedor, Pabs a pressão absoluta em $\mathrm{cm} \mathrm{H}_{2} \mathrm{O}$ e Pbar a pressão atmosférica em $\mathrm{cm} \mathrm{H}_{2} \mathrm{O}$.

Em razão da oscilação da pressão atmosférica e da limitação do equipamento utilizado, foi feita uma análise para verificar se a pressão relativa realmente variava, ou se a variação que poderia ocorrer era devido à influência da pressão barométrica.

Esta análise consistiu em normalizar as pressões barométrica e absolutas das calhas e analisar graficamente o comportamento da variação. Além disto, foi calculado o desvio padrão das médias das pressões absolutas das calhas Parshall e da pressão barométrica, com a finalidade de observar a semelhança das flutuações.

Para a remoção dos ruídos nos dados obtidos pela compensação barométrica, foi aplicado um tipo de filtro passa - baixa em toda a série de dados, conhecido como Regressão Polinomial Local Ponderada (LOESS) (CLEVELAND; DEVLIN, 1988).

O filtro LOESS suaviza as distâncias entre os pontos vizinhos por um ajuste usando uma regressão polinomial de segunda ordem entre os pontos. Para definir quais pontos são mais favoráveis a essa regressão, a expressão tri cúbica de Kernel é utilizada Equação 4.2. Na equação é atribuído um peso maior aos pontos vizinhos que estão mais próximos, esperando que apresentem o melhor ajuste possível.

$$
w(x)=\left(1-\left|\frac{y-y i}{d(y)}\right|^{3}\right)^{3}
$$

2 Os manuais de instruções e de fabricação (Datasheet) deste transdutor, podem ser acessados neste endereço eletrônico <https://www.swstechnology.com/novametrix/pdfs/equipment/Diver ${ }_{m}$ anuals/Diver $_{P}$ roduct $_{M}$ anual $_{e}$ n.pdf 
Em que $w(x)$ representa o peso, y o dado associado com o valor da resposta, $y_{i}$ os dados que sem encontram mais próximos a y e $d(y)$ é o tamanho da faixa de valores dos dados vizinhos de $\mathrm{y}$.

Em conjunto com o DIVER $R^{\circledR}$, na calha 2, foi utilizado um data logger montado com a plataforma $\operatorname{Arduino}^{\circledR}$. A frequência de leitura também foi de $10 \mathrm{~min}$, já que a intenção foi testar o seu funcionamento em condições de campo e comparar com os resultados obtidos pelo $D I V E R^{\circledR}$, visando ser uma alternativa mais econômica para futuros trabalhos.

\subsubsection{Data logger usando Arduino}

Apesar do modelo $U N O$ ser o mais usual, já que é o mais conhecido da série, foi escolhido o modelo Pro mini ${ }^{3}$ (Figura 39), possuindo o mesmo microcontrolador ${ }^{4}$ (ATmega328) que o modelo anterior, além da quantidade de portas analógicas e digitais serem iguais. As razões para essa preferência é que o modelo Pro mini consome menos energia e foi desenvolvido para projetos permanentes com restrição de espaço.

Figura 39 - Arduino Pro mini

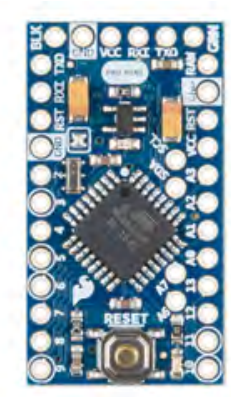

Fonte: Elaborado pelo autor.

O modelo de arduino utilizado requer uma alimentação de no mínimo $5 \mathrm{~V}$ e no máximo $12 \mathrm{~V}$. Todos os componentes conectados ao arduino funcionaram com tensão de operação de $5 \mathrm{~V}$, sendo que essa tensão é definida por um regulador de voltagem presente na própria placa do arduino Pro mini.

A Tabela 10 apresenta os materiais usados para montar o data logger, bem como suas respectivas funções.

Para proteger o arduino e os componentes, de sobretensões em campo e possíveis inversões de polaridade no momento da conexão com a alimentação externa, foram utilizados na entrada da alimentação do sistema, uma ponte de diodos e um regulador de voltagem da série $L 7805$. 
Tabela 10 - Componentes do data logger

\begin{tabular}{lr}
\hline Arduino Pro mini & Microcontrolador do sistema \\
RTC DS 3231 & Real Time Clock (relógio) \\
Módulo SD Card & Armazena as informações em um SD card \\
\hline
\end{tabular}

Fonte: Elaborado pelo autor.

O sensor ${ }^{5} \mathrm{HC}$ - SR04 mostrado na Figura 40 foi o responsável pelas medições da cota do nível d'água na seção convergente da calha Parshall de jusante. A Figura 41 apresenta um resumo das suas principais especificações.

Figura 40 - Sensor de medição de distância ultrassônico HC-SR04.

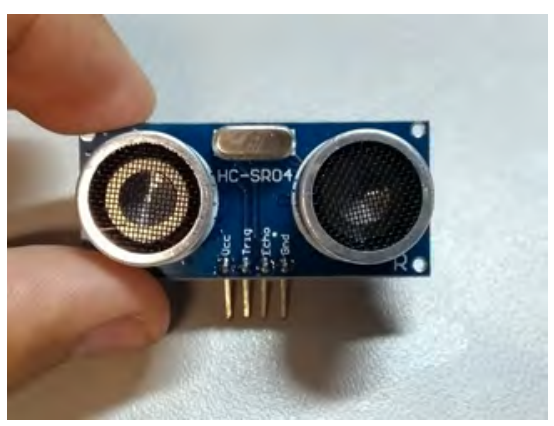

Fonte: Elaborado pelo autor.
Figura 41 - Especificações do HC - SR04

\begin{tabular}{ll}
\hline Voltagem de trabalho & $\mathrm{DC} 5 \mathrm{~V}$ \\
Corrente de trabalho & $15 \mathrm{~mA}$ \\
Frequência de trabalho & $40 \mathrm{~Hz}$ \\
Distância máxima & $4 \mathrm{~m}$ \\
Distância mínima & $2 \mathrm{~cm}$ \\
Ângulo de medição & 15 graus \\
Dimensão & $45^{*} 20^{*} 15 \mathrm{~mm}$ \\
\hline
\end{tabular}

Fonte: Elaborado pelo autor.

Foi necessário desenvolver um código computacional ${ }^{6}$ programação para controlar o data logger, em linguagem $\mathrm{C}++$ no IDE (Ambiente de Desenvolvimento Integrado) que é disponibilizado no site do ${ }^{7}$ Arduino ${ }^{\circledR}$. A Figura 42 apresenta o fluxograma da lógica escrita.

Figura 42 - Fluxograma linear de funcionamento do sistema de medição de nível elaborado.

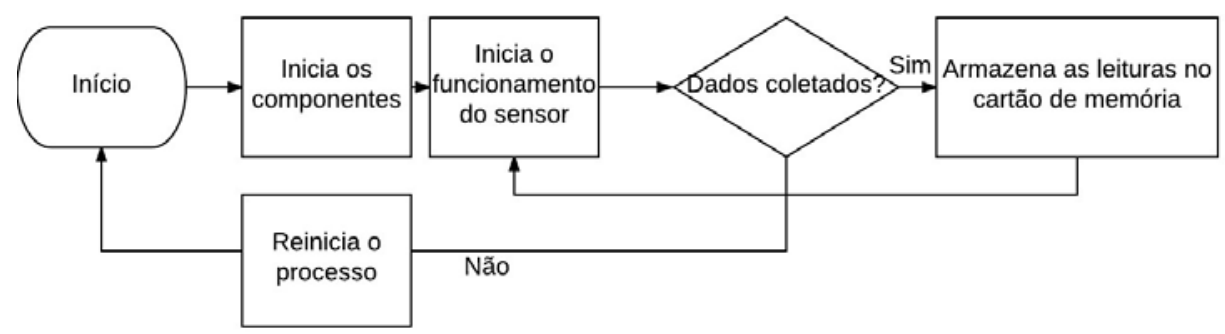

Fonte: Elaborado pelo autor.

Todos os componentes apresentados na Tabela 10 foram conectados ao Arduino Pro mini através de um circuito impresso em placa de fenolite com uma camada condutora de

5 <http://www.micropik.com/PDF/HCSR04.pdf>

6 A programação utilizada, se encontra no Apêndice B deste trabalho

7 <https://www.arduino.cc/en/Main/Software> 
cobre (transferência térmica), o qual pode ser visto na Figura 43. As fotos da fabricação do circuito e o mesmo já pronto com a conexão dos componentes encontram-se no Apêndice C.

Figura 43 - Desenho do circuito impresso na placa controladora do medidor de nível.

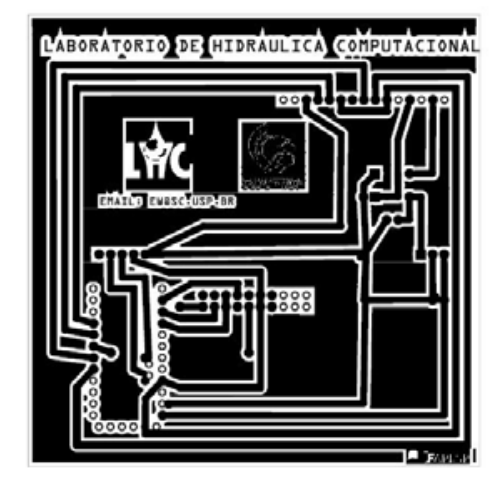

Fonte: Elaborado pelo autor.

Após montar o data logger, foi necessário realizar a calibração do sensor HC SR04. Essa calibração foi feita no Laboratório de Fenômenos de Transportes (LFT - EESC) usando um tubo de PVC de $100 \mathrm{~mm}$ de diâmetro e $1 \mathrm{~m}$ de altura, com uma fita métrica ao lado de um piezômetro conectado ao tubo (Figura 44).

Figura 44 - Tubo de PVC usado na calibração do sensor de nível.

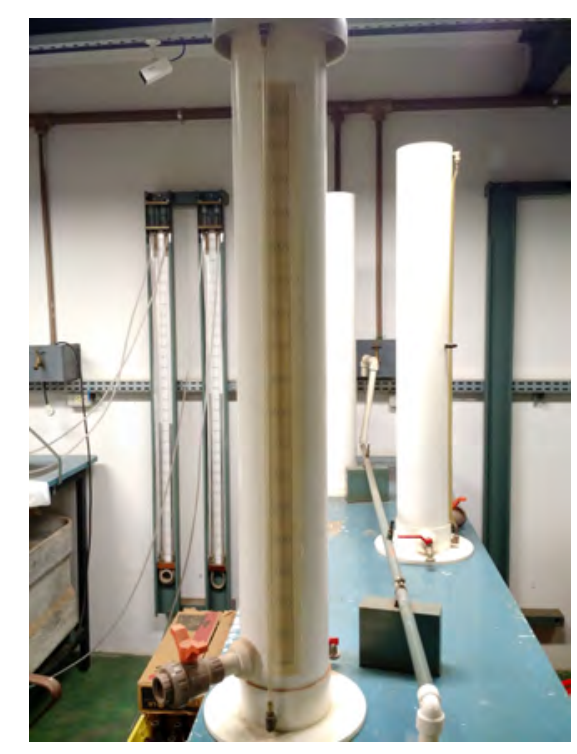

Fonte: Elaborado pelo autor.

Na parte de cima desse tubo foi colocado o sensor (conectado ao data logger) e, para diferentes alturas de água, foram anotados os valores lidos pelo sensor e os valores 
observados pela mangueira do piezômetro. Após este procedimento, foi possível encontrar uma equação de calibração por regressão polinomial.

Para determinar o consumo de energia do equipamento em funcionamento, foi usado um multímetro da UNI-T, modelo DT830B. Para essa determinação, foi preciso conectar o multímetro, em série, na alimentação do data logger. Um esquema dessa conexão em série é apresentado na Figura 45.

Figura 45 - Esquema da ligação em série do multímetro com o data logger.

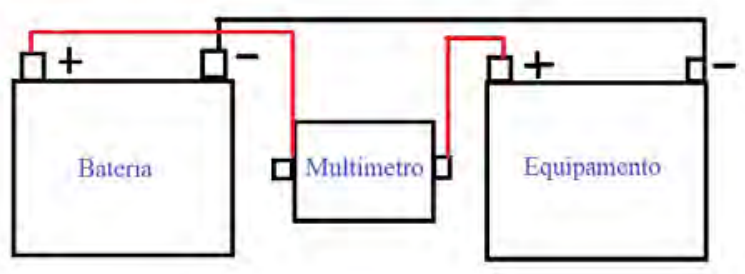

Fonte: Elaborado pelo autor.

O consumo, em funcionamento, do equipamento foi de $70 \mathrm{mAh}$. Desta forma, foi escolhida uma bateria externa de 7A, conectada a um controlador de carga e a um painel solar com voltagem máxima de $20 \mathrm{~V}$ e corrente máxima de $550 \mathrm{mAh}$, para alimentar o data logger. Em dias com pouca luminosidade (nublados), a capacidade da bateria utilizada seria suficiente para manter o equipamento funcionando por 4 dias. A Figura 46 (a) e a Figura 46 (b) mostram a bateria conectada ao controlador de carga, ao equipamento e à placa solar em campo.

Figura 46 - Data logger e placa solar instalados em campo.

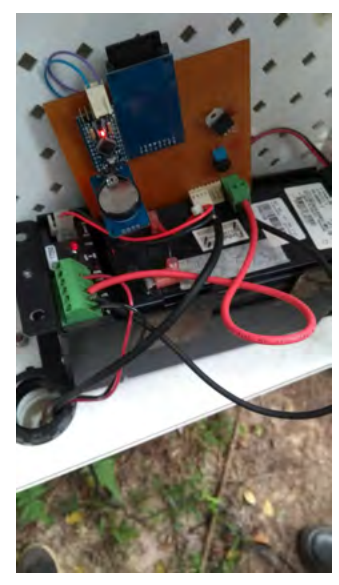

(a) Data logger em campo. Fonte: Elaborado pelo autor.

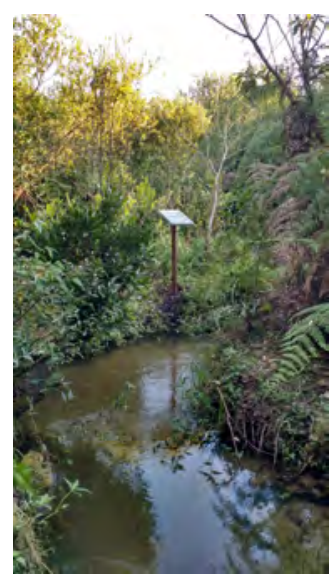

(b) Placa solar em campo. Fonte: Elaborado pelo autor. 
Um suporte e uma estrutura montada com perfil de fiação elétrica e fusos de rosca foram utilizados para sustentar o sensor a uma cota de $127 \mathrm{~cm}$ da base da calha Parshall, como pode ser visto na Figura $4 \%$.

Figura 47 - Estrutura para sustentar o sensor acima da calha.

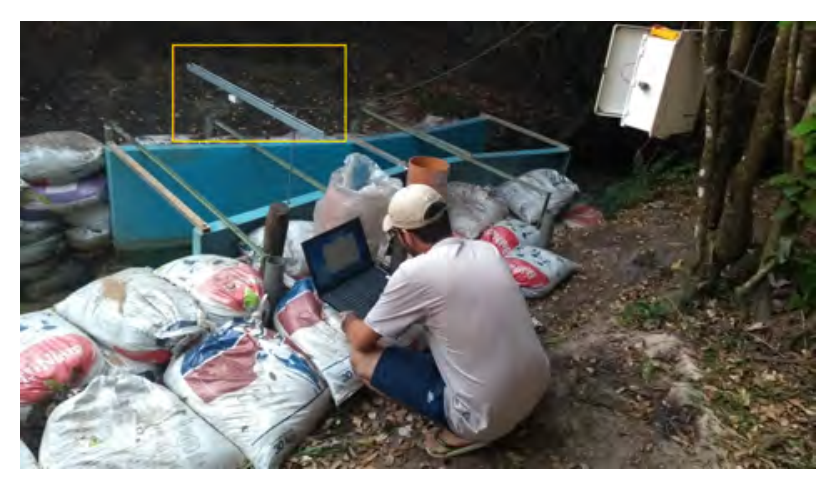

Fonte: Elaborado pelo autor. 


\subsubsection{Estatísticas de precisão do HC - SR04}

Para testar a performance do data logger, foram adotados alguns indicadores estatísticos listados na Tabela 11.

Tabela 11 - Indicadores estatísticos aplicados ao data logger

\begin{tabular}{lll}
\hline Descrição & Símbolo & Fórmula de cálculo \\
\hline Viés & BIAS & Equação 4.3 \\
Coeficiente PBias & PBIAS & Equação 4.4 \\
Raiz do erro quadrático médio & RMSE & Equação 4.5 \\
Média do erro absoluto & MAE & Equação 4.6 \\
Média percentual do erro relativo & PMRE & Equação 4.7 \\
Intervalo de confiança para $\alpha=0,95$ & IC & Equação 4.8 \\
\hline
\end{tabular}

Fonte: Elaborado pelo autor.

$$
\begin{gathered}
\frac{1}{n} \sum_{i=1}^{n}\left(m_{i}-e_{i}\right) \\
\frac{\sum_{i}^{n}\left(m_{i}-e_{i}\right)}{\sum_{i}^{n}\left(m_{i}\right)} * 100 \\
\sqrt{\frac{1}{n} \sum_{i=1}^{n}\left(m_{i}-e_{i}\right)^{2}} \\
\frac{1}{n} \sum_{i=1}^{n}\left|m_{i}-e_{i}\right| \\
\frac{100}{n} \sum_{i=1}^{n}\left|\frac{m_{i}-e_{i}}{m_{i}}\right| \\
z_{\alpha / 2} * \frac{\sqrt{\frac{\sum(y-\bar{y})}{n}}}{\sqrt{(n)}}
\end{gathered}
$$

em que $e_{i}$ é o valor estimado pelo sensor e $m_{i}$ é o valor registrado pelo $D I V E R^{\circledR}, \mathrm{n}$ é o tamanho da amostra, e z é o coeficiente de confiança $(1,96$ para $\alpha=0,95)$.

\subsubsection{Cálculo das vazões das sub-bacias}

Como visto na subseção 3.2.1.2 a calha Parshall pode trabalhar em dois tipos diferentes de escoamento (livre ou submerso), os quais apresentam equações diferentes. Com base nessa característica, após instalar as calhas, foi necessário identificar o tipo de 
regime que ocorria. Para isso a relação $H_{b} / H_{a}$ foi calculada. Para condições de escoamento livre, o resultado deve ser igual ou inferior a 0,64 (SKOGERBOE et al., 1966).

A relação $H_{b} / H_{a}$ para a calha Parshall de montante ficou compreendida entre 0,50 e 0,55 e para a de jusante, entre 0,50 e 0,60 durante o período de estudo. Portanto a Equação 3.18) foi utilizada, bem como seus coeficientes e expoentes para a largura da garganta de 18 " como é apresentado na Equação 4.9.

$$
Q\left(m^{3} / s\right)=1,038 * h^{1,521}
$$

Para o vertedor foi aplicada a Equação 4.10, já que foi empregado um vertedor do tipo Thomson neste trabalho.

$$
Q\left(m^{3} / s\right)=1,4 * h^{\frac{5}{2}}
$$

O vertedor foi instalado no dia 14/11/2017. Para estimar os valores de vazão na seção do vertedor anteriores a sua instalação, foi necessário aplicar um preenchimento de falhas na série de dados. Para isso, na calha Parshall 1 e 2 foi realizada uma regressão polinomial entre os valores de vazão observados no vertedor com a finalidade de verificar qual calha apresentou a melhor correlação e assim estender a série temporal.

Depois de gerar os hidrogramas dos quatro pontos de monitoramento (calha de montante, calha de jusante, vertedor e ADCP) foi feito um balanço de vazão para cada sub-bacia estudada (1,2 e 3), semelhante ao descrito na Equação 3.4. Para isso, foi feita a subtração da vazão de montante da de jusante das respectivas sub-bacias, no mesmo instante, como mostra a Equação 4.11.

$$
Q_{r t}=Q_{j t}-Q_{m t}
$$

Em que $Q_{r t}$ é a vazão total resultante do trecho em $\left(m^{3} / h\right), Q_{j t}$ é a vazão total do ponto de monitoramento de jusante em $\left(m^{3} / h\right)$ e $Q_{m t}$ é a vazão total do ponto de monitoramento de montante em $\left(\mathrm{m}^{3} / h\right)$.

Assim foi possível calcular os hidrogramas resultantes de cada sub-bacia e proceder com a análise da interação rio aquífero (seção 4.6).

\subsection{Análise da interação rio aquífero}

A análise da interação entre o rio e o aquífero na BRO foi feita a partir do índice de escoamento de base $(B F I)$ e do volume do escoamento de base em cada sub-bacia. O $B F I$ foi calculado usando a divisão entre o volume do escoamento de base e o volume do escoamento total, para o período desse estudo. 
Foi necessário separar a vazão de base $\left(Q_{b}\right)$, da vazão total resultante de cada subbacia $Q_{r t}$ (Equação 4.11). Foi utilizado o filtro dos mínimos locais, proposto no trabalho de Sloto e Crouse (1996), encontrado no Software HYSEP, citado na subseção 3.3.2.

Esse filtro verifica em cada dia da série de vazões se a vazão que está sendo analisada é a menor descarga do intervalo $[0,5(2 N-1)]$, antes e depois do dia considerado. Caso seja, então essa vazão é um mínimo local e é conectada por uma linha reta aos mínimos locais adjacentes. O escoamento de base para os dias entre os mínimos locais, é calculado por interpolação linear (SLOTO; CROUSE, 1996). A Figura 48 apresenta um exemplo desse método.

Figura 48 - Exemplo da separação do escoamento de base pelo método dos mínimos locais.

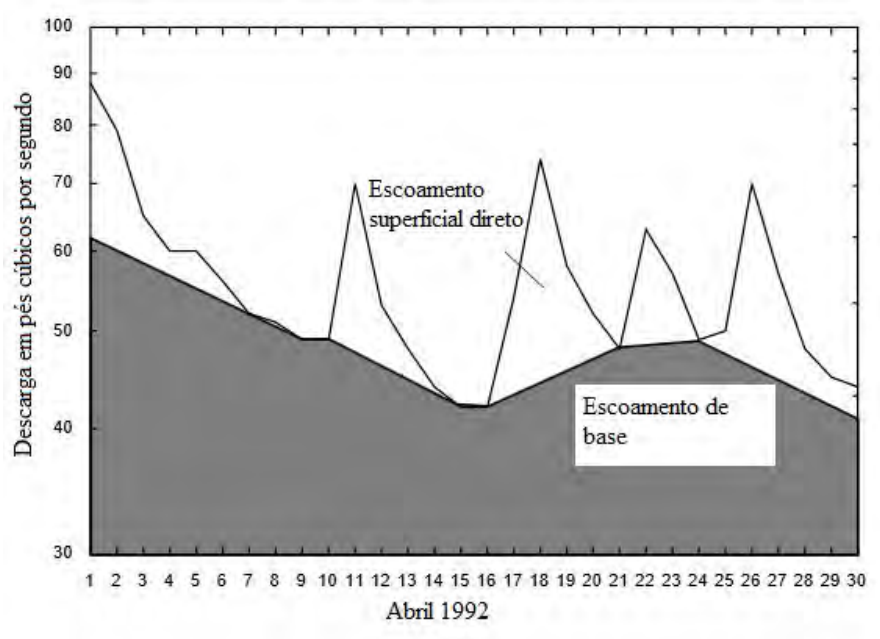

Fonte: Adaptado de Sloto e Crouse (1996).

Após calcular o $Q_{b}$ para cada sub-bacia e, consequentemente, o volume de base escoado $V_{b}$, foi calculado o valor de contribuição de base de cada sub-bacia, por meio da divisão do volume de base escoado na área, durante todo o período do estudo, em $\mathrm{m}^{3}$ pelo valor da área em $m^{2}$. Desta forma foi possível observar as diferenças entre as contribuições das sub-bacias e discuti-las.

Também foi estimado o valor do coeficiente de recessão, a partir dos dados de vazão do período de estiagem do hidrograma resultante de cada sub-bacia. Foram utilizadas a Equação 3.28 (Maillet) e a Equação 3.29 (Boussinesq), sendo que, o valor de $\alpha$ e o valor da vazão inicial $\left(Q_{0}\right)$ foram definidos pelo algoritmo de otimização (SOLVER do Software $E X C E L$ ). A partir destes valores, as vazões foram calculadas para cada instante $t+1$ (escala diária). A partir disto foi possível realizar a diferença entre os valores observados de vazão e os valores obtidos pelas equações e realizar o melhor ajuste, ou seja, a menor diferença possível entre os dados observados e os simulados (método dos mínimos quadrados).

Além disto, foi escolhida a sub-bacia 2 (área 2), por possuir a menor extensão, 
para calcular a taxa de contribuição superficial e linear do aquífero. A taxa de contribuição superficial é o escoamento de base distribuído pela área de troca (área média do leito do ribeirão), na sub-bacia 2 , em $\left[\mathrm{mm} \cdot \mathrm{dia}^{-1}\right]$. Para isto foi necessário calcular o hidrograma resultante desta área descontando a contribuição da afluência, como é apresentado na Figura 49. A Equação 4.12 descreve o cálculo do hidrograma resultante desta área.

Figura 49 - Desenho esquemático da contribuição do aquífero para o Ribeirão.

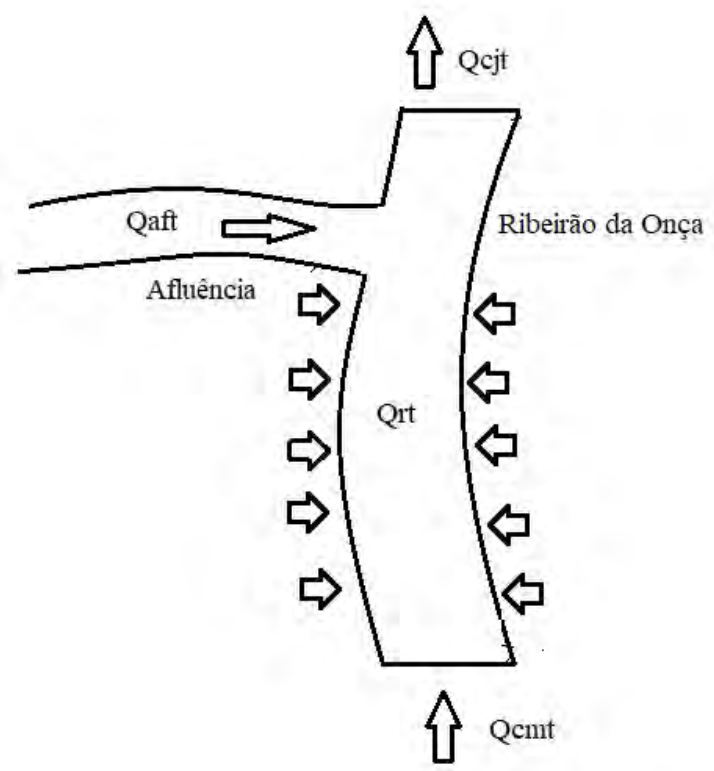

Fonte: Elaborado pelo autor.

$$
Q_{r t}=Q_{C j t}-Q_{C m t}-Q_{A f t}
$$

Em que $Q_{C j t}$ é a vazão total da calha Parshall $2 \mathrm{em}\left(m^{3} / h\right), Q_{C m t}$ é a vazão total da calha Parshall $1 \mathrm{em}\left(m^{3} / h\right)$ e $Q_{A f t}$ é a vazão total do afluente em $\left(m^{3} / h\right)$.

Após calcular a vazão resultante da sub-bacia 2 foi novamente aplicado o filtro dos mínimos locais, para separar o $Q_{b}$ do $Q_{r t}$. A taxa de contribuição superficial do aquífero nessa área foi calculada a partir da razão entre o valor do volume de base escoado diário $V_{b}$ e a área média do leito do ribeirão, no trecho da sub-bacia 2, exemplificada na Figura 50.

Esta área foi calculada pelo produto entre o perímetro molhado do leito do ribeirão da Onça e o comprimento do trecho da sub-bacia 2. Para isso, foi considerada uma profundidade média de cerca de $1 \mathrm{~m}$, uma largura média igual a 2,5 $\mathrm{m}$ e, a extensão total do trecho igual a $1300 \mathrm{~m}$ totalizando cerca de $5.850 \mathrm{~m}^{2}$.

A taxa de contribuição linear em $m^{2} \cdot d i a^{-1}$ é o $V_{b}$ dividido pela extensão total do trecho $(1300 \mathrm{~m})$. 
Figura 50 - Esquema da seção do leito do Ribeirão da Onça.

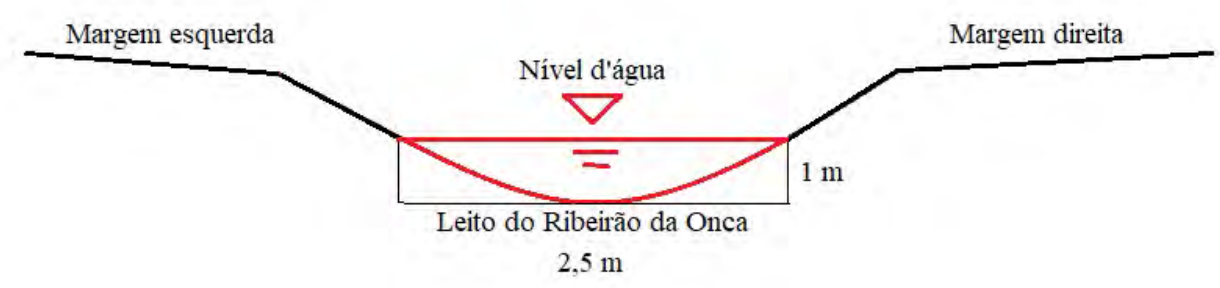

Fonte: Elaborado pelo autor.

\subsubsection{Identificação dos pontos de interação rio - aquífero}

Outra técnica também foi utilizada na sub-bacia 2 para avaliar a interação entre o rio e o aquífero, a qual consiste em utilizar a temperatura da água do aquífero como traçador. A partir deste método foi possível verificar pontualmente onde ocorria a interação, seu tipo e a sua intensidade.

Para verificar se a temperatura poderia ser utilizada como traçador no Ribeirão da Onça, foi realizada uma análise da série histórica da ${ }^{8}$ temperatura (06/2011 a 06/2017) do poço 16, um dos poços de monitoramento instalados na bacia, e do línigrafo.

Após a análise, foi necessário montar um aparato para coletar as temperaturas no leito do ribeirão. Foram utilizados 4 termopares do tipo $K$ da marca $O M E G A^{\circledR}$, um termômetro modelo RDXL4SD, também da $O M E G A^{\circledR}$ (Figura $51(a)$ ) e uma haste de bambu.

Os termopares foram distribuídos na haste, a uma distância de $10 \mathrm{~cm}$ entre eles, como mostra a Figura 51 (b). No dia 13/07/2017 foram realizadas medições da temperatura, em profundidade, do leito do Ribeirão da Onça, entre a calha 1 e a calha 2.

As coletas de temperatura foram realizadas perfurando o leito do ribeirão com a haste, de forma que o primeiro termopar ficasse em contato com o leito e os outros três abaixo. Os pontos onde foram coletadas as temperaturas foram registrados com GPS da marca Garmin $^{\circledR}$, modelo Etrex. A Figura 52 ilustra o trabalho em campo.

Para realizar estas medições foram registrados os pontos onde foram coletadas as informações com o auxílio de um GPS da marca, modelo Etrex. Assim, as coletas de temperatura foram realizadas perfurando a base do ribeirão com a vara, de forma que o

$8 \overline{\text { As temperaturas foram coletadas por } D I V E R}{ }^{\circledR}$ instalados no poço 16 e no línigrafo (na seção 3 onde se encontra o ADCP). 
Figura 51 - Equipamento para levantamento do gradiente de temperatura no leito do Ribeirão.

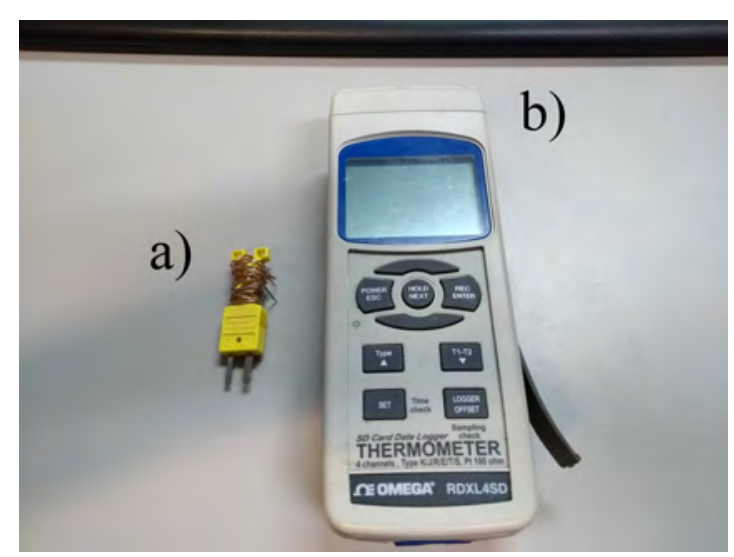

(a) a) Termopar b) termômetro utilizado. Fonte: Elaborado pelo autor.

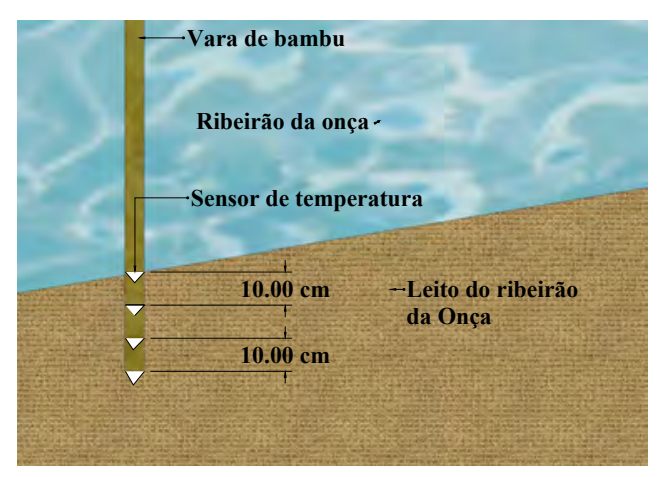

(b) Desenho da distribuição dos termopares na haste. Fonte: Elaborado pelo autor.

primeiro termopar ficasse em contato com a base e os outros três abaixo da base (solo). A Figura 52 mostra o trabalho sendo realizado em campo.

Figura 52 - Trabalho sendo realizado no Ribeirão da Onça.

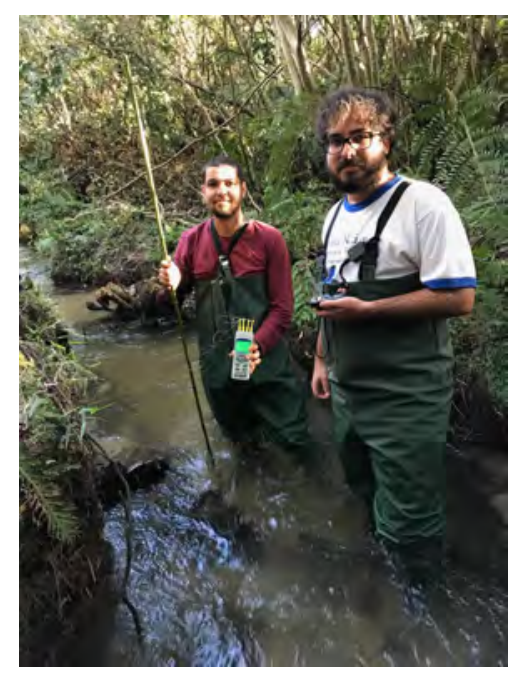

(a) Equipe com o termômetro e o GPS em campo. Fonte: Elaborado pelo autor.

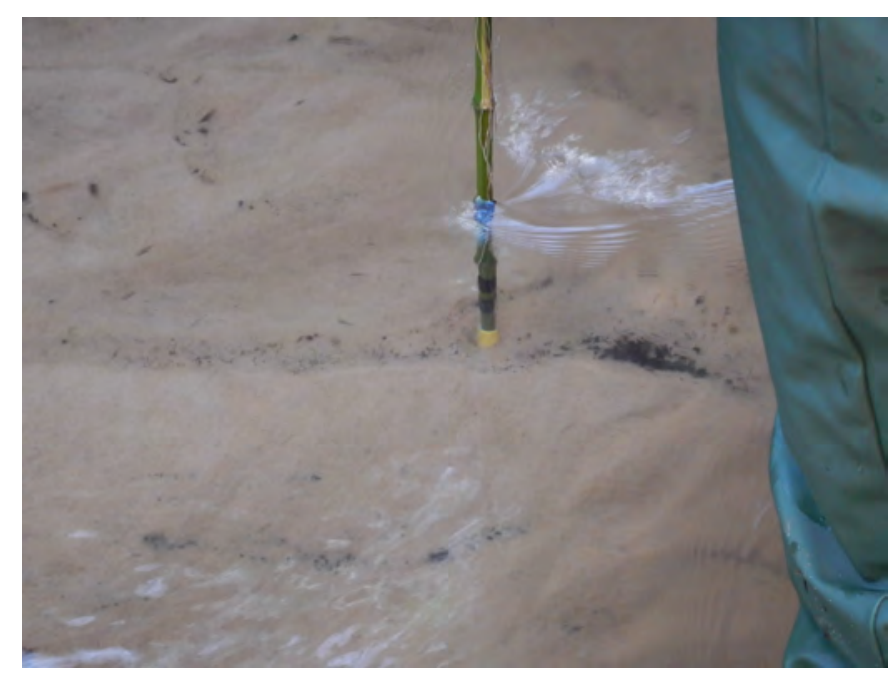

(b) Vara de bambu com os termopares distribuidos, posicionado no leito do ribeirão. Fonte: Elaborado pelo autor.

Após as leituras, um gráfico de contorno foi construído com o auxílio do software Matla $b^{\circledR}$ para identificar e analisar os pontos de interação. 


\section{RESULTADOS E DISCUSSÃO}

\subsection{Análise do escoamento superficial}

\subsubsection{Variação da pressão atmosférica (barométrica) e filtragem - passa baixa}

Para discutir a influência da pressão atmosférica na leitura dos transdutores de pressão, foi escolhido um período de uma semana, de 11/6/17 a 18/6/17 durante o período de estiagem. A Figura 53 apresenta a variação da pressão absoluta e da pressão barométrica, em função do tempo, nas duas calhas utilizadas para o monitoramento do escoamento superficial.

Figura 53 - Variação da pressão absoluta e da pressão atmosférica nas calhas Parshall.

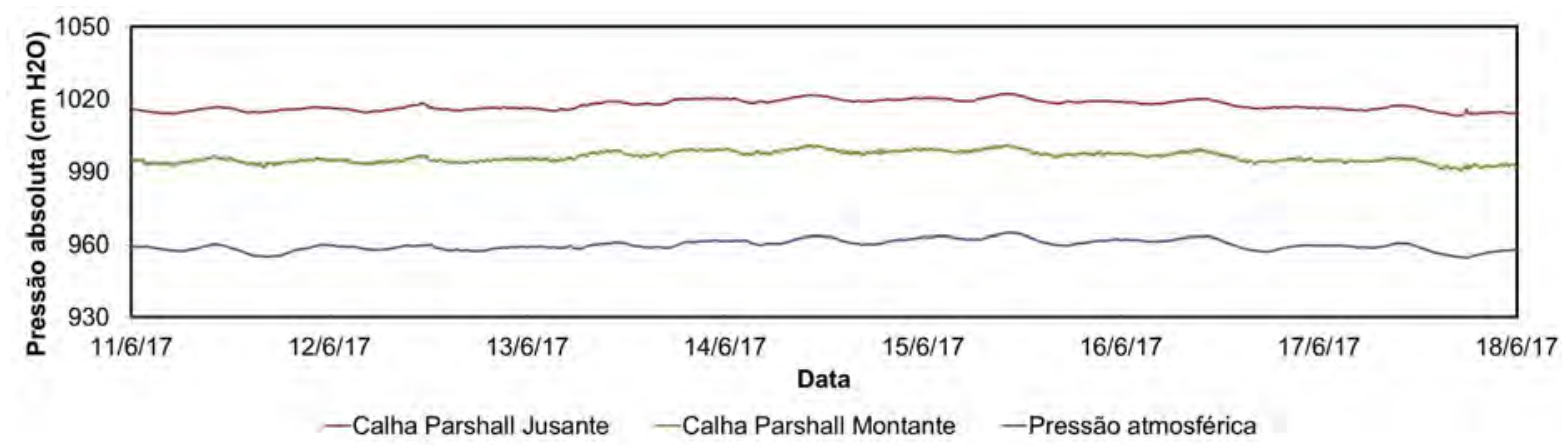

Fonte: Elaborado pelo autor.

É possível perceber, a partir de uma análise da Figura 53 que a pressão absoluta, registrada nas calhas, e a pressão barométrica, variam ao longo do tempo, mesmo na ausência de chuvas. Verifica-se que a variação da pressão registrada nos linígrafos das calhas em períodos de estiagem, deve-se à dinâmica da pressão atmosférica. A análise estatística na Tabela 12, mostra que os valores dos desvios e das variâncias calculados são muito próximos.

A Figura 54 apresenta as normalizadas pelos respectivos valores médios. 
Tabela 12 - Indicadores estatísticos para as pressões absolutas registradas pelo transdutor de pressão nas calhas e para a pressão atmosférica registrada pela estação meteorológica Monte Alegre (EMMA)

\begin{tabular}{lccc}
\hline & $\begin{array}{c}\text { Calha } \\
\text { montante }\end{array}$ & $\begin{array}{c}\text { Calha } \\
\text { jusante }\end{array}$ & $\begin{array}{c}\text { Pressão } \\
\text { atmosférica } \\
\text { (EMMA) }\end{array}$ \\
\hline Média (cm $\left.\mathrm{H}_{2} \mathrm{O}\right)$ & 996,03 & 1017,47 & 959,84 \\
Mediana $\left(\mathbf{c m ~} \mathrm{H}_{2} \mathrm{O}\right)$ & 995,7 & 1017,11 & 959,68 \\
Desvio padrão $\left(\mathbf{c m ~} \mathrm{H}_{2} \mathrm{O}\right)$ & 2,27 & 2,13 & 2,10 \\
Variância $\left(\mathbf{c m ~} \mathrm{H}_{2} \mathrm{O}\right)$ & 5,17 & 4,52 & 4,42 \\
\hline
\end{tabular}

Fonte: Elaborado pelo autor.

Figura 54 - Variação da pressão absoluta, normalizada, nas calhas Parshall, e da pressão atmosférica.

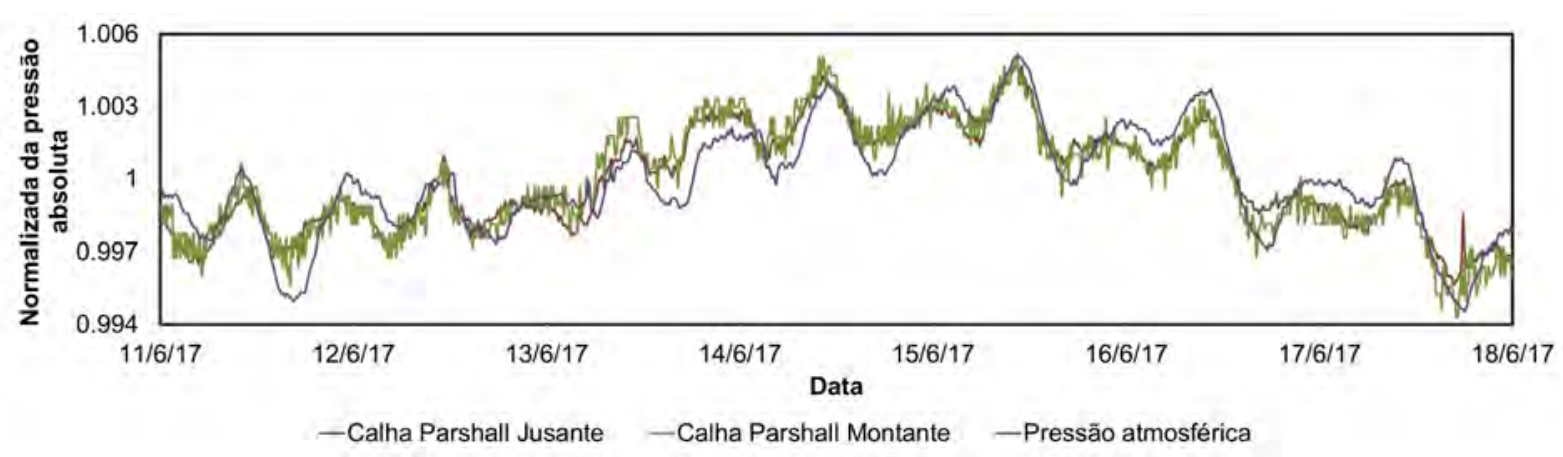

Fonte: Elaborado pelo autor.

É possível perceber que a amplitude da variação diária da pressão barométrica é similar à variação das pressões registradas nas duas calhas. Também, a partir da Figura 54, infere-se que as pressões registradas pelo transdutor apresentam um comportamento praticamente iguais entre si e diferentes comparados com a pressão atmosférica da EMMA. Isso pode ser explicado pelo próprio erro agregado às leituras feitas pelo transdutor, já que o equipamento apresenta acurácia máxima de $\pm 2.5 \mathrm{~cm} \mathrm{H}_{2} \mathrm{O}$, maior que os valores dos desvios encontrados.

Em razão dessa flutuação diária da pressão atmosférica, e dos erros de leitura do próprio equipamento, existe uma flutuação diária nos valores da pressão medidos nas calhas. Dessa forma, existe a necessidade de utilizar um filtro digital (e.g. LOESS) nos dados brutos para suavizar os efeitos subsidiários dessa flutuação. A Figura 55 apresenta a variação dos níveis d'água bruto e filtrado nas calhas de montante e jusante.

A Tabela 13 apresenta alguns indicadores estatísticos dos dados brutos,sem o filtro, e o dos dados pós-processados pelo filtro LOESS. Por essa tabela, percebe-se que as variâncias dos dados brutos são maiores que os dados filtrados, o que evidencia a 
Figura 55 - Variação nos níveis d'água medidos nas calhas Parshall 1 e 2.

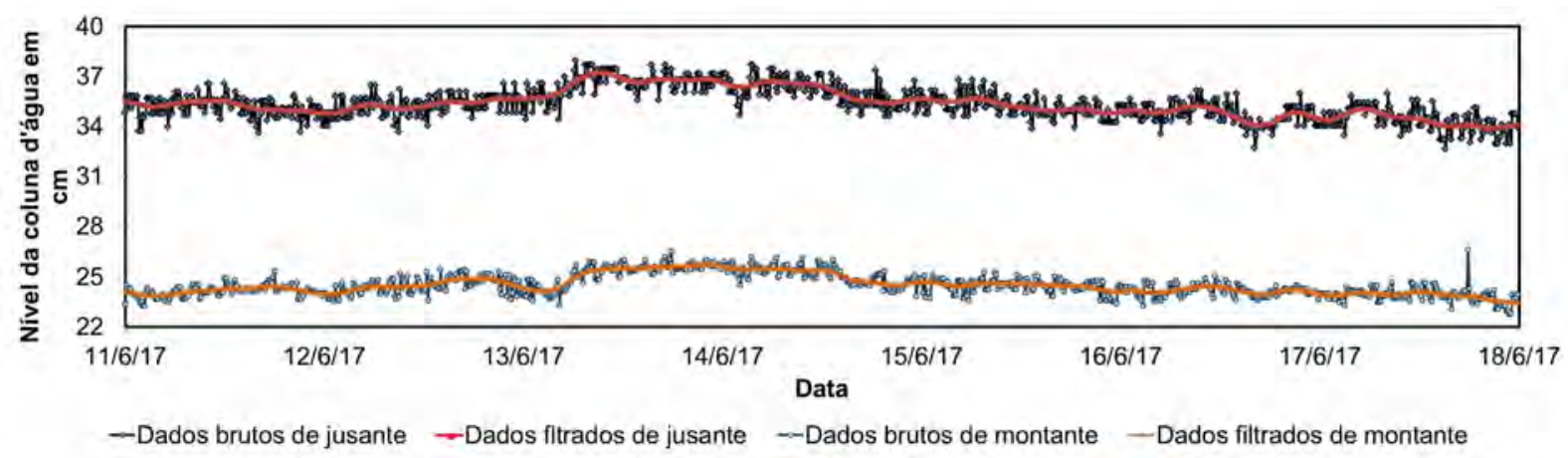

Fonte: Elaborado pelo autor.

necessidade de realizar um pós-processamento dos dados coletados.

Tabela 13 - Indicadores estatísticos para os dados brutos e corrigidos das calhas 1 e 2

\begin{tabular}{lcccc}
\hline & $\begin{array}{c}\text { Nível } \\
\text { d'água da } \\
\text { calha 1 }\end{array}$ & $\begin{array}{c}\text { Nível } \\
\text { d'água da } \\
\text { calha 1 }\end{array}$ & $\begin{array}{c}\text { Nível } \\
\text { d'água da } \\
\text { calha 2 }\end{array}$ & $\begin{array}{c}\text { Nível } \\
\text { d'água da } \\
\text { calha 2 }\end{array}$ \\
\hline Média $(\mathbf{c m})$ & 24,49 & 24,49 & 35,35 & 35,35 \\
Mediana (cm) & 24,40 & 24,38 & 35,27 & 35,23 \\
Desvio padrão (cm) & 0,66 & 0,56 & 0,97 & 0,80 \\
Variância (cm) & 0,44 & 0,31 & 0,93 & 0,64
\end{tabular}

Fonte: Elaborado pelo autor.

\subsubsection{Performance do Arduino}

A Figura 56 apresenta o resultado da calibração do sensor de distância HC - SR04. A distância observada é a distância do nível d'água, verificada no piezômetro, até o sensor e a estimada é o valor obtido pelo sensor utilizado. Por esta figura é possível perceber que o ajuste da linha de tendência foi bom, devido ao alto valor do coeficiente de determinação $R^{2}=0,9998$. Também foi possível perceber durante a calibração que o deslocamento da curva, portanto o erro do sensor, cresceu com o aumento da distância entre o sensor e o obstáculo, no caso o nível d'água.

O data logger montado na plataforma Arduino operou durante 190 dias [(13/04/2017 - 19/05/2017) e (10/07/2017 - 20/12/2017)]. É possível perceber que durante o período em que ele operou houve interrupção dos registros devido a falhas no equipamento. Essas falhas ocorreram em razão de problemas na alimentação do equipamento, pois em dias chuvosos e nublados, o processo de carga da bateria era interrompido. Outro problema identificado em campo, foi a forte oxidação dos pinos de dados e da alimentação do sensor 
Figura 56 - Resultado (Equação e coeficiente de determinação - $R^{2}$ ) da calibração do sensor ultrassônico $\mathrm{HC}$ SR04.

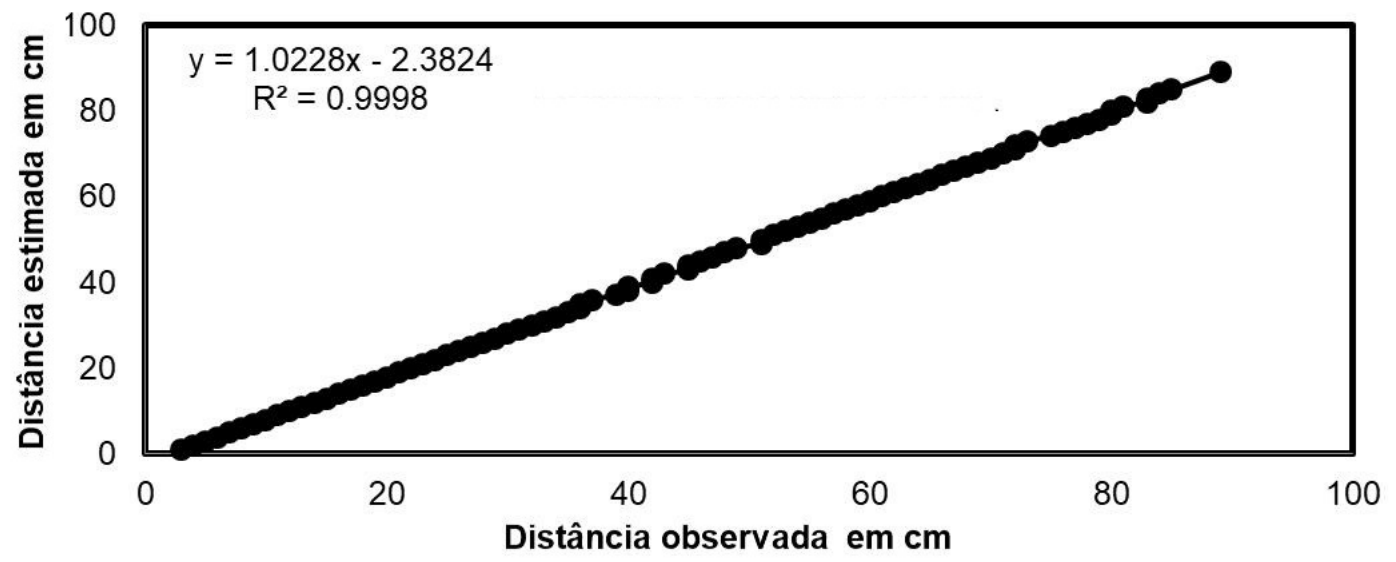

Fonte: Elaborado pelo autor.

(Figura 57), provocada pela exposição do sensor às condições adversas de umidade no campo.

Figura 57 - Pinos oxidados do sensor HC - SR04.

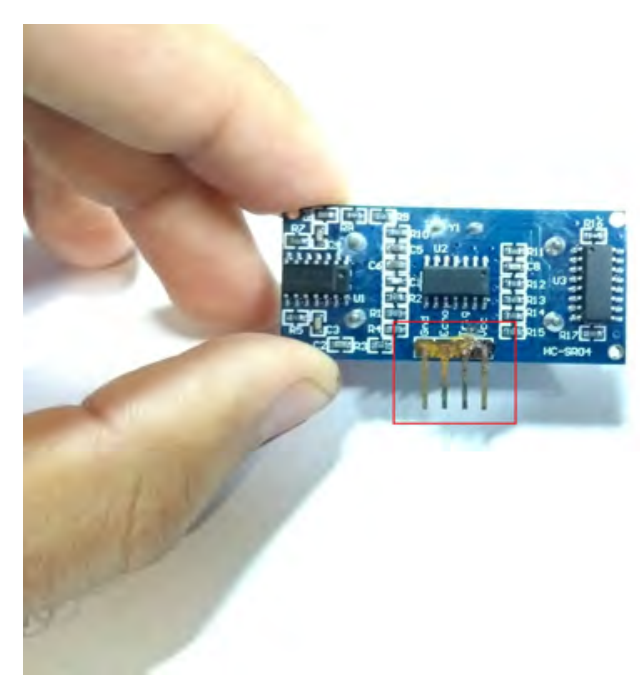

Fonte: Elaborado pelo autor.

O sensor ficou exposto a eventos de precipitação, pois a função da estrutura apresentada na Figura 477 era de só sustentar o equipamento. Esses problemas levaram o sensor a realizar medições erradas do nível d'água na calha Parshall, a exemplo de valores negativos.

Além disso, o data logger parou de funcionar quatro vezes durante o período em que operou, o que fazia com que não fossem armazenados os valores medidos pelo 
sensor. Esses travamentos na execução do código no Arduíno podem ser explicados pela fragmentação da memória do microprocessador Atmega328p durante o período da execução do código. Esse microprocessador apresenta $2 K b$ de memória SRAM, responsável por armazenar, temporariamente, as variáveis da execução do código, que ao longo do tempo de monitoramento pode ser preenchida em razão do uso.

Uma alternativa para esse problema seria utilizar um microprocessador com maior memória SRAM, diminuir o tamanho que as variáveis do código ocupam na memória de processamento do microprocessador e limpar a memória do Arduino após a coleta dos dados armazenados no cartão de memória.

As medições do sensor ultrassônico podem ser vistas na Figura 58, em que são apresentadas as variações do nível d'água na calha Parshall de jusante. é possível perceber que existe um ruído nas medições do transdutor de pressão como também nas medições realizadas pelo sensor ultrassônico. No caso do transdutor de pressão, esse ruído estava diretamente relacionado com a flutuação subdiária da pressão atmosférica e, também, a erros sistemáticos do próprio transdutor de pressão.

Figura 58 - Comparação das medições realizadas pelo transdutor de pressão (DIVER) e pelo sensor HC - SR04.

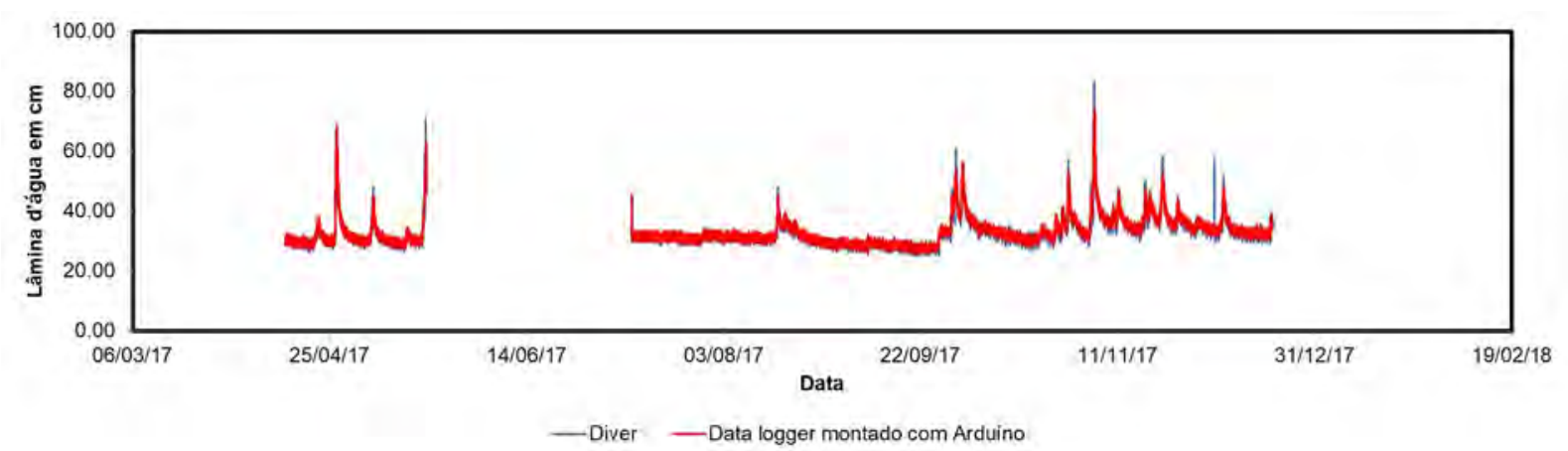

Fonte: Elaborado pelo autor.

Já no caso do HC - SR04 (sensor ultrassônico), o sensor mede a distância até a lâmina d'água. Na entrada da calha Parshall (seção convergente), foi observado que o escoamento ocorre em pequenas e suaves ondas, devido à mudança da seção de escoamento natural do ribeirão. Isso, agregado às limitações do sensor, pode gerar ruídos nas medições, que são maiores que os gerados pelo transdutor de pressão. Uma alternativa para amenizar essa situação seria o uso de um filtro digital, como o LOESS, para reduzir a flutuação desses ruídos.

Os indicadores estatísticos de funcionamento do sensor são apresentados na $T a$ bela 14 . 
Tabela 14 - Valores dos indicadores estatísticos de operação do sensor HC - SR04

\begin{tabular}{lcc}
\hline Indicador & Símbolo & Valor \\
\hline Bias & BIAS & $-0,56$ \\
Coeficiente Pbias & PBIAS & $-9,82$ \\
Erro quadrático médio $(\mathrm{cm})$ & RMSE & 1,72 \\
Média do erro absoluto $(\mathrm{cm})$ & MAE & 1,15 \\
Média do erro relativo & PMRE & 0,035 \\
Intervalo de confiança $\alpha=0,95(\mathrm{~cm})$ & IC & $1,15 \pm 0,27$ \\
\hline
\end{tabular}

Fonte: Elaborado pelo autor.

Os valores negativos dos coeficientes Bias e Pbias, indicam que o sensor ultrassônico tende a subestimar as medições obtidas pelo transdutor de pressão.

Apesar disso, o valor do RMSE foi de aproximadamente 1,7 cm e o PMRE foi de 3,5\%, o que indica um erro baixo, já que a flutuação horária da pressão atmosférica também pode influenciar nas medições feitas pelo transdutor de pressão e apresentam valores superiores aos encontrados nos indicadores estatísticos. $\mathrm{O}$ valor de IC mostra que em 95\% das medições feitas pelo sensor ultrassônico os valores do erro do sensor estão compreendidos entre 1,41 $\pm 0,27 \mathrm{~cm}$. Esses erros na leitura podem estar relacionados também com a variação da temperatura e da umidade relativa do ar, que influenciam na velocidade do som no ar, como mostra o trabalho de Panda et al. (2016). De forma semelhante ao observado por SILVA SOUZA et al. (2017), Jordão et al. (2017) o uso do Arduino $^{\circledR}$ apresentou simplicidade na utilização e na confecção do data logger, com precisão satisfatória, comparada a outras ferramentas comerciais.

Embora o Arduino ${ }^{\circledR}$ tenha se mostrado como uma alternativa econômica e simples de ser empregada, o sensor HC - SR04 apresentou elevada sensibilidade em campo, quando comparado com o transdutor de pressão. Outro fator é que se deve ter o cuidado de otimizar o uso da memória do microprocessador que equipa o modelo do Arduíno, para evitar mau funcionamento e inclusive travamentos. Além disto deve-se ter o cuidado em otimizar o consumo de energia do sistema e escolher a fonte de alimentação mais adequada.

Uma solução para tornar esse data logger mais robusto e empregá-lo com maior segurança no monitoramento seria adicionar um sistema de telemetria online. Assim, seria possível desenvolver um script e verificar, em tempo real, se o equipamento está funcionando corretamente.

\subsubsection{Preenchimento de falhas de dados do vertedor triangular}

Foram realizadas regressões polinomiais entre os dados do vertedor e os dados das calhas de montante e de jusante. Os resultados dessas regressões estão na Figura 59 e na 


\section{Figura 60 .}

Figura 59 - Gráfico da regressão e coeficiente de determinação - $R^{2}$ entre os dados do vertedor e os dados da calha Parshall 1.

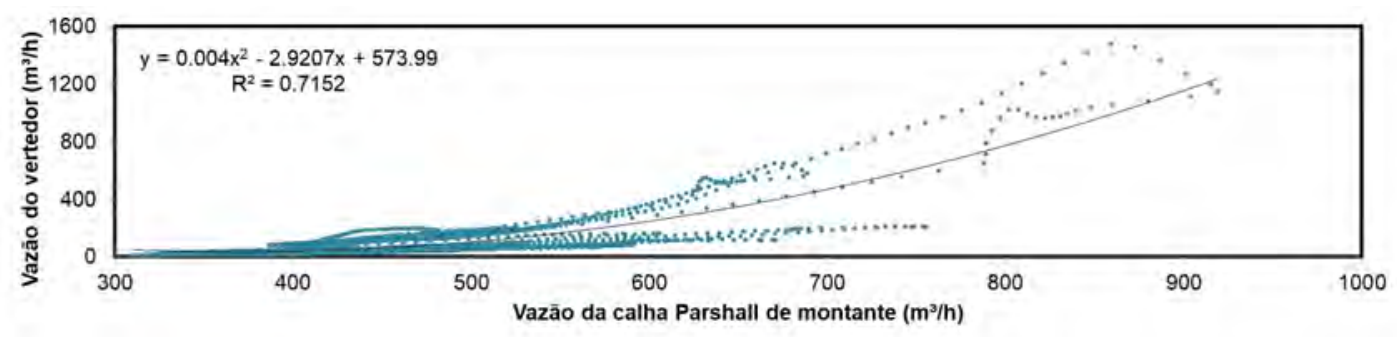

Fonte: Elaborado pelo autor.

Figura 60 - Gráfico da regressão e coeficiente de determinação - $R^{2}$ entre os dados do vertedor e os dados da calha 2.

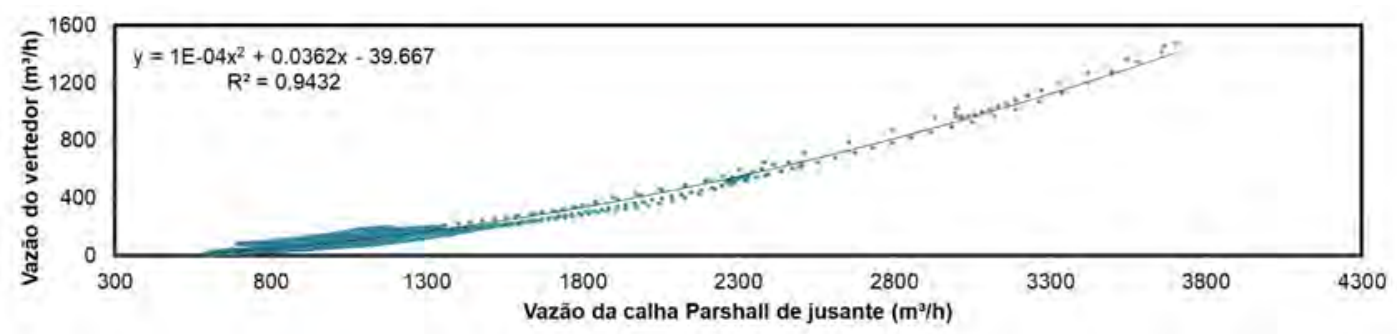

Fonte: Elaborado pelo autor.

Os dados do vertedor ajustam-se melhor aos da calha 2. Espera-se que o comportamento do hidrograma, gerado pelos dados da calha de jusante, sejam similares aos do vertedor, com picos de vazão em resposta a eventos de precipitação.

A variação da vazão na sub-bacia 2 (Figura 21) em resposta a eventos de precipitação é captada pelo transdutor de pressão instalado na calha de jusante. Essa variação também depende do tipo e das condições da vegetação da área acima da calha 2 (grande parte solo exposto), o que é semelhante ao vertedor, uma vez que também se encontra na sub-bacia 2. Isso não é observado na calha 1, que recebe apenas a contribuição da subbacia 1 (Figura 21), com uso do solo diferente (citros) e, consequentemente, escoamento superficial diferente da sub-bacia 2. 


\subsubsection{Vazão do ribeirão na área de estudo}

Os valores lidos pelo ADCP nas calhas 1 e 2 foram $0,1 \mathrm{~m}^{3} / \mathrm{h}$ e $0,16 \mathrm{~m}^{3} / \mathrm{h}$ e os valores calculados para as respectivas calhas foram $0,102 \mathrm{~m}^{3} / \mathrm{h}$ e $0,163 \mathrm{~m}^{3} / \mathrm{h}$. Isso demonstra que as ambas as calhas Parshall operam corretamente.

As vazões podem ser percebidas, nas Figura 61, Figura 62 e Figura 63, nas quais são apresentados os hidrogramas das sub-bacias 1, 2 e 3.

Figura 61 - Hidrograma do escoamento superficial para a sub-bacia 1.

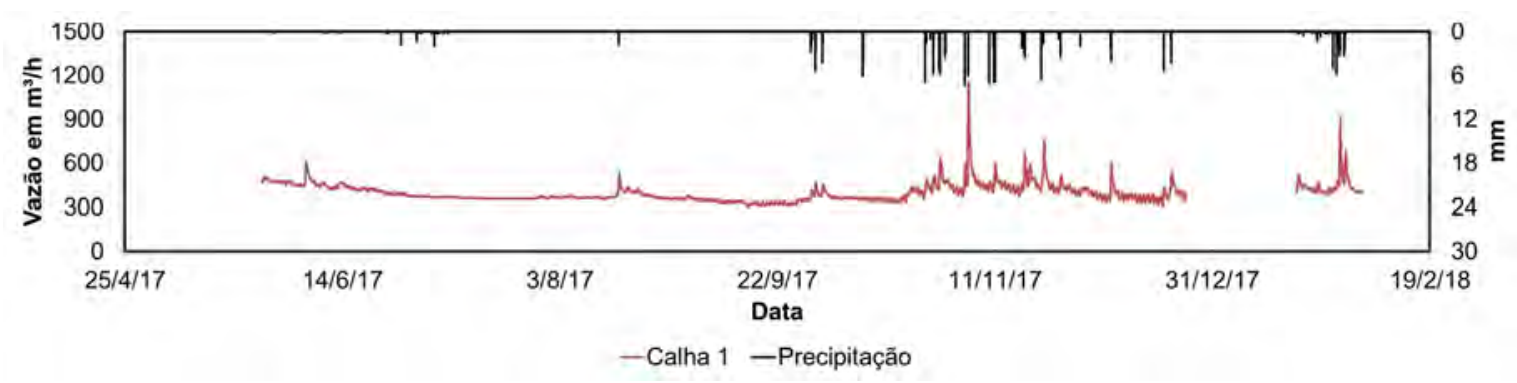

Fonte: Elaborado pelo autor.

Figura 62 - Hidrograma do escoamento superficial para a sub-bacia 2.

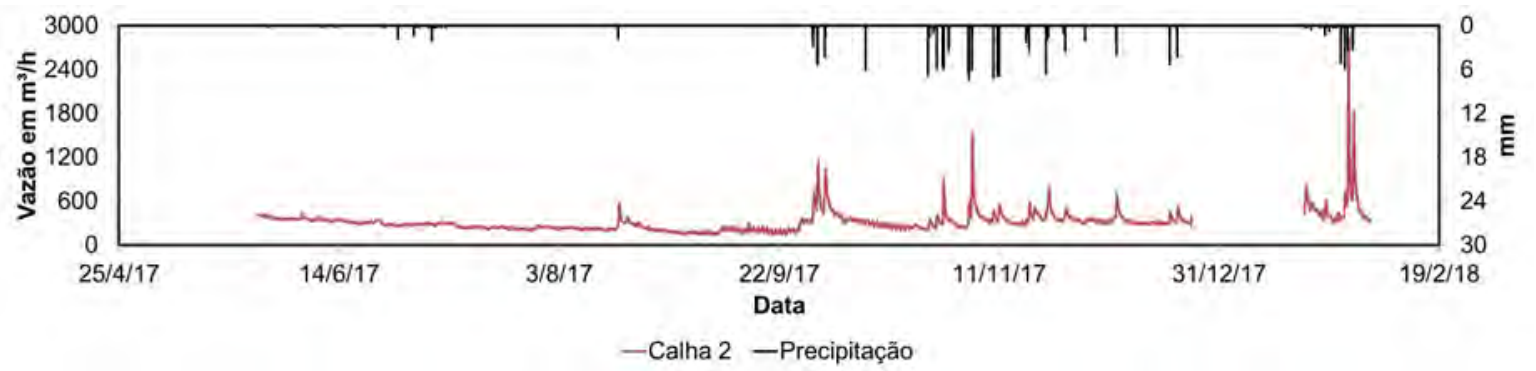

Fonte: Elaborado pelo autor.

Fica evidente que, quanto maior a área da sub-bacia, maior a vazão que é escoada e, consequentemente, maior foi o ruído do monitoramento. Na sub-bacia 3 o ruído também pode ocorrer devido à precisão deste equipamento.

Além disto, os hidrogramas mostram que quanto maior a sub-bacia, maiores foram os picos de cheia. Na Tabela 15 são apresentados os valores médios e os respectivos desvios do escoamento superficial para cada sub-bacia.

Por esses valores, é possível perceber que a média do escoamento superficial na sub-bacia 3 é maior que o da sub-bacia 2, que por sua vez é menor que o da sub-bacia 22 e da sub-bacia 3, podem ser explicados em razão da cobertura vegetal das áreas. 
Figura 63 - Hidrograma do escoamento superficial para a sub-bacia 3.

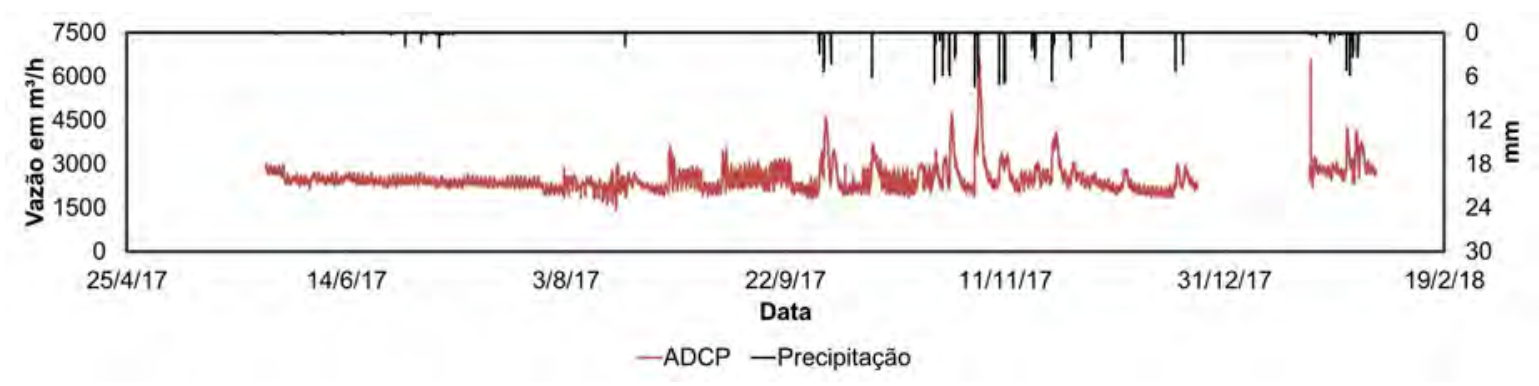

Fonte: Elaborado pelo autor.

Tabela 15 - Dados estatísticos do escoamento superficial, expresso em unidade de vazão, para cada sub-bacia

\begin{tabular}{lccc}
\hline & Sub-bacia 1 & Sub-bacia 2 & Sub-bacia 3 \\
\hline Área drenada $\left(\mathrm{km}^{2}\right)$ & 12,88 & 7,16 & 33,5 \\
Média $\left(\mathrm{m}^{3} / h\right)$ & 400 & 320 & 2590 \\
Desvio Padrão $\left(\mathrm{m}^{3} / h\right)$ & 56,3 & 133,2 & 483,3 \\
Mediana $\left(\mathrm{m}^{3} / h\right)$ & 374 & 300 & 2450 \\
Mínimo $\left(\mathrm{m}^{3} / h\right)$ & 318 & 160 & 2016 \\
Máximo $\left(\mathrm{m}^{3} / h\right)$ & 690 & 1321 & 5201 \\
\hline
\end{tabular}

Fonte: Elaborado pelo autor.

A cobertura vegetal da sub-bacia 1 é predominantemente, composta por citros (67\%), na sub-bacia 2 por eucaliptos (44\%), e na sub-bacia 3 por eucaliptos (43\%) e citros (24\%). Além desses usos, as sub-bacias 2 e a 3 apresentam grandes áreas de solo exposto, $42 \%$ e $14 \%$, respectivamente, que aliados aos diferentes usos do solo, justificam esta variação no escoamento superficial médio, em razão dos picos de vazão nestas áreas serem maiores.

A análise da Tabela 15, mostra que a média do escoamento superficial da sub-bacia 2 é menor que a da sub-bacia 1. Apesar disso, o desvio padrão da média do escoamento, da sub-bacia 2, é praticamente o dobro da sub-bacia 1, mostrando a maior resposta do solo exposto a eventos de precipitação. Isso também pode ser observado na sub-bacia 3 que apresenta um valor médio do escoamento superficial de cerca de $5 x$ maior que o da sub-bacia 2, no entanto o desvio padrão do escoamento não acompanha essa proporção, revelando que a sub-bacia 2 , dentre as sub-bacias, é a que proporcionalmente, apresenta os maiores picos de vazão.

Esse resultado condiz com o que Silva et al. (2011) observaram, que as perdas de água em solos expostos foram maiores que em áreas de cultivo de eucalipto (áreas florestadas). Além disso, Liu et al. (2012) também observaram que práticas conservacionistas de solo, em culturas de citros, foram eficazes para reduzir o escoamento superficial nessas áreas. 


\subsection{Variação do escoamento de base entre as áreas de contribuição}

\subsubsection{Escoamento de base}

Nas Figura 64 à Figura 66 são apresentados os resultados da separação do escoamento de base com o método dos mínimos locais do Software HYSEP.

Figura 64 - Hidrograma do escoamento superficial e escoamento de base para a sub-bacia 1.

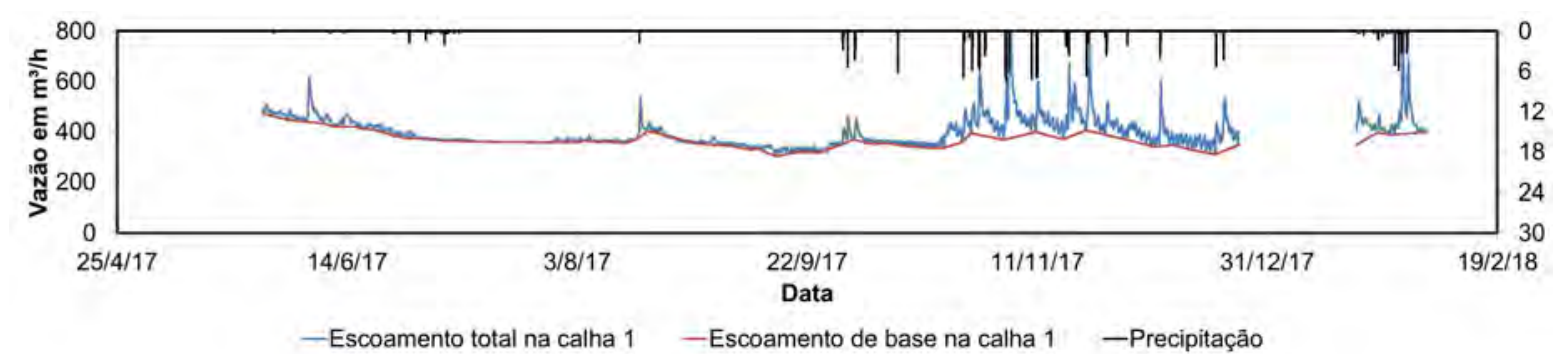

Fonte: Elaborado pelo autor.

Figura 65 - Hidrograma do escoamento superficial e escoamento de base para a sub-bacia 2.

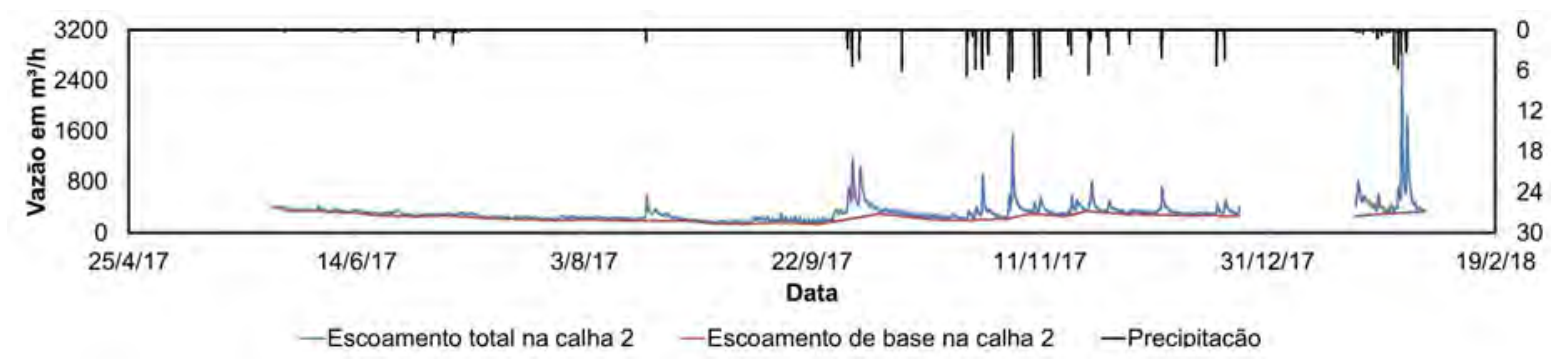

Fonte: Elaborado pelo autor.

Também foram calculadas as contribuições de base para cada sub-bacia, da área de estudo, como mostra a Tabela 16. 
Figura 66 - Hidrograma do escoamento superficial e escoamento de base para a sub-bacia 3 .

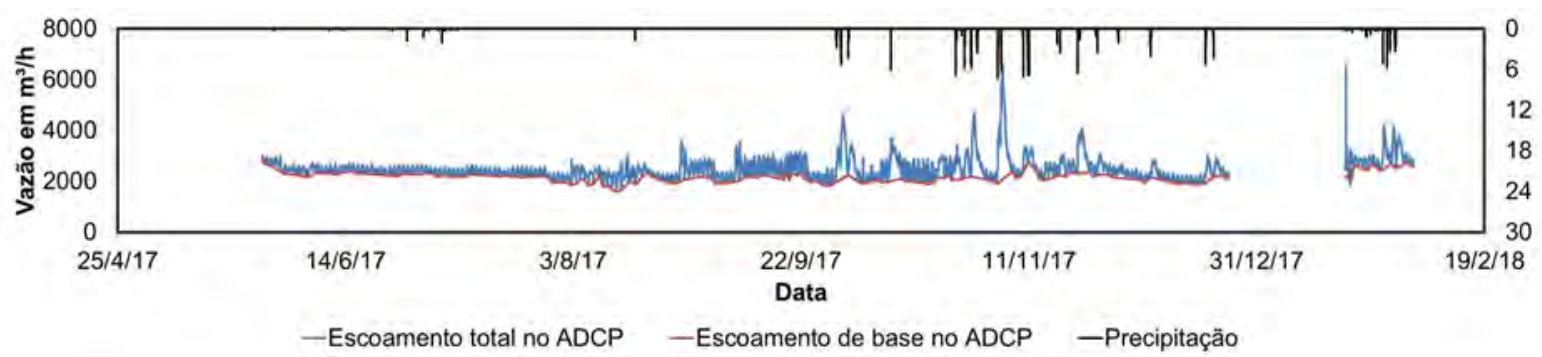

Fonte: Elaborado pelo autor.

Tabela 16 - Contribuição de base para as sub-bacias 1 e 2 e 3

\begin{tabular}{lccc}
\hline & Calha 1 & Calha 2 & ADCP \\
\hline *Volume precipitado (EMMA)( $\mathbf{m m})$ & & 784 & \\
Volume total do escoamento (mm) & 168 & 243 & 407 \\
Volume do escoamento de base (mm) & 155 & 207 & 350 \\
Índice do escoamento de base (BFI) & 0.92 & 0.85 & 0.86 \\
\hline
\end{tabular}

*Data dos dados de precipitação: (26/5/17 - 03/2/18). Fonte: Elaborado pelo autor.

Foi possível perceber a seguinte relação ${ }^{1} V b$ Área $1<V b$ Área $2<V b$ Área3 . Isso pode ser explicado pela influência do uso do solo na recarga do aquífero, nessas áreas.

Na sub-bacia 1, o uso predominante é o citros (67\%), na sub-bacia 2 o uso predominante é o eucalipto (44\%), no entanto o segundo maior uso é o solo exposto $(42 \%)$ e na sub-bacia 3 a maior porcentagem de uso do solo é o eucalipto (43\%). Lucas e Wendland (2015) apresentaram em seu estudo as estimativas de recarga do aquífero para áreas com diferentes usos do solo, na BRO. Foi observado que, as sub-bacias ocupadas com o eucalipto obtiveram a menor taxa de recarga anual $\left(135 \mathrm{~mm}^{\mathrm{anno}} \mathrm{C}^{-1}\right)$, seguida pelas de citros $\left(248 \mathrm{~mm}^{\mathrm{ano}} \mathrm{o}^{-1}\right)$, cana - de - açúcar $\left(296 \mathrm{~mm} . a n o^{-1}\right)$ e as com o pasto (401 $\left.m m . a n o^{-1}\right)$, com a maior taxa de recarga.

Com base nessa informação, pode-se explicar o motivo da sub-bacia 2 ter apresentado uma contribuição maior que a sub-bacia 1. O solo exposto, apesar de possibilitar elevado escoamento superficial, permite maior recarga que o citros, que utiliza mais água para o seu desenvolvimento, (FISHER; HEALY, 2008). Isso foi observado por Lucas (2013), que encontrou maiores valores de recarga em uma área de eucalipto recém cortado, que em áreas de cultivo de citros.

A sub-bacia 1 apresentou o maior BFI (92\%), seguido da sub-bacia 3 (86\%) e da 
sub-bacia 2 (85\%), valores similares aos encontrados por Lucas (2013) (79 a 85\%), para os anos hidrológicos de 2008 a 2011. Isso, possivelmente foi devido à sub-bacia 1 possibilitar menores picos de cheia, em resposta a eventos de precipitação, que as outras sub-bacias. Já na sub-bacia 2 esses picos foram os maiores observados dentre as outras, uma vez que apresentou grande porcentagem de solo exposto em relação às outras.

Também foi analisada a evolução da contribuição superficial e linear do escoamento de base na sub-bacia 2 durante o período deste estudo (Figura 67) e (Figura 68).

Figura 67 - Contribuição superficial do escoamento de base, diário, na sub-bacia 2, situada na área de estudo.

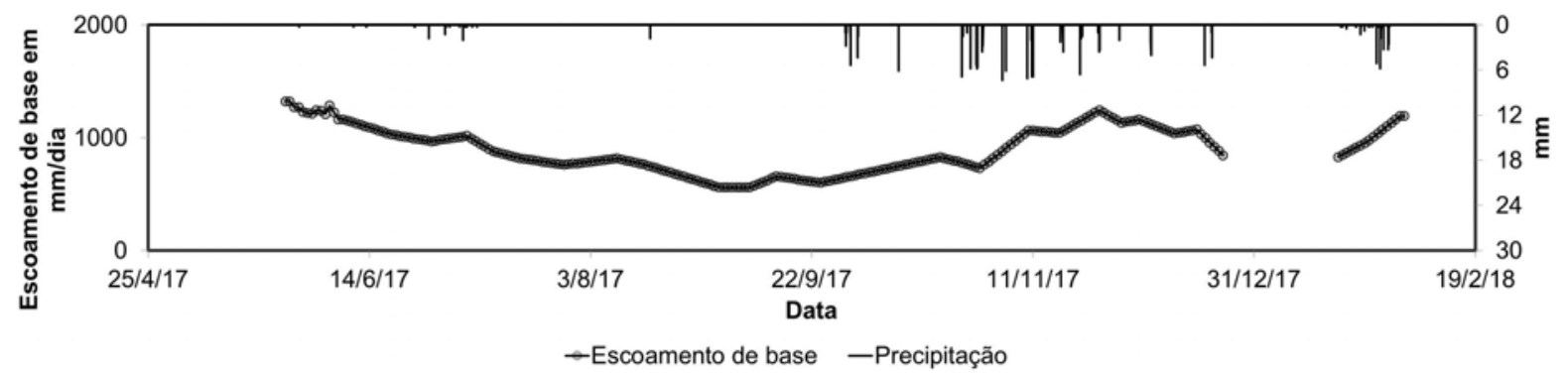

Fonte: Elaborado pelo autor.

Figura 68 - Contribuição linear do escoamento de base, diário, na sub-bacia 2, situada na área de estudo.

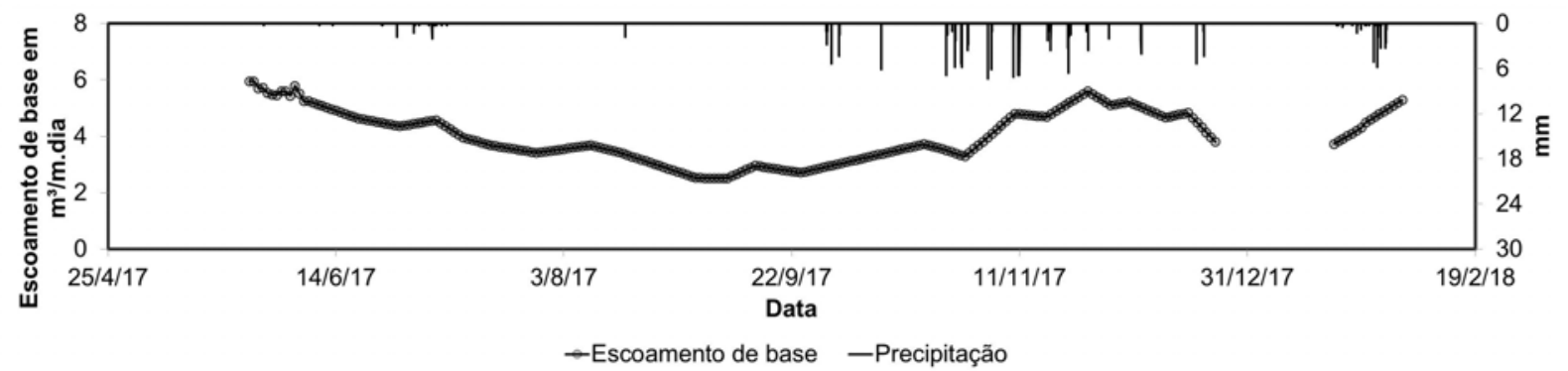

Fonte: Elaborado pelo autor.

Por meio da análise da Figura 67, nota-se que os valores da contribuição encontrados na sub-bacia 2, foram superiores aos valores encontrados por Arantes, Marcussi e Chaudhry (2006), em média $300 m m . d^{-1}$.

Arantes, Marcussi e Chaudhry (2006) analisaram, por meio de infiltrômetros, as relações de troca entre o aquífero e a base do ribeirão da Onça em três pontos de estudo, localizados na sub-bacia 3 deste estudo, sendo que neste trabalho foram utilizadas medições 
de vazão, na sub-bacia 2, para verificar a evolução da contribuição do escoamento de base ao longo de um trecho e não de um ponto.

Os períodos em que foram realizados esse estudo e o de Arantes, Marcussi e Chaudhry (2006), não permitem uma comparação entre os valores obtidos. Além disso, são trechos diferentes, o que também dificulta a comparação entre os valores.

Pelo método do balanço de massa do rio foi possível perceber um aumento na contribuição superficial e linear do escoamento de base, no período de cheia, evidenciando a resposta da vazão do Ribeirão da Onça pela componente mais rápida do escoamento de base, cerca de 60 dias (GARCÍA, 2016). Apesar dessa contribuição ser influenciada pelo período chuvoso, a média observada para a contribuição superficial do escoamento de base foi de cerca de $850 \mathrm{~mm} / \mathrm{d}$ e de aproximadamente $4 \mathrm{~m}^{3} / \mathrm{m}$.d para a contribuição linear.

\subsubsection{Coeficiente de recessão}

Para as sub-bacias deste trabalho, foram calculados os coeficientes de recessão, conforme o melhor ajuste, como já apresentado na seção 4.6.

O período que foi utilizado para esse cálculo foi do dia 26/05/2017 ao dia 24/07/2017, cerca de 60 dias, por não apresentar eventos de precipitação. Na Tabela 17 são apresentados os valores dos coeficientes de recessão, obtidos a partir dos dois métodos (Boussinesq e Maillet), e seus respectivos coeficientes de determinação do ajuste. Os valores do coeficiente de determinação no ADCP (sub-bacia 3) ficaram menores com o aumento da flutuação da vazão média.

Tabela 17 - Valores dos coeficientes de recessão $(\alpha)$ calculados pelos métodos de Boussinesq e Maillet para cada sub-bacia.

\begin{tabular}{ccccc}
\hline & \multicolumn{2}{c}{ Boussinesq } & \multicolumn{2}{c}{ Maillet } \\
\hline Sub-bacia 1 & 0,00424 & 0,90281 & 0,00763 & 0,89807 \\
Sub-bacia 2 & 0,00571 & 0,89814 & 0,00251 & 0,89856 \\
Sub-bacia 3 & 0,00170 & 0,50186 & 0,00045 & 0,48850 \\
\hline
\end{tabular}

Fonte: Elaborado pelo autor.

A partir dos valores do coeficiente de determinação $\left(R^{2}\right)$, pode-se observar que a formulação quadrática proposta por Boussinesq foi a que teve o melhor ajuste para as sub-bacias 1 e 3, com uma mínima diferença em relação à sub-bacia 2. As Figura 69, Figura 70 e Figura 71, apresentam o ajuste das vazões calculadas a partir do valor do coeficiente de recessão de cada uma.

Os valores do coeficiente de recessão variaram de 0,0017 a 0,00571, valores próximos aos encontrados por outros autores na literatura, sendo mais próximos aos observados nos 
Figura 69 - Ajuste da vazão observada na calha 1 e dos modelos quadrático (Boussinesq) e exponencial (Maillet).

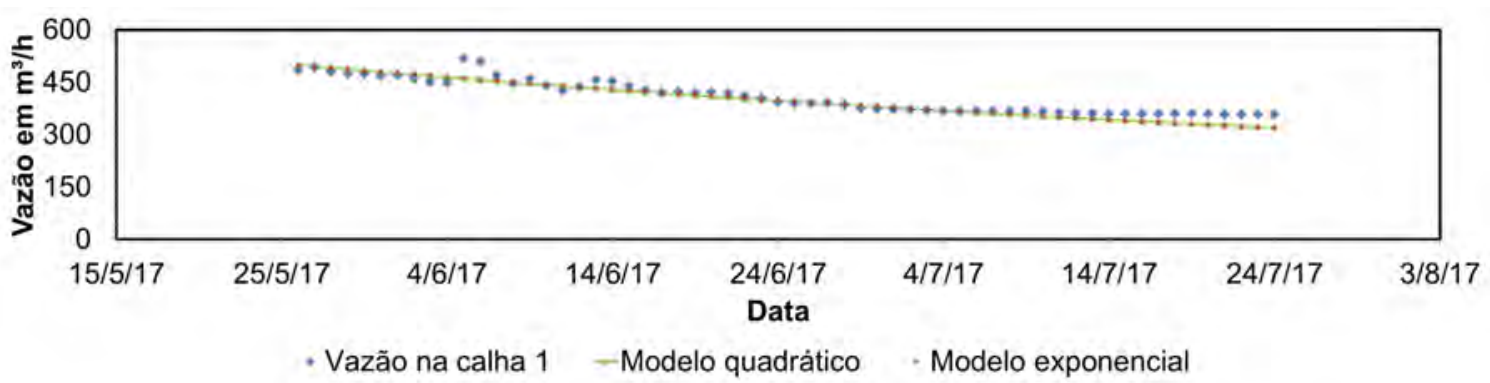

Fonte: Elaborado pelo autor.

Figura 70 - Ajuste da vazão observada na calha 2 e dos modelos quadrático (Boussinesq) e exponencial (Maillet).

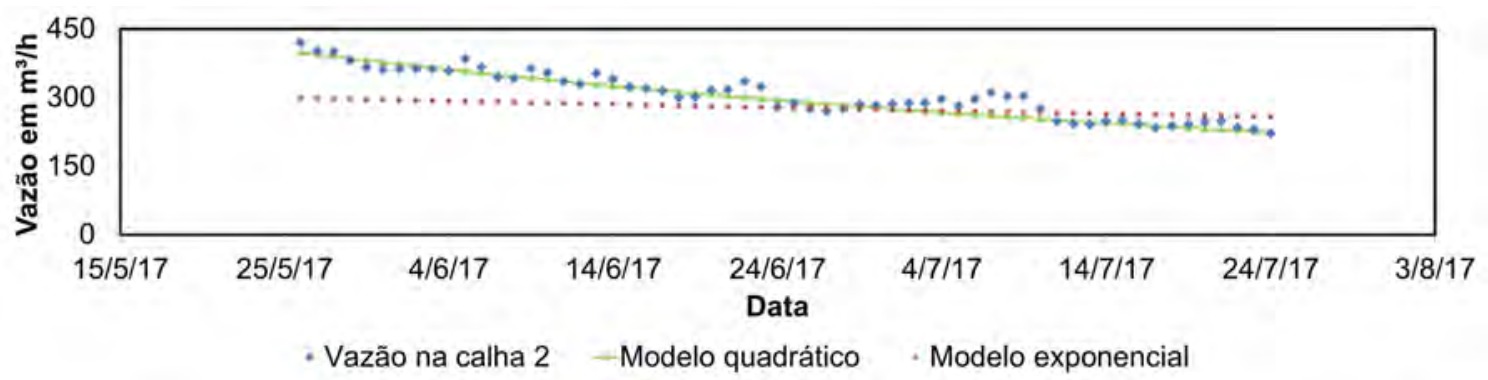

Fonte: Elaborado pelo autor.

trabalhos de Lyon et al. (2015) e Costa, Almeida e Bacellar (2010), apesar das áreas de estudo estarem compreendidas em formações geológicas diferentes.

O coeficiente de recessão é uma função da condutividade hidráulica $(K)$, do rendimento específico $\left(S_{y}\right)$ e da espessura da camada saturada do aquífero $(H)$, portanto, ainda que os valores tenham sido próximos aos encontrados na literatura, isso não significa que os valores de condutividade hidráulica observados na área de estudo sejam similares aos dos outros.

Foi possível também, a partir da média dos coeficientes de recessão, calculados para as 3 sub-bacias, $\left(\alpha=0.00388 \mathrm{dia}^{-1}\right)$ e dos valores médios do rendimento específico e da condutividade hidráulica, calcular a transmissividade e a profundidade média da camada saturada no aquífero livre da BRO. Foram utilizados os seguintes valores:

- $\mathrm{K}=2,308 \mathrm{~m} / \mathrm{d}$ (média da condutividade hidráulica observada por Mattos (2015))

- $S_{y}$ 0,122 (Rendimento específico médio, observado por Gomes (2008)) 
Figura 71 - Ajuste da vazão observada no ADCP e dos modelos quadrático (Boussinesq) e exponencial (Maillet).

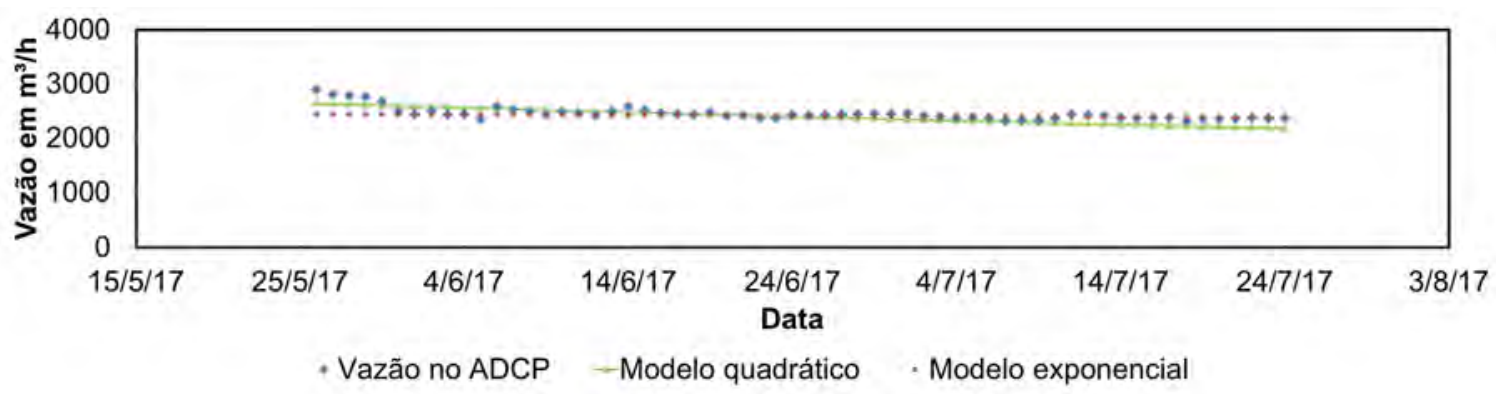

Fonte: Elaborado pelo autor.

A partir do uso desses valores na Equação 3.35, foi obtido a média da espessura da camada saturada, igual a 50,88 m, e a transmissividade média da bacia, igual a 130,96 $m^{2} . d i a^{-1}$. O valor obtido, da profundidade da camada saturada, foi muito próximo ao observado por Melo, Cabrera e Wendland (2017), $50 \mathrm{~m}$.

A grande dificuldade de utilizar um valor médio para o rendimento específico e para a condutividade hidráulica está na heterogeneidade do aquífero. No entanto, a vantagem em utilizar esse método está na sua simplicidade, devido aos poucos dados de entrada, justamente, por necessitar apenas do monitoramento da vazão e estimativas do rendimento específico e da condutividade hidráulica.

\subsection{Temperatura como traçador}

A série histórica da temperatura da água do poço 16 e da temperatura da água do Ribeirão da Onça (registrada pelo linígrafo na seção de controle de vazão) é apresentada na Figura 72. Foi possível perceber que a temperatura do Ribeirão da Onça varia entre 16 ${ }^{\circ} \mathrm{C}$, durante o inverno (Julho) a $23^{\circ} \mathrm{C}$ no verão (Janeiro).

A temperatura da água do aquífero livre mantém-se praticamente uniforme durante o inverno e o verão com variação entre 23,26 e $24,1{ }^{\circ} \mathrm{C}$, com média de, aproximadamente, $23,5{ }^{\circ} \mathrm{C}$, sendo próxima à temperatura do SAG na porção do extremo Leste do Estado de São Paulo $\left(25^{\circ} \mathrm{C}\right)$ (ARAÚJO; FRANÇA; POTTER, 1999).

A Figura 73 apresenta o gradiente de temperatura no leito do Ribeirão. A profundidade $0 \mathrm{~cm}$ corresponde ao leito e $30 \mathrm{~cm}$ à zona hiporreica.

A partir dos dados de temperatura coletados no fundo do ribeirão da onça, no trecho da sub-bacia 2, foi possível comprovar a contribuição do aquífero para o ribeirão, como descrito nos trabalhos de Arantes, Marcussi e Chaudhry (2006), Wendland, Barreto e Gomes (2007). No entanto, é possível verificar que em alguns pontos a temperatura a 30 
Figura 72 - Variação da temperatura da água do aquífero (poço 16) e do ribeirão da Onça (linígrafo) no período de 2011 a 2017.

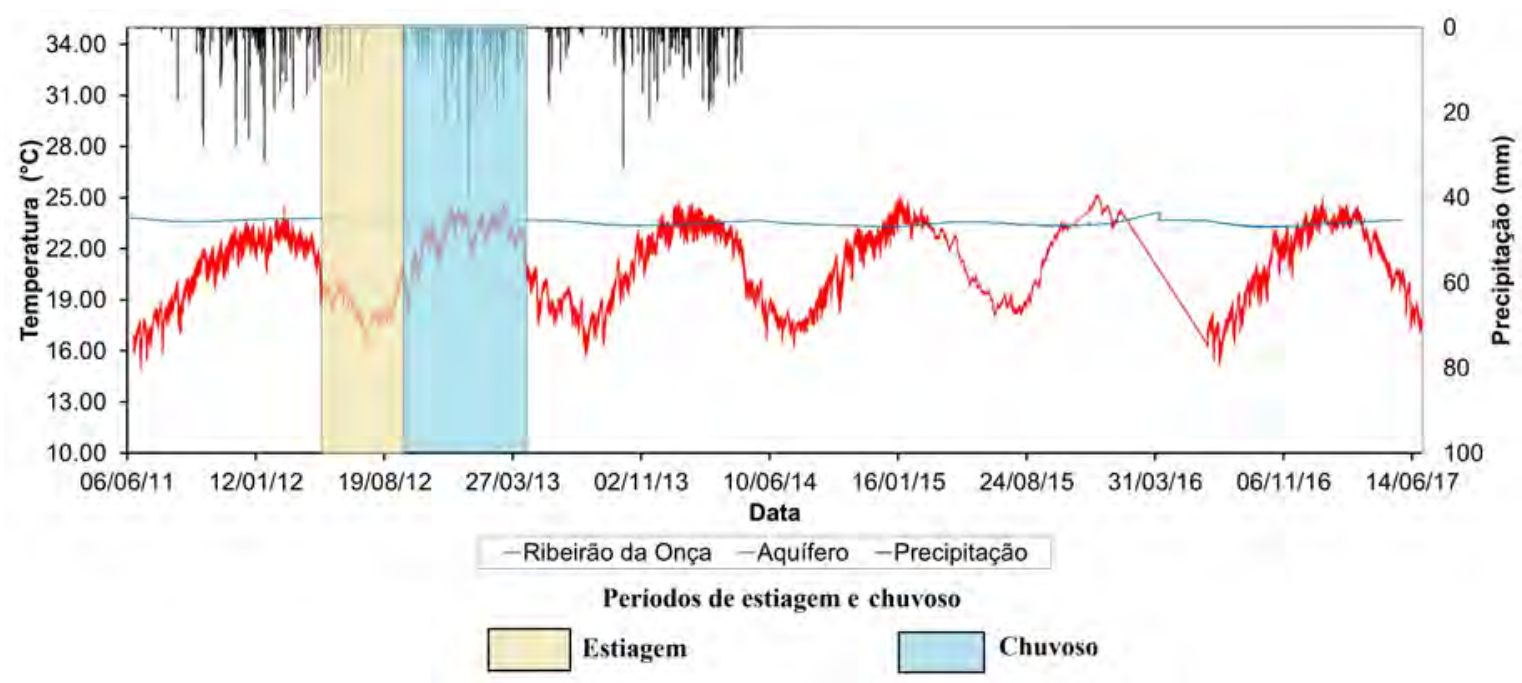

Fonte: Elaborado pelo autor.

Figura 73 - Gradiente de temperatura no leito do ribeirão da Onça para o trecho entre as calhas (sub-bacia 2).

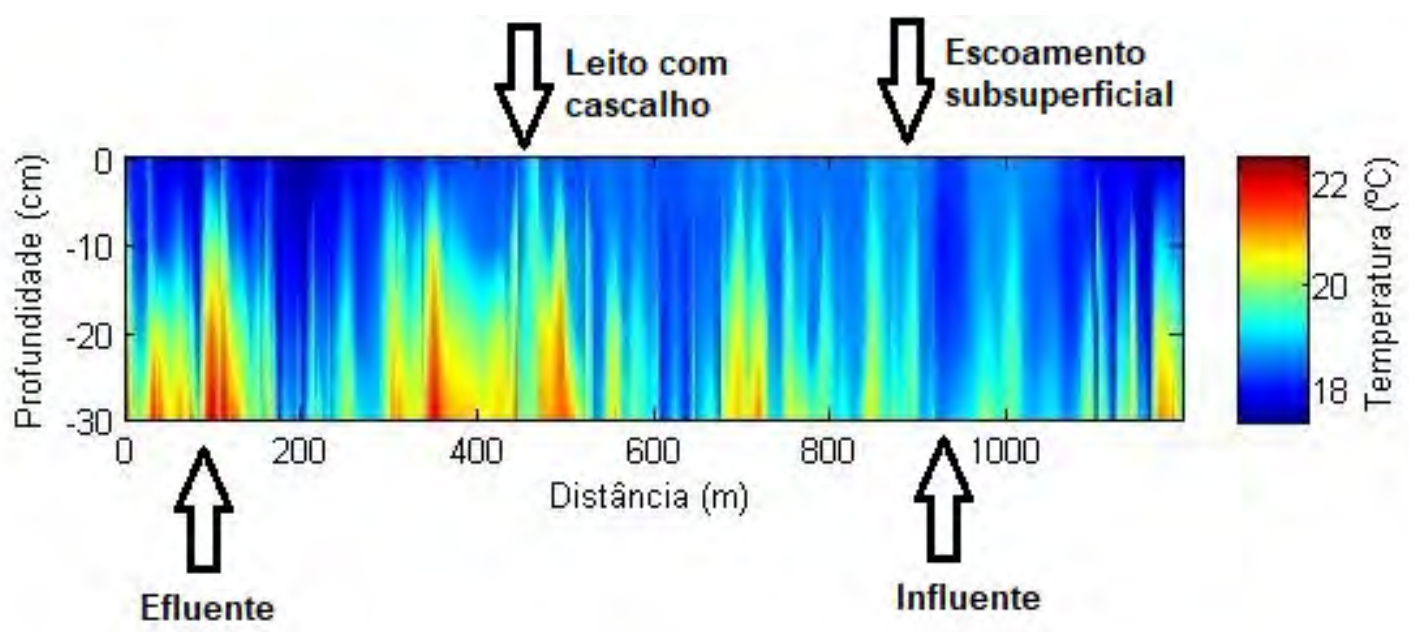

Fonte: Elaborado pelo autor.

cm abaixo da base do ribeirão não apresenta diferença com o leito, o que provavelmente indica uma interação de influência nessas regiões, ou seja, o ribeirão contribuindo para o aquífero. Essa interação de influência pode ser explicada por diferenças no gradiente hidráulico entre o ribeirão e o aquífero, que ocorrem nesses pontos.

Ainda na Figura 73 é possível inferir que há locais no trecho em que a diferença de 
temperatura é maior $\left(4^{\circ} \mathrm{C}\right)$. Em alguns desses pontos foi possível observar, visualmente, um escoamento subsuperficial (Figura 74), já que era possível visualizar pequenos surgimentos nas margens do ribeirão, provavelmente em razão de um alto gradiente hidráulico nesta área. Isto demonstra que nestes locais, nos quais o gradiente de temperatura foi maior, ocorrem maiores taxas de descarga do aquífero para o ribeirão, provando que a contribuição do aquífero não é uniforme ao longo da extensão do ribeirão. Nos pontos onde a diferença de temperatura foram pequenas ou nulas, possivelmente ocorre a contribuição do Ribeirão da Onça para o aquífero (Influência).

Figura 74 - Escoamento subsuperficial ao longo do trecho entre as calhas Parshall.

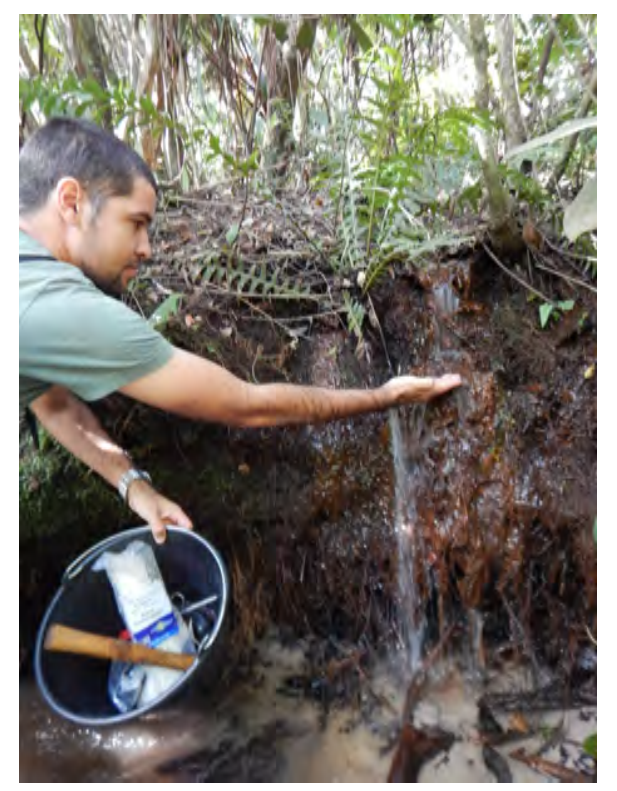

Fonte: Elaborado pelo autor.

Em alguns pontos onde foram encontrados os maiores gradientes de temperatura havia cascalho na base do ribeirão, como mostra a Figura 75. O tamanho desses grãos (cascalho) é diferente da dimensão dos sedimentos geralmente encontrados na base do ribeirão da Onça, que foram coletados a cerca de $7 \mathrm{~km}$ a jusante e descritos no trabalho de Arantes (2003), como areia média a fina e areia silte - argilosa. Isso indica que a permeabilidade da base nesses pontos é maior, justificando essas diferenças no gradiente de temperatura no trecho. A Figura 76 mostra o tipo de sedimento arenoso de fundo geralmente encontrado no trecho entre as calhas 1 e 2 . 
Figura 75 - Cascalho encontrado na base do ribeirão da Onça.

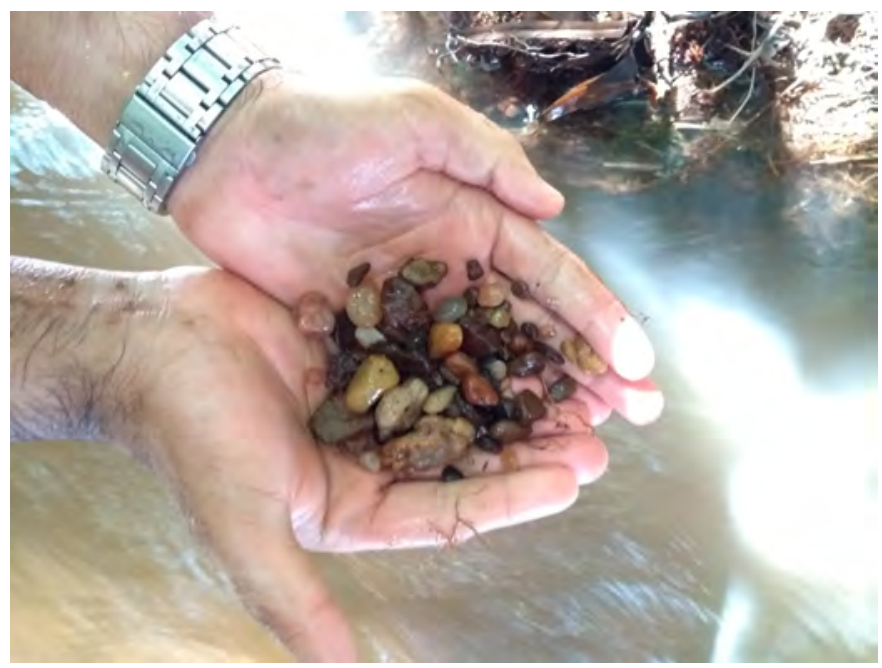

Fonte: Elaborado pelo autor.

Figura 76 - Logger de temperatura fixado por meio de uma vara de bambu na base arenosa do ribeirão da Onça.

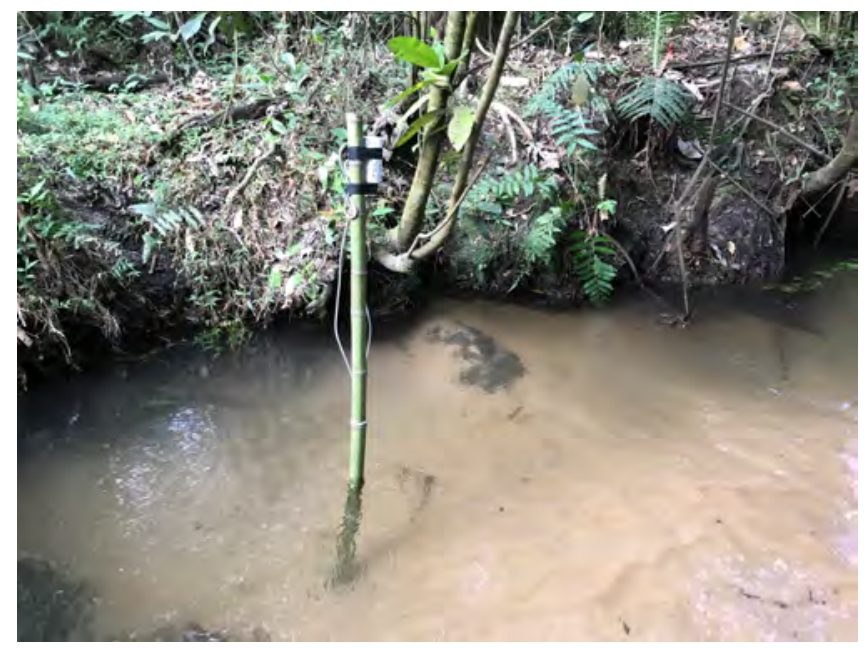

Fonte: Elaborado pelo autor.

A diferença entre a média dos valores obtidos pelo primeiro canal $(0 \mathrm{~cm})$ e o quarto canal $(-30 \mathrm{~cm})$ foi de aproximadamente $2{ }^{\circ} \mathrm{C}$, sendo que o mínimo valor registrado pelo primeiro canal foi de $17,4{ }^{\circ} \mathrm{C}$ e o máximo valor registrado pelo canal quatro foi $22,5{ }^{\circ} \mathrm{C}$. A Figura 77 apresenta um gráfico Boxplot, com a amplitude e a média da temperatura para cada profundidade em que foram coletadas.

A variação média de temperatura na zona hiporreica $(-30 \mathrm{~cm})$ e na superfície (leito) do ribeirão da Onça foi menor que os valores encontrados por outros pesquisadores, para outras áreas de estudo, sendo que se assemelha mais com a variação encontrada no 
Figura 77 - Boxplot das temperaturas observadas em campo nos 4 canais.

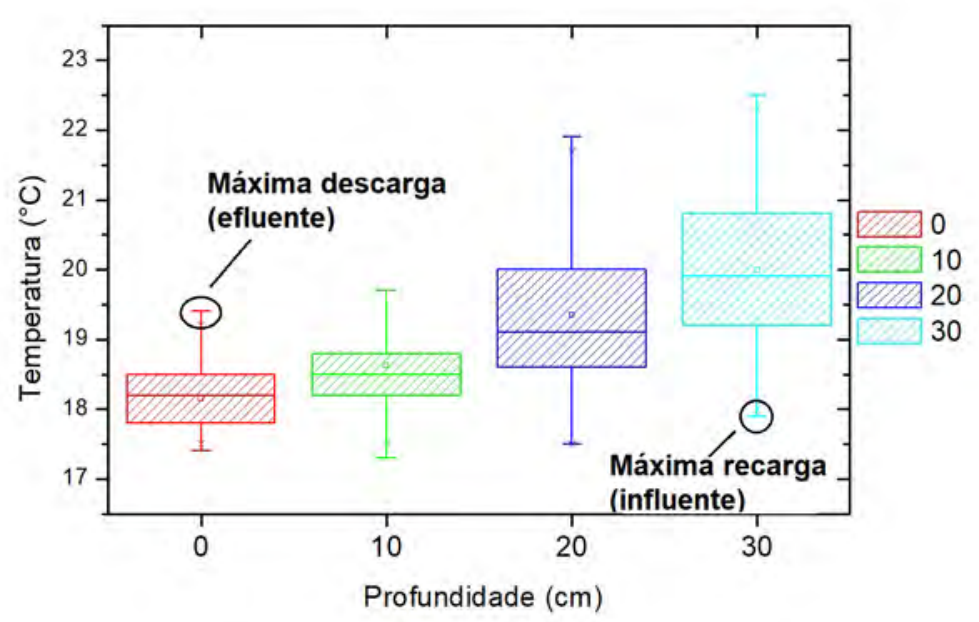

Fonte: Elaborado pelo autor.

trabalho de Bastola e Peterson $(2016)\left(3{ }^{\circ} \mathrm{C}\right)$, o qual realizou seu trabalho em uma bacia localizada no centro rural de Illinois. A amplitude da diferença de temperatura apresentada na Figura 72 está compreendida entre 5 e $6{ }^{\circ} \mathrm{C}$, valores próximos aos encontrados por Lowry et al. (2007), Duque, Calvache e Engesgaard (2010), Lee et al. (2013), apesar das áreas de estudo serem diferentes, tanto nas características climáticas, quanto nas condições de escoamento dos rios, já que nos Estados Unidos a água do aquífero é mais fria no verão e mais quente no inverno. 



\section{Conclusão}

Um estudo sobre a interação rio aquífero, aplicando um balanço de massa do rio e a temperatura da água do aquífero como traçador, foi realizado, na bacia do Ribeirão da onça, predominantemente de uso agrícola.

A bacia foi dividida em 3 sub-bacias, nas quais foram instaladas 2 calhas Parshall e 1 vertedor triangular, para monitorar o escoamento superficial total. Também foi montado um data logger, alternativo e de baixo custo, utilizando a plataforma Arduino ${ }^{\circledR}$, para verificar sua potencial utilização no monitoramento dos níveis d'água nos linígrafos das calhas. O data logger montado neste trabalho, apresenta uma tendência em subestimar com um erro relativo médio de 3,5\%. Apesar do valor do erro ser baixo, o data logger apresenta maior sensibilidade que o transdutor de pressão comercial e necessita da inclusão de um sistema de transmissão de dados online para manter a sua operação.

O tipo de cobertura vegetal, encontrado em cada sub-bacia, aliado ao tamanho da sub-bacia, influencia tanto na intensidade dos picos de vazão, quanto na intensidade dos ruídos observados. Além disso, o cultivo de citros possui maior atenuação a picos de vazão, comparado ao solo exposto.

Também foi utilizado o método dos mínimos locais, encontrado no Software HYSEP, para realizar a separação do escoamento de base do escoamento superficial total. A partir do escoamento de base das três sub-bacia, é possível concluir que o BFI da sub-bacia que contém citros é maior, comparado aos outros usos do solo. Além disso foi possível concluir que a contribuição da sub-bacia1, coberta por citros, é menor que a contribuição da sub-bacia 2 e da sub-bacia 3 , com grandes taxas de solo exposto, indicando maiores recargas nas sub-bacias de solo exposto, em comparação com as de citros.

Através da análise do coeficiente de recessão foi possível concluir que, a recessão (decaimento) do escoamento de base foi menor para a sub-bacia 3 e maior para a sub-bacia 2.

A transmissividade média calculada foi de $131 \mathrm{~m}^{2}$. dia $^{-1}$ e a espessura média da camada saturada foi igual a $51 \mathrm{~m}$. O valor do coeficiente de recessão, obtido pela análise dos hidrogramas das sub-bacia, se mostrou eficaz para a estimativa da profundidade média da camada saturada do aquífero, o qual pode ser aplicado em áreas nas quais existe carência de dados de níveis piezométricos do lençol freático.

O uso do balanço de massa no ribeirão, também foi suficiente para estimar a contribuição superficial e linear média do escoamento de base da sub-bacia $2,850 \mathrm{~mm} / \mathrm{d}$ e $4 \mathrm{~m}^{3} / m . d$, respectivamente. 
No monitoramento do gradiente de temperatura, realizado no ribeirão, foram utilizados termopares conectados a um termômetro digital de quatro canais, revelando a simplicidade do método e a possibilidade de ser empregado em outras bacias com condições semelhantes de gradiente de temperatura.

O gradiente de temperatura mostrou-se eficiente, durante os meses de inverno (seco), apresentando cerca de 5 a $6{ }^{\circ} \mathrm{C}$. O ribeirão da Onça também apresentou condições de contribuição para o aquífero e que a contribuição do aquífero para o ribeirão não foi uniforme, demonstrando a heterogeneidade da descarga do aquífero.

Recomenda-se continuar as análises de contribuição do escoamento de base entre as sub-bacias, para acompanhar a evolução do uso do solo na bacia e seu impacto no escoamento do ribeirão, principalmente em relação ao eucalipto. Além disso,é necessário ampliar o período de monitoramento do gradiente de temperatura e a instrumentação, em campo, para observar se existe variação da contribuição ao longo do tempo e do espaço.

Sugere-se também, o emprego do gradiente de temperatura, encontrado no campo, em conjunto com modelos de fluxo, para ampliar o conhecimento sobre o fluxo de base e as relações térmicas que existem na zona hiporreica do Ribeirão da Onça.

Outra recomendação é ajustar o sistema de monitoramento montado, para as condições de campo e disseminar o uso do Arduíno em outras pesquisas. 


\section{Referências}

ANDERSON, M. P. Heat as a ground water tracer. Ground Water, v. 43, n. 6, p. 951-968, 2005. ISSN 0017467X. Citado na página 48.

ARANTES, E.; MARCUSSI, F.; CHAUDHRY, F. Caracterização da interação entre rio e aqüífero com o uso de infiltrômetros. Águas Subterrâneas, v. 20, n. 2, p. 97-108, 2006. ISSN 2179-9784. Citado 7 vezes nas páginas 13, 26, 62, 63, 96, 97 e 99.

ARANTES, E. J. Emprego De Infiltrômetros Na Caracterização Da Interação Entre Rio e Aquifero. [S.l.]: Dissertação (mestrado), Escola de Engenharia de São Carlos, Universidade De São Paulo, São Carlos, 2003. 88 p. Citado na página 101.

ARAÚJO, L. M.; FRANÇA, A. B.; POTTER, P. E. Hydrogeology of the Mercosul aquifer system in the Paraná and Chaco-Paraná Basins, South America, and comparison with the Navajo-Nugget aquifer system, USA. Hydrogeology Journal, v. 7, n. 3, p. 317-336, 1999. ISSN 1431-2174. Disponível em: <http://link.springer.com/10.1007/s100400050205>. Citado 3 vezes nas páginas 57, 58 e 99 .

Arduino. 2017. Disponível em: < https://www.arduino.cc/en/Guide/Introduction>. Citado 2 vezes nas páginas 52 e 53.

BARTOLINO, J. How we have examined ground-water/ surface-water interaction of the Rio Grande, in Bartolino, J.R., and Cole, J.C., eds.,. [S.l.], 2002. Citado na página 49.

BASTOLA, H.; PETERSON, E. W. Heat tracing to examine seasonal groundwater flow beneath a low-gradient stream in rural central Illinois, USA. Hydrogeology Journal, v. 24, n. 1, p. 181-194, 2016. ISSN 1431-2174. Disponível em: < http: //link.springer.com/10.1007/s10040-015-1320-8>. Citado 4 vezes nas páginas 49, 50, 52 e 103.

BECK, A. E.; GARVEN, G.; STEGENA, L. Hydrogeological Regimes and Their Subsurface Thermal Effects. [S.1.]: Geophysical Monograph Series, 2013. ISBN 9780875904511. Citado na página 48.

BEVEN, K. Interflow. In: Morel-Seytoux H.J. (eds) Unsaturated Flow in Hydrologic Modeling. NATO ASI Series (Series C: Mathematical and Physical Sciences). vol 275. [S.l.]: Springer, Dordrecht, 1989. ISBN 978-94-010-7559-6. Citado na página 40.

BLUMSTOCK, M. et al. Baseflow dynamics: Multi-tracer surveys to assess variable groundwater contributions to montane streams under low flows. Journal of Hydrology, Elsevier B.V., v. 527, p. 1021-1033, 2015. ISSN 00221694. Disponível em: <http://dx.doi.org/10.1016/j.jhydrol.2015.05.019>. Citado na página 26.

BOUSSINESQ, J. Essai sur la the orie des eaux courantes du mouvement nonpermanent des eaux souterraines. Acad. Sci. Inst. Fr., n. 23, p. 252 - 260, 1877. Citado 2 vezes nas páginas 42 e 43.

BOUSSINESQ, J. Sur un mode simple d'e coulement des nappes d'eau d'infiltration a ' lit horizontal, avec rebord vertical tout autour lorsqu'une partie de ce rebord est enleve $e$ 
depuis la surface jusqu'au fond. [S.1.]: C. R. Acad. Sci. 137, 5-11., 1903. Citado 3 vezes nas páginas 42,43 e 45 .

BOUYOUCOS, G. Effects of temperature on some of the most important physical process in soils: Mich.Coll.Ag.Tech.Bull. [S.l.: s.n.], 1915. Citado na página 48.

BRIGGS, M. A. et al. Using high-resolution distributed temperature sensing to quantify spatial and temporal variability in vertical hyporheic flux. Water Resources Research, v. 48, n. 2, p. 1-16, 2012. ISSN 00431397. Citado na página 49.

CABRERA, M. et al. Performance of evaporation estimation methods compared with standard 20 m^2 tank. Revista Brasileira de Engenharia Agricola e Ambiental, v. 20, n. 10, p. 874-879, 2016. ISSN 18071929. Citado na página 61.

CARDENAS, M. B. Stream-aquifer interactions and hyporheic exchange in gaining and losing sinuous streams. Water Resources Research, v. 45, n. 6, p. 1-13, 2009. ISSN 00431397. Citado na página 25.

CHOW, V. Open Channel Hydraulics. Internatio. [S.l.]: McGraw-Hill, 1959. Citado na página 35.

CHOW, V. te; MAIDMENT, D. R.; MAYS, L. W. Applied Hydrology. [S.l.]: McGraw Hill Book Company, 1988. ISBN 0-07-010810-2. Citado 3 vezes nas páginas 31, 45 e 46.

CHRISTENSEN, J.; HERRICK, L. Mississipi River Test. California - US, 1982. A5-A10 p. Citado na página 33.

CLEVELAND, W. S.; DEVLIN, S. J. Locally Weighted Regression : An Approach to Regression Analysis by Local Fifing. v. 83, n. 403, p. 596-610, 1988. Citado na página 73.

COLLISCHONN, W.; DORNELLES, F. Hidrologia para engenharia e ciências ambientais. Segunda ed. Porto Alegre - RS: Assossiação Brasileira de Recursos Hídricos - ABRH, 2015. 335 p. ISBN 978-85-88686-34-2. Citado na página 29.

CONSTANTZ, J. Heat as a tracer to determine streambed water exchanges. Water Resources Research, v. 46, n. 4, p. 1-20, 2008. ISSN 00431397. Citado na página 48.

COSTA, F. M.; ALMEIDA, L. D.; BACELLAR, P. Caracterização Hidrogeológica de Aquíferos a Partir do Fluxo de Base. Revista Brasileira de Recursos Hídricos, v. 15, n. 1994, p. 173-183, 2010. Citado 4 vezes nas páginas 43, 44, 45 e 98.

DALLAS, H. Water temperature and riverine ecosystems: An overview of knowledge and approaches for assessing biotic responses, with special reference to South Africa. Water SA, v. 34, n. 3, p. 393-404, 2008. ISSN 03784738. Citado na página 25.

DEWANDEL, B. et al. Evaluation of aquifer thickness by analysing recession hydrographs. Application to the Oman ophiolite hard-rock aquifer. Journal of Hydrology, v. 274, n. 1-4, p. 248-269, 2003. ISSN 00221694. Citado na página 42.

DUQUE, C.; CALVACHE, M. L.; ENGESGAARD, P. Investigating river-aquifer relations using water temperature in an anthropized environment (Motril-Salobreña aquifer). Journal of Hydrology, Elsevier B.V., v. 381, n. 1-2, p. 121-133, 2010. ISSN 00221694. Disponível em: <http://dx.doi.org/10.1016/j.jhydrol.2009.11.032>. Citado 3 vezes nas páginas 51, 52 e 103. 
EAGLESON, P. Introduction to Water Balance Dynamics. Water Resources Research, v. 14, n. 5, p. 705-712, 1978. ISSN 00431397. Citado na página 30.

ECKHARDT, K. How to construct recursive digital filters for baseflow separation. Hydrological Processes, v. 19, n. 2, p. 507-515, 2005. ISSN 08856087. Citado na página 47.

ECKHARDT, K. A comparison of baseflow indices, which were calculated with seven different baseflow separation methods. Journal of Hydrology, v. 352, n. 1-2, p. 168-173, 2008. ISSN 00221694. Citado 2 vezes nas páginas 47 e 48.

FANELLI, R. M.; LAUTZ, L. K. Patterns of water, heat, and solute flux through streambeds around small dams. Ground Water, v. 46, n. 5, p. 671-687, 2008. ISSN 0017467X. Citado na página 49.

FATEHNIA, M. et al. Automating double ring infiltrometer with an Arduino microcontroller. Geoderma, v. 262, p. 133-139, 2016. ISSN 00167061. Citado na página 54 .

FERDOUSH, S.; LI, X. Wireless sensor network system design using Raspberry Pi and Arduino for environmental monitoring applications. Procedia Computer Science, Elsevier Masson SAS, v. 34, p. 103-110, 2014. ISSN 18770509. Disponível em: <http://dx.doi.org/10.1016/j.procs.2014.07.059>. Citado 2 vezes nas páginas 53 e 54 .

FISHER, L. H.; HEALY, R. W. Water Movement within the Unsaturated Zone in Four Agricultural Areas of the United States. Journal of Environment Quality, v. 37, n. 3, p. 1051, 2008. ISSN 1537-2537. Disponível em: <https: //www.agronomy.org/publications/jeq/abstracts/37/3/1051>. Citado na página 95.

FU, T.; CHEN, H.; WANG, K. Structure and water storage capacity of a small karst aquifer based on stream discharge in southwest China. Journal of Hydrology, Elsevier B.V., v. 534, p. 50-62, 2016. ISSN 00221694. Disponível em: <http://dx.doi.org/10.1016/j.jhydrol.2015.12.042>. Citado 2 vezes nas páginas 44 e 45.

GARCÍA, D. E. G. Modelo empírico linear para previsão da disponibilidade hídrica integrada em função da média móvel da precipitação Modelo empírico linear para previsão da disponibilidade hídrica integrada em função da média móvel da precipitação. [S.1.]: Dissertação (mestrado), Escola de Engenharia de São Carlos, Universidade De São Paulo, São Carlos, 2016. Citado 2 vezes nas páginas 47 e 97.

GOMES, L. H. Determinação da recarga profunda na bacia-piloto do ribeirão da Onça em zona de afloramento do Sistema Aquífero Guarani a partir de balanço hídrico em zona saturada. enharia de São Carlos,Universidade de São Paulo, São Carlos, 2008. 167 p. Disponível em: <http://www.teses.usp.br/teses/disponiveis/18/18138/ tde-28042009-132417/pt-br.php>. Citado 3 vezes nas páginas 61, 62 e 98.

GRIFFITHS, G. A.; CLAUSEN, B. Streamflow recession in basins with multiple water storages. Journal of Hydrology, v. 190, n. 1-2, p. 60-74, 1997. ISSN 00221694. Citado na página 32.

HALL, F. R. Base-Flow Recessions-A Review. Water Resources Research, v. 4, n. 5, p. 973-983, 1968. ISSN 19447973. Citado na página 32. 
HARPER, C. A. Eletronic Materials \& Processes Handbook. Third edit. [S.l.]: McGraw-Hill, 2004. ISBN 9780071402149. Citado na página 55.

HEALY, R. W. Estimating groundwater recharge. [S.l.]: RU: Cambridge University Press, 2010. 245 p. Citado na página 43.

JORDÃO, M. D. L. et al. Low-cost automatic station for compost temperature monitoring de temperatura da compostagem. Revista Brasileira de Engenharia Agrícola e Ambiental, p. 809-813, 2017. Citado 2 vezes nas páginas 54 e 90.

KHANDPUR, R. Printed Circuits Boards Design, Fabrication, And Assembly. New Delhi: McGraw Hill Professional, 2005. 704 p. ISBN 0-07-058814-7. Citado na página 54.

LANGBEIN, W. B. Some channel-storage studies and their application to the determination of infiltration. Eos, Transactions American Geophysical Union, v. 19, n. 1, p. 435-447, 1938. ISSN 23249250. Citado na página 42.

LAPHAM, W. W. Use of temperature profiles beneath streams to determine rates of vertical ground-water flow and vertical hydraulic conductivity. [S.l.], 1989. $35 \mathrm{p}$.

Disponível em: <http://agris.fao.org/agris-search/search/display.do?f=1991/US/US91293. xml;US9101682\$\delimiter"026E30F\$nhttp:/ /www.csa.com/partners/viewrecord.php? requester $=\mathrm{gs}\{\&\}$ collection $=\mathrm{ENV}\{\&\}$ recid $=9>$. Citado na página 48.

LARKIN, R. G.; SHARP, J. M. On the relationship between river-basin geomorphology, aquifer hydraulics, and ground-water flow direction in alluvial aquifers. Geological Society of America Bulletin, v. 104, n. 12, p. 1608-1620, 1992. ISSN 00167606. Citado na página 40.

LEDESMA, P. A. M. RELAÇ ÃO DO ESCOAMENTO DE BASE COM A FISIOGRAFIA E A HIDROGEOLOGIA EM RIO EFLUENTE: RIO GRAVATAÍ/RS. [S.l.]: Dissertação (mestrado),Programa de Pós - Graduação em Recursos Hídricos e Saneamento Ambiental,Universidade Federal do Rio Grande do Sul, Porto Alegre, 2016. Citado na página 45.

LEE, J. Y. et al. Stream water and groundwater interaction revealed by temperature monitoring in agricultural areas. Water (Switzerland), v. 5, n. 4, p. 1677-1698, 2013. ISSN 20734441. Citado 4 vezes nas páginas 26, 51, 52 e 103.

Lerner, D.N.;Issar, A.S.;Simmers, I. Groundwater Recharge. A Guide to Understanding and Estimating Natural Recharge (Volume 8, International Contributions to Hydrogeology). International Association of Hydrogeologists, v. 21, n. April, p. 512, 1992. ISSN 03418162. Citado na página 30.

LINSLEY, R.; KOHLER, M.; PAUlHUS, J. Applied Hydrology. New York: [s.n.], 1949. Citado 3 vezes nas páginas 31, 32 e 46.

LIU, Y. et al. Runoff and nutrient losses in citrus orchards on sloping land subjected to different surface mulching practices in the Danjiangkou Reservoir area of China. Agricultural Water Management, Elsevier B.V., v. 110, p. 34-40, 2012. ISSN 03783774. Disponível em: <http://dx.doi.org/10.1016/j.agwat.2012.03.011>. Citado na página 93.

LOWRY, C. S. et al. Identifying spatial variability of groundwater discharge in a wetland stream using a distributed temperature sensor. Water Resources Research, v. 43, n. 10, p. 1-9, 2007. ISSN 00431397. Citado 4 vezes nas páginas 48, 51, 52 e 103. 
LUCAS, M.; WENDLAND, E. Recharge estimates for various land uses in the Guarani aquifer system outcrop area. Hydrological Sciences Journal, Taylor \& Francis, v. 61, n. 7, p. 1253-1262, 2015. ISSN 21503435. Disponível em: <http://dx.doi.org/10.1080/02626667.2015.1031760>. Citado na página 95.

LUCAS, M. C. Influência da precipitação e do uso do solo sobre a taxa de recarga em zona de afloramento do Sistema Aquífero Guarani. [S.l.]: Dissertação (mestrado), Escola de Engenharia de São Carlos, Universidade De São Paulo, São Carlos, 2013. 104 p. Citado 4 vezes nas páginas 44, 66, 95 e 96.

LYNE, V.; HOLLICK, M. Stochastic time-variable rainfall-runoff modelling. Hydrology and Water Resources Symposium, p. 89-92, 1979. Citado na página 47.

LYON, S. W. et al. Seasonal and regional patterns in performance for a Baltic Sea Drainage Basin hydrologic model. Journal of the American Water Resources Association, v. 51, n. 2, p. 550-566, 2015. ISSN 17521688. Citado 3 vezes nas páginas 44, 45 e 98.

MAILLET, E. Essais d'hydraulique souterraine et fluviale. Librairie Sci. [S.l.]: A. Hermann, Paris, 218, 1905. Citado na página 42.

MALDONADO, L. H. Validação experimental de metodologias para quantificação contínua de vazão no Ribeirão da Onça. Dissertação (mestrado), Escola de Engenharia de São Carlos, Universidade De São Paulo, São Carlos, 2009. 181 p. Disponível em: <http: //www.teses.usp.br/teses/disponiveis/18/18138/tde-27042010-154503/pt-br.php>. Citado 4 vezes nas páginas 32, 33, 69 e 70.

MANRÍNQUEZ, I. A. G.; ESPINOSA, O. L.; VEGA, J. A. de la. Diseño y desarrollo de un pluviógrafo semiautomático tipo Hellman * Design and development of a Hellmann-type semiautomatic pluviograph Resumen Introducción. Revista Mexicana de Ciências Agrícolas, v. 7, p. 95-101, 2016. Citado na página 54.

MATTOS, T. Avaliação do impacto da substituição de pastagem por eucalipto na recarga de aquífero freático. Dissertação (Mestrado em Hidráulica e Saneamento), Escola de Engenharia de São Carlos,Universidade de São Paulo, São Carlos, 2015. 143 p. Disponível em: <http://www.teses.usp.br/teses/disponiveis/18/18138/tde-14082015-144441/pt-br. php>. Citado 3 vezes nas páginas 58, 62 e 98.

MAU, D. P.; WINTER, T. C. Estimating Ground-Water Recharge from Streamflow Hydrographs for a Small Mountain Watershed in a Temperate Humid Climate, New Hampshire, USA. 1997. 291-304 p. Disponível em: < http://onlinelibrary.wiley.com/ doi/10.1111/j.1745-6584.1997.tb00086.x/abstract \$ \delimiter"026E30F \$npapers2: //publication/doi/10.1111/j.1745-6584.1997.tb00086.x>. Citado na página 44.

MCCALlUM, A. M.; ANDERSEN, M. S.; ACWORTH, R. I. A New Method for Estimating Recharge to Unconfined Aquifers Using Differential River Gauging. Groundwater, v. 52, n. 2, p. 291-297, 2014. ISSN 17456584. Citado 2 vezes nas páginas 25 e 30 .

MELO, D. d. C. D.; CABRERA, M. C. M.; WEnDLAND, E. Balanço hídrico e modelagem computacional visando estimar recarga subterrânea. Águas Subterrâneas, v. 31, n. 1, p. 66-78, 2017. Citado 2 vezes nas páginas 62 e 99. 
MILLER, M. P. et al. The importance of base flow in sustaining surface water flow in the Upper Colorado River Basin. Water Resources Research, v. 52, n. 5, p. 3547-3562, 2016. ISSN 00431397. Citado na página 25.

NARASIMHAN, T. Hydrological Cycle and Water Budgets. Encyclopedia of Inland Waters, p. 714-720, 2009. Disponível em: <http://www.sciencedirect.com/science/article/ pii/B9780123706263000107>. Citado na página 29.

NATHAN, R. J.; MCMAHON, T. A. Evaluation of automated techniques for base flow and recession analyses. Water Resources Research, v. 26, n. 7, p. 1465-1473, jul 1990. ISSN 00431397. Disponível em: <http://doi.wiley.com/10.1029/WR026i007p01465>. Citado na página 47.

OLIVEIRA, P. T. et al. The water balance components of undisturbed tropical woodlands in the Brazilian cerrado. Hydrology and Earth System Sciences, v. 19, n. 6, p. 2899-2910, 2015. ISSN 16077938. Citado na página 61.

PAIVA, J. B. D. de; PAIVA, E. M. C. D. de. Hidrologia aplicada à gestão de pequenas bacias hidrográficas. Reimpressã. Porto Alegre - RS: [s.n.], 2001. d. 625 p. ISBN 8588686058, 9788588686052. Citado na página 32.

PANDA, K. G. et al. Effects of environment on accuracy of ultrasonic sensor operates in millimetre range. Perspectives in Science, Elsevier GmbH, v. 8, p. 574-576, 2016. ISSN 22130209. Disponível em: < http://linkinghub.elsevier.com/retrieve/pii/ S221302091630163X>. Citado na página 90.

PARSHALL, R. Measuring Water in Irrigation Channels With Parshall Flumes and Small Weirs. Washington, D.C, 1950. 62 p. Citado na página 35.

PORTO, R. HIDRÁULICA BÁSICA. 4 edição. ed. São Carlos: EESC-USP, 2006. 519 p. ISBN 85-7656-084-4. Citado 3 vezes nas páginas 37, 38 e 39.

RAO, W. et al. Chemical and strontium isotopic characteristics of shallow groundwater in the Ordos Desert Plateau, North China: Implications for the dissolved Sr source and waterrock interactions. Chemie der Erde - Geochemistry, Elsevier GmbH., v. 75, n. 3, p. 365-374, 2015. ISSN 00092819. Disponível em: <http://dx.doi.org/10.1016/j.chemer.2015.07.003>. Citado na página 47.

RIBEIRO, M. A. Instrumentação. 8 $^{\mathrm{a}}$. ed. Salvador: Tek treinamento \& Consultoria Ltda, 1999. 478 p. Citado na página 32.

Rodriguez Suarez, J. A. et al. Assessing the influence of afforestation with Eucalyptus globulus on hydrological response from a small catchment in northwestern Spain using the HBV hydrological model. Hydrological Processes, v. 28, n. 22, p. 5561-5572, 2014. ISSN 10991085. Citado 2 vezes nas páginas 44 e 45.

RORABAUGH, M. Streambed percolation in development of water supplies. [S.1.], 1954. Citado na página 48.

RORABAUGH, M. Estimating changes in bank storage and ground-water contribution to streamflow. International Asso- ciation of Scientific Hydrology Publication, n. 63, p. 432-441., 1964. Citado na página 43. 
RUSHTON, K. R.; TOMLINSON, L. M. Possible mechanisms for leakage between aquifers and rivers. Journal of Hydrology, v. 40, n. 1-2, p. 49-65, 1979. ISSN 00221694. Citado na página 41.

RUTLEDGE, A. Model-estimated ground-water recharge and hydrograph of ground-water discharge to a stream. [S.l.], 1997. 29 p. Citado na página 43.

RUTlEDGE, A. T.; DANIEL, C. C. Testing an Automated Method to Estimate Ground-Water Recharge from Streamflow Records. 1994. 180-189 p. Citado na página 44.

SCHMIDT, S. et al. Characterisation and modelling of conduit restricted karst aquifers - Example of the Auja spring, Jordan Valley. Journal of Hydrology, Elsevier B.V., v. 511, p. 750-763, 2014. ISSN 00221694. Disponível em: < http: //dx.doi.org/10.1016/j.jhydrol.2014.02.019>. Citado 2 vezes nas páginas 44 e 45.

SELKER, J. S. et al. Distributed fiber-optic temperature sensing for hydrologic systems. Water Resources Research, v. 42, n. 12, p. 1-8, 2006. ISSN 00431397. Citado na página 51.

SILVA, M. A. da et al. Sistemas de manejo em plantios florestais de eucalipto e perdas de solo e água na região do vale do Rio Doce, MG. Ciencia Florestal, v. 21, n. 4, p. 765-776, 2011. ISSN 01039954. Citado na página 93.

SILVA SOUZA, A. et al. A flood warning system to critical region. Procedia Computer Science, v. 109, n. 2016, p. 1104-1109, 2017. ISSN 18770509. Citado 2 vezes nas páginas 54 e 90 .

SIMPSON, M. R. Discharge Measurements using a broad-band acoustic Doppler current profiler. United States Geological Survey OPEN-FILE REPORT 01-1, p. 134, 2001.

Citado 2 vezes nas páginas 33 e 34.

SKOGERBOE, G. V. et al. Measuring Water with Parshall Flumes. n. January, 1966. Citado 2 vezes nas páginas 35 e 80.

SKOGERBOE, G. V. et al. Design and Calibration of Submerged Open Channel Flow Measurement Structures : Part 2 - Parshall Flumes. Utah, 1967. 55 p. Citado 5 vezes nas páginas 35, 36, 37, 38 e 68 .

SLOTO, R. a.; CROUSE, M. Y. Hysep: a computer program for streamflow hydrograph separation and analysis. [S.l.], 1996. 54 p. Citado 2 vezes nas páginas 46 e 81.

SMAKHTIN, V. Low flow hydrology: a review. Journal of Hydrology, Elsevier, v. 240, n. 3-4, p. 147-186, jan 2001. ISSN 0022-1694. Disponível em: <https: //www.sciencedirect.com/science/article/pii/S0022169400003401>. Citado 2 vezes nas páginas 32 e 44.

SOPHOCLEOUS, M. Interactions between groundwater and surface water: The state of the science. Hydrogeology Journal, v. 10, n. 1, p. 52-67, 2002. ISSN 14312174. Citado 3 vezes nas páginas 25, 32 e 41.

STACEY, M. T.; MONISMITH, S. G.; BURAU, J. R. Measurements of Reynolds stress profiles in unstratified tidal flow. Journal of Geophysical Research: Oceans, v. 104, n. C5, p. 10933-10949, 1999. ISSN 01480227. Disponível em: <http: //doi.wiley.com/10.1029/1998JC900095>. Citado na página 33. 
STALLMAN, R. W. Steady one-dimensional fluid flow in a semi-infinite porous medium with sinusoidal surface temperature. Journal of Geophysical Research, v. 70, n. 12, p. 2821-2827, 1965. ISSN 0148-0227. Citado na página 48.

STONESTROM, D. a.; CONSTANTZ, J. Heat as a Tool for Studying the Movement of Ground Water Near Streams - Circular 1260. [s.n.], 2003. 105 p. ISSN 1067084X. ISBN 0607940719. Disponível em: <http://pubs.water.usgs.gov/circ1260/>. Citado 3 vezes nas páginas 25, 48 e 49 .

SU, G. W. et al. Estimation of Hydraulic Conductivity in an Alluvial System Using Temperatures. Ground Water, v. 42, n. 6, p. 890-901, 2004. ISSN 0017-467X. Disponível em: <http://doi.wiley.com/10.1111/j.1745-6584.2004.t01-7-.x>. Citado na página 49.

SWANSON, T. E.; CARDENAS, M. B. Diel heat transport within the hyporheic zone of a pool-riffle-pool sequence of a losing stream and evaluation of models for fluid flux estimation using heat. Limnology and Oceanography, v. 55, n. 4, p. 1741-1754, 2010. ISSN 00243590. Citado na página 49.

THOMAS, B. F.; VOGEL, R. M.; FAMIGLIETTI, J. S. Objective hydrograph baseflow recession analysis. Journal of Hydrology, Elsevier B.V., v. 525, p. 102-112, 2015. ISSN 00221694. Disponível em: < http://dx.doi.org/10.1016/j.jhydrol.2015.03.028>. Citado na página 26.

TREESE, S.; MEIXNER, T.; HOGAN, J. F. Clogging of an effluent dominated semiarid river: A conceptual model of stream-aquifer interactions. Journal of the American Water Resources Association, v. 45, n. 4, p. 1047-1062, 2009. ISSN 1093474X. Citado na página 25.

VERAS, T. B. et al. Vertical hydraulic gradient research in hyporheic zone of Beberibe river in Pernambuco State (Brazil). Rbrh, v. 21, n. 4, p. 674-684, 2016. ISSN 2318-0331. Disponível em: <http://www.scielo.br/scielo.php?script=sci $\left\{\backslash \_\right\}$arttext $\{\&\}$ pid= S2318-03312016000400674\{\&\}lng=e>. Citado na página 26.

WENDLAND, E.; BARRETO, C.; GOMES, L. H. Water balance in the Guarani Aquifer outcrop zone based on hydrogeologic monitoring. Journal of Hydrology, v. 342, n. 3-4, p. 261-269, 2007. ISSN 00221694. Citado 2 vezes nas páginas 41 e 99.

WENDLAND, E.; GOMES, L. H.; TROEGER, U. Recharge contribution to the Guarani aquifer system estimated from the water balance method in a representative watershed. Anais da Academia Brasileira de Ciencias, v. 87, n. 2, p. 595-609, 2015. ISSN 16782690. Citado 2 vezes nas páginas 30 e 61.

WENDLAND, E.; RABELO, J.; ROEHRIG, J. Guarani Aquifer System - The Strategic Water Source In South America. n. May 2014, p. 192-201, 2004. Citado na página 57.

WINTER, T. C. Recent advances in understanding the interaction of groundwater and surface water. Reviews of Geophysics, v. 33, n. 2 S, p. 985-994, 1995. ISSN 19449208. Citado na página 25.

WINTER, T. C. et al. Ground water and surface water: a single resource. [s.n.], 1999. 88 p. ISBN 0607893397. Disponível em: < http://pubs.usgs.gov/circ/1998/1139/report.pdf>. Citado 3 vezes nas páginas 25, 39 e 40. 
WISHKERMAN, A.; WISHKERMAN, E. Application note: A novel low-cost open-source LED system for microalgae cultivation. Computers and Electronics in Agriculture, Elsevier B.V., v. 132, p. 56-62, 2017. ISSN 01681699. Disponível em: <http://dx.doi.org/10.1016/j.compag.2016.11.015>. Citado na página 54.

XIE, Y. et al. Uncertainty of natural tracer methods for quantifying river-aquifer interaction in a large river. Journal of Hydrology, Elsevier B.V., v. 535, p. 135-147, 2016. ISSN 00221694. Disponível em: <http://dx.doi.org/10.1016/j.jhydrol.2016.01.071>. Citado na página 52. 

Apêndices 



\section{APÊNDICE A - Imagens da instalação das calhas Parshall}

Figura 78 - Instalação da calha Parshall 1.

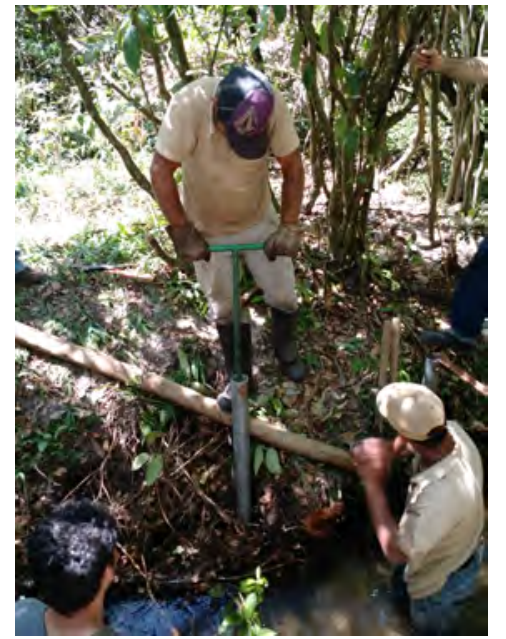

(a)

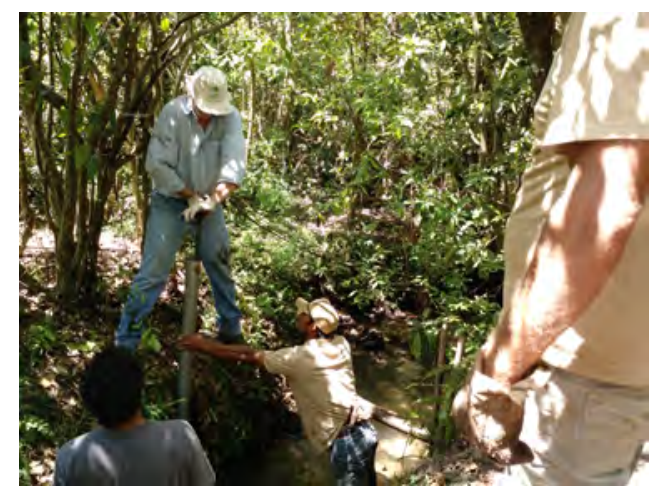

(d)

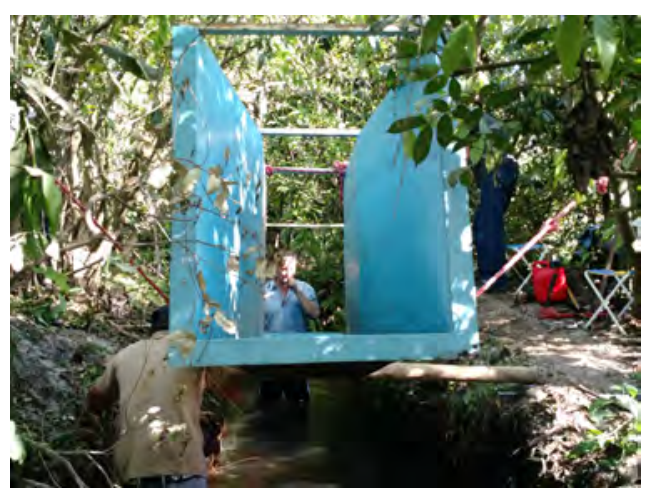

(f)

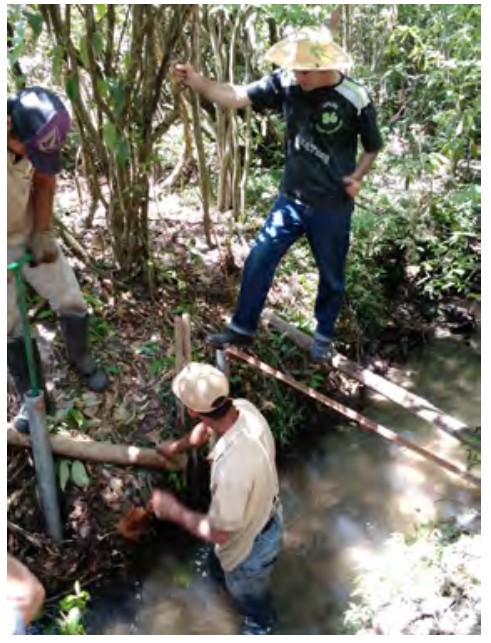

(b)

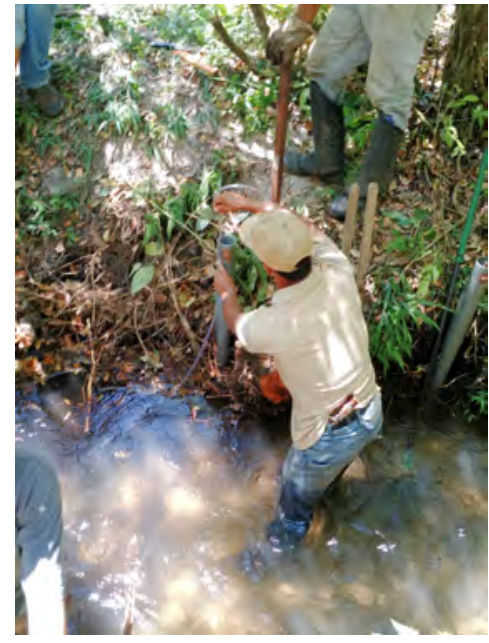

(c)

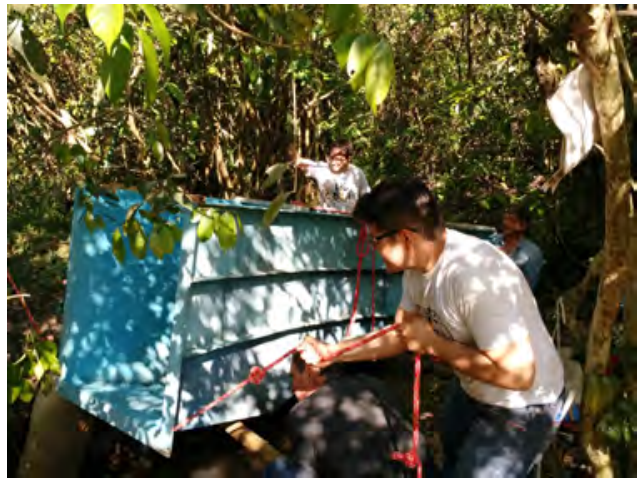

(e)

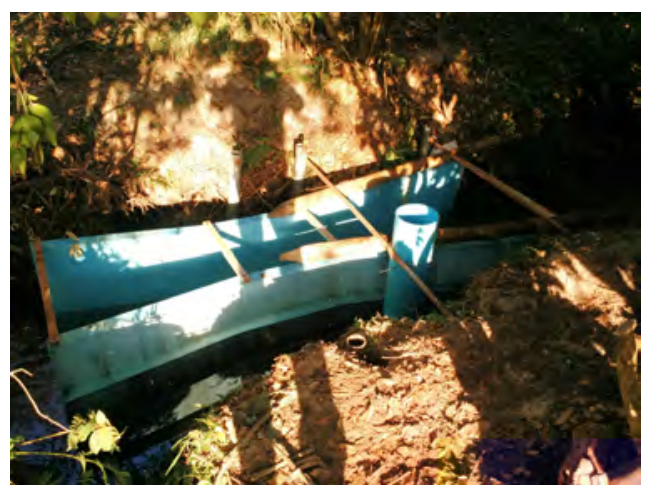

(g) 
Figura 79 - Instalação da calha Parshall 2.

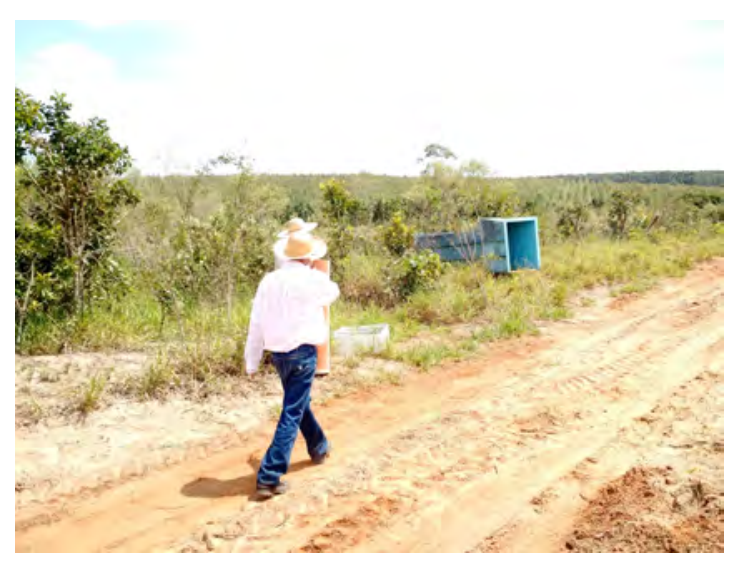

(a)

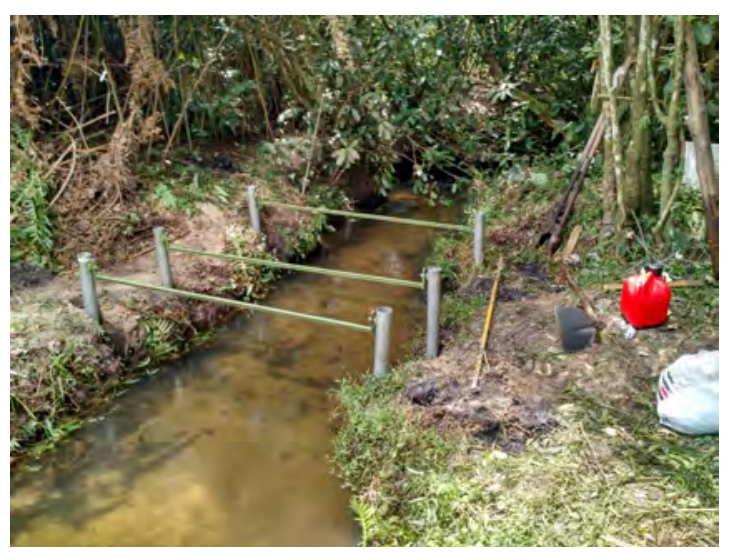

(c)

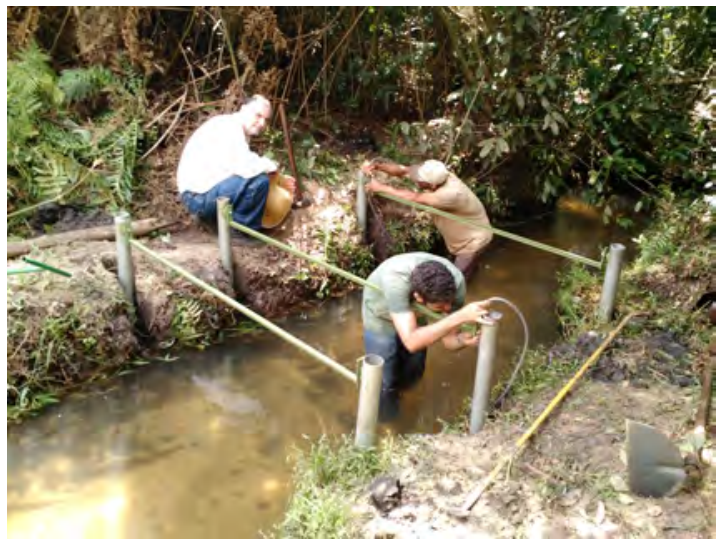

(b)

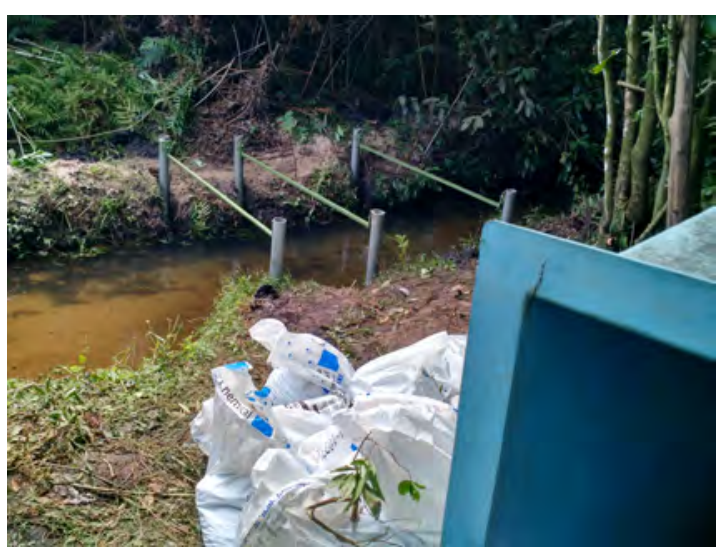

(d)

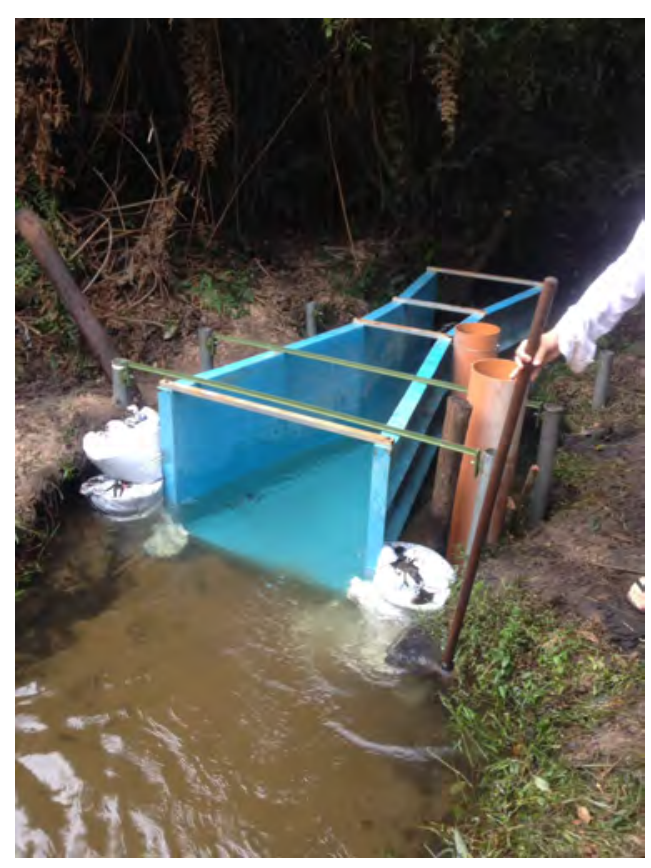

(e) 


\section{APÊNDICE B - Código do Arduino}

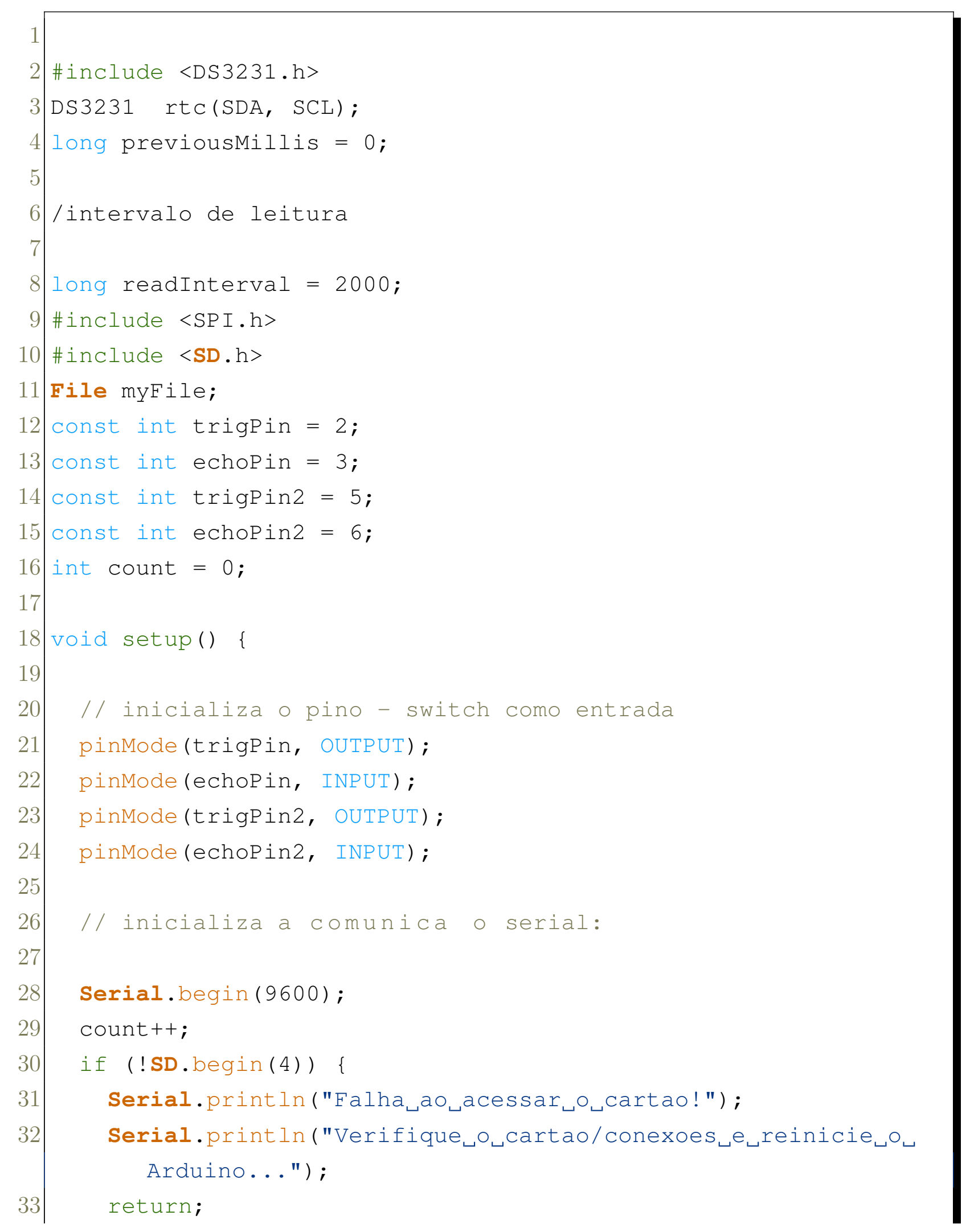




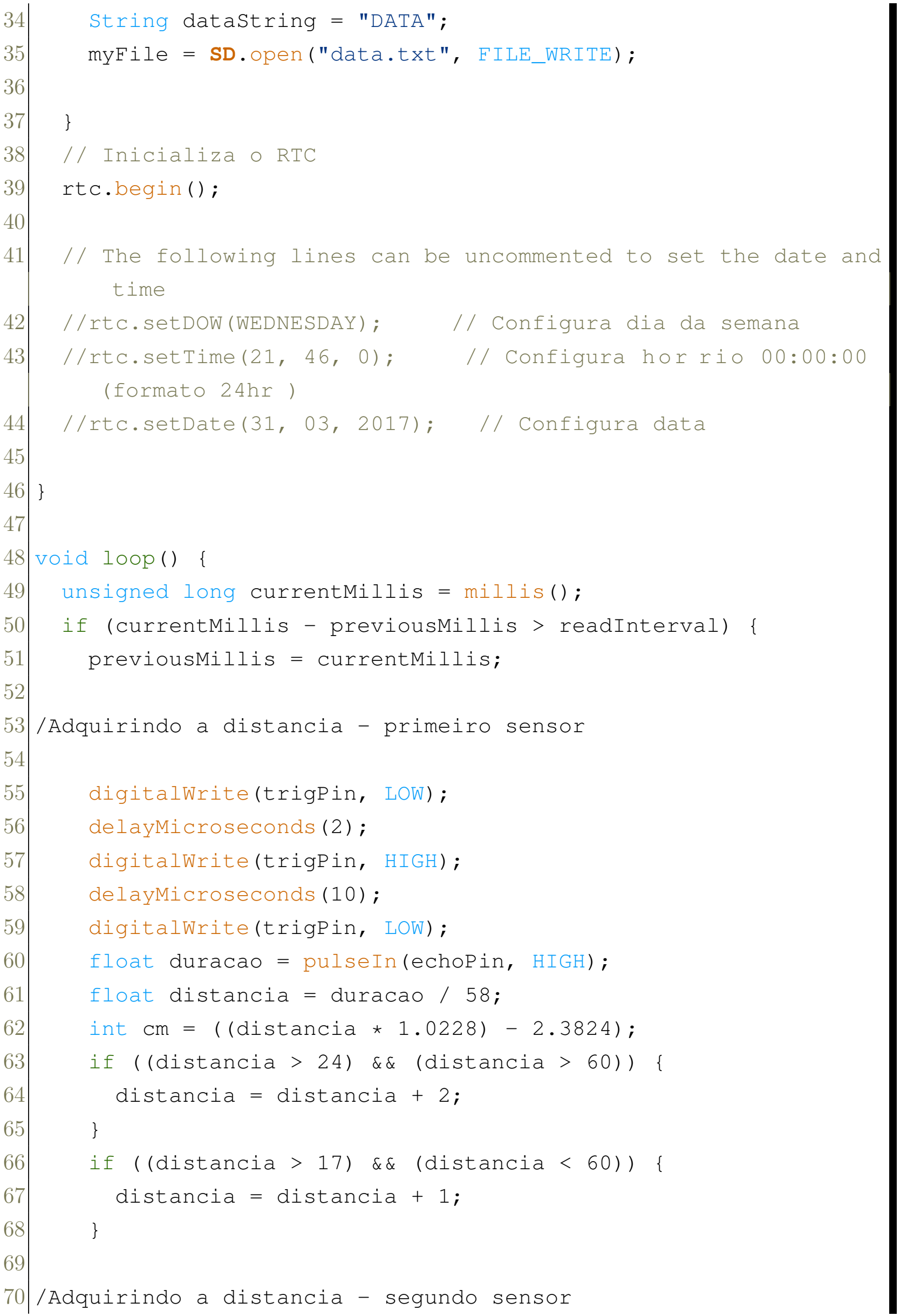




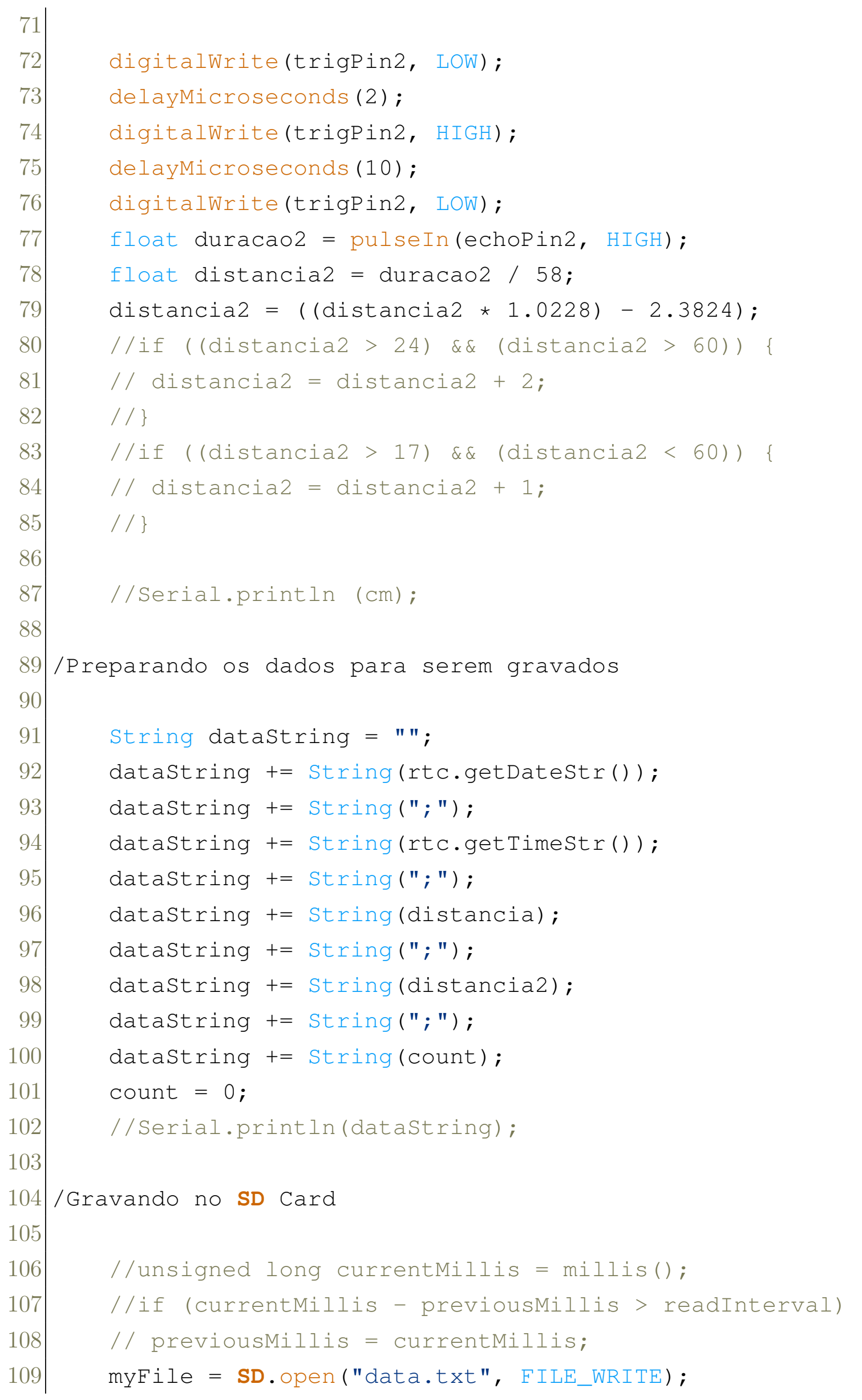




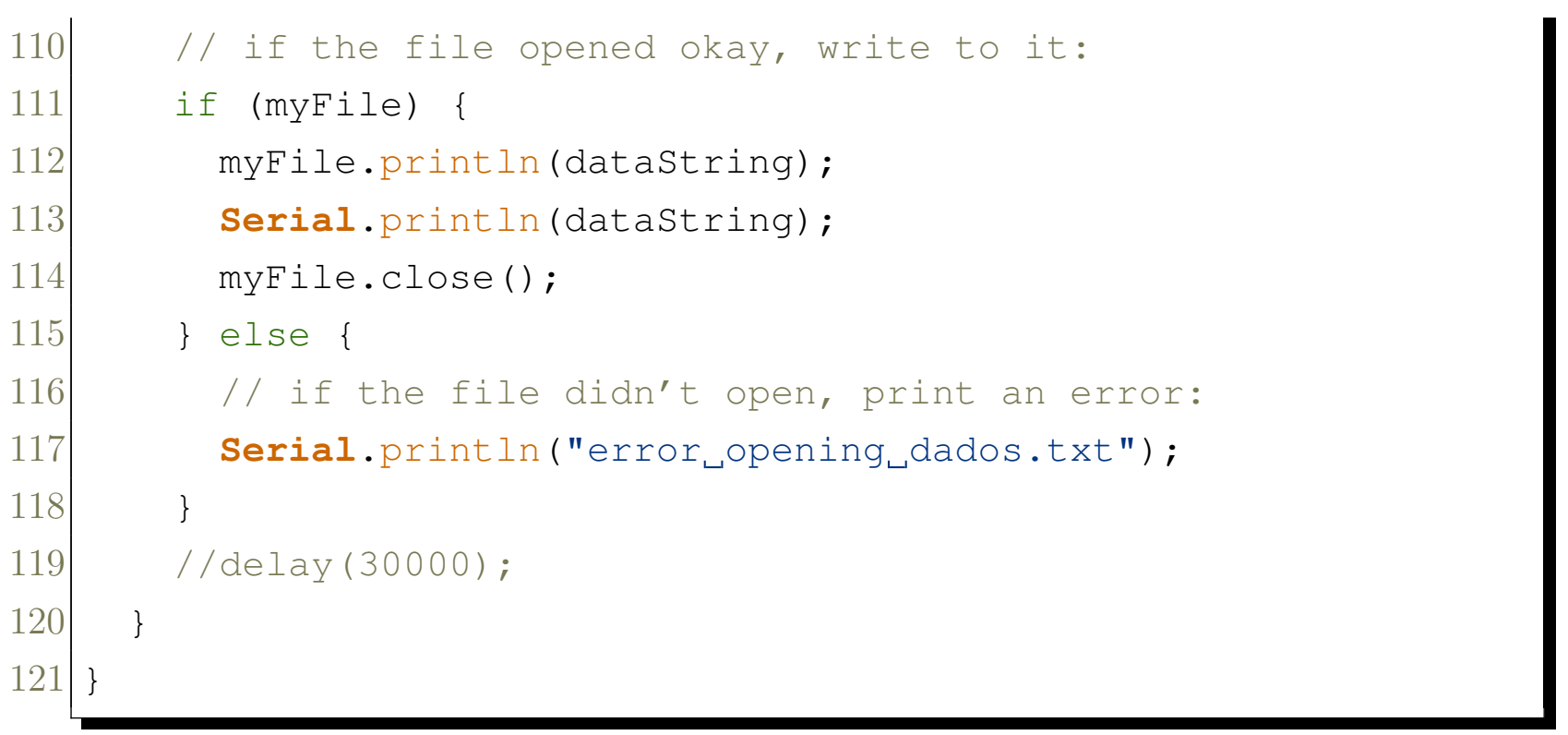




\section{APÊNDICE C - Imagens da impressão do circuito na placa condutora}


Figura 80 - Impressão do circuito na placa condutora (a)-(e). Datalogger instalado em campo (f)-(g).

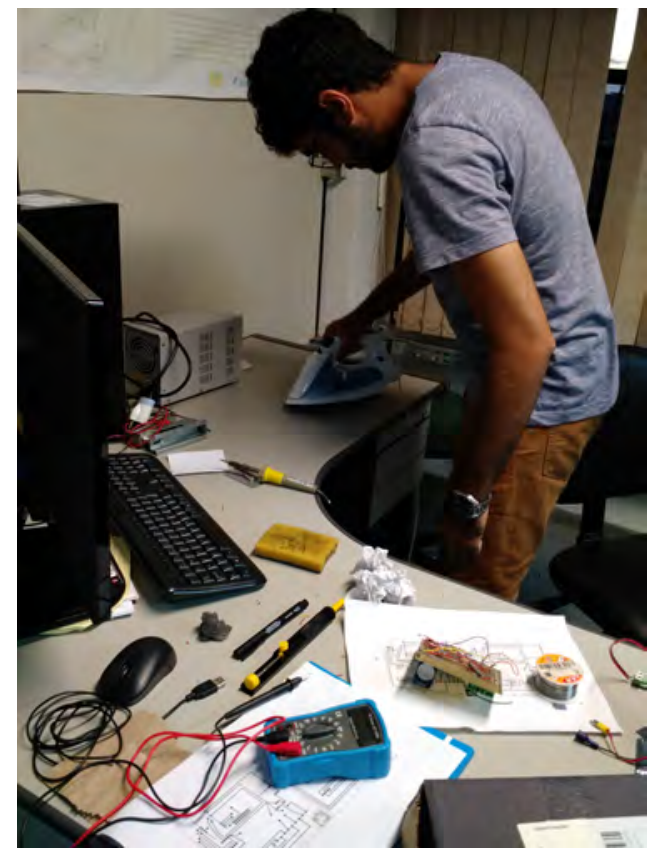

(a)

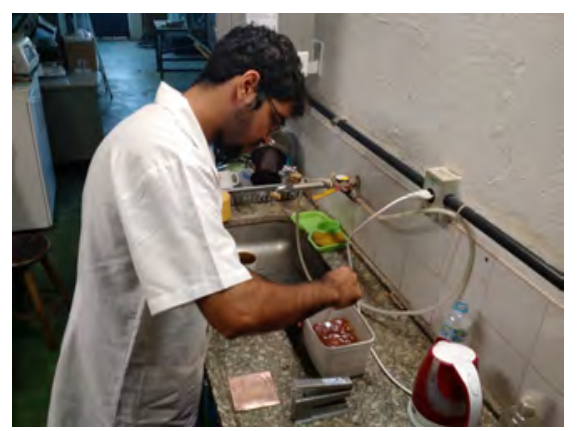

(c)

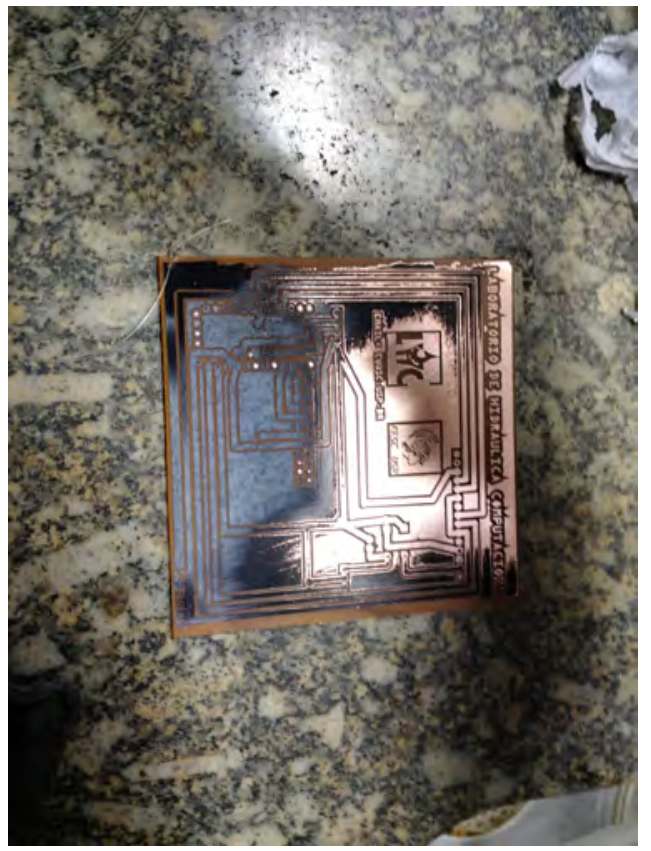

(b)

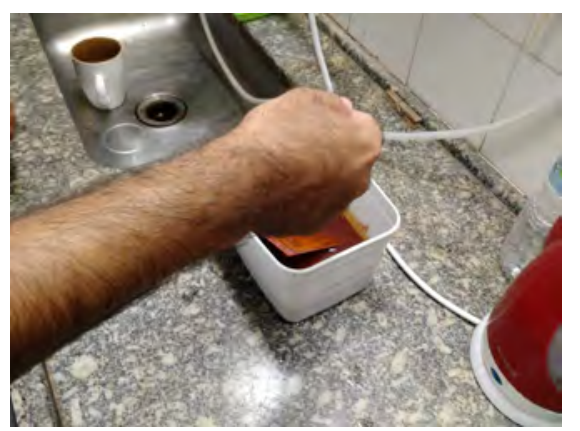

(d)

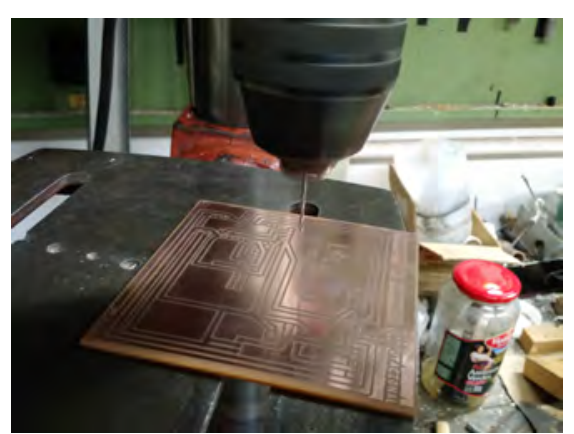

(e)

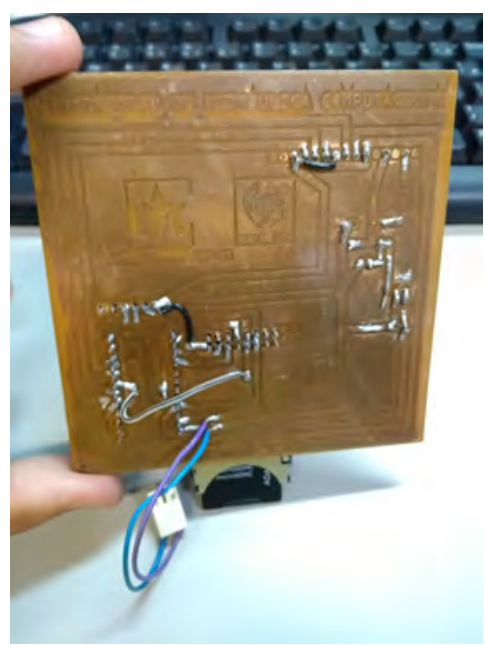

(f)

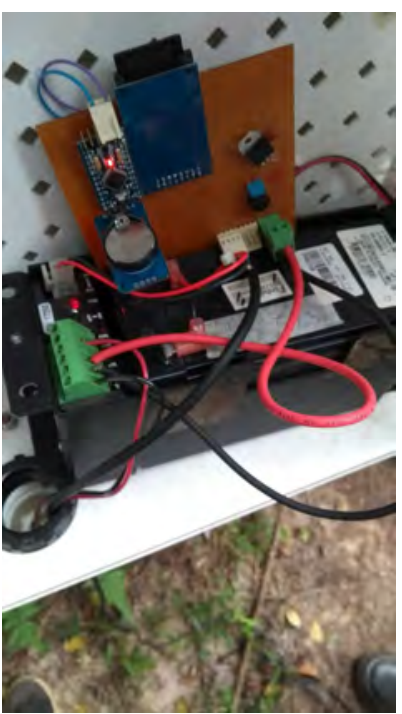

(g) 
Anexos 

ANEXO A - Datasheet do Arduino Pro mini 


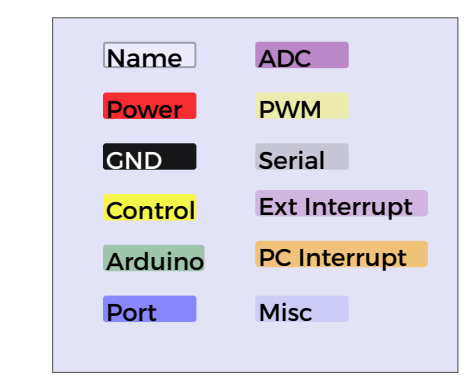

\section{Arduino Pro Mini (DEV-11113)}

Programmed as Arduino Pro Mini w/ ATMega328

$16 \mathrm{MHz} / 5 \mathrm{~V}$

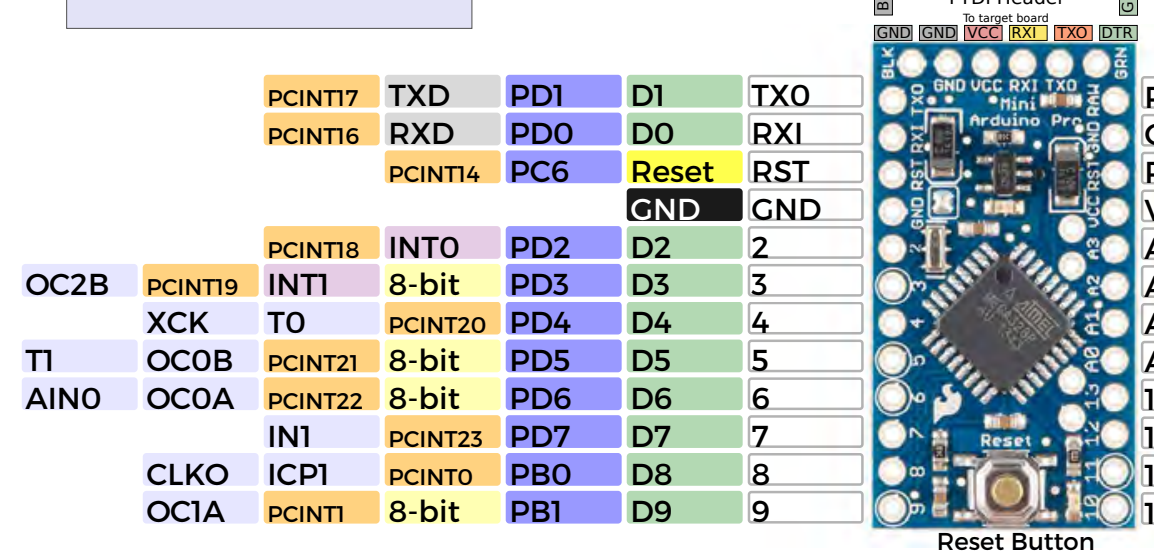

\begin{tabular}{|c|c|c|c|c|c|c|}
\hline RAW & RAW & & & & & \\
\hline GND & GND & & & & & \\
\hline RST & Reset & PC6 & PCINT74 & & & \\
\hline VCC & VCC & & & & & \\
\hline$A 3$ & A3/D17 & PC3 & ADC3 & PCINTIII & & \\
\hline A2 & A2/D16 & PC2 & ADC2 & PCINTIO & & \\
\hline Al & $\mathrm{Al} / \mathrm{D} 15$ & $\mathrm{PCl}$ & $\mathrm{ADCl}$ & PCINT9 & & \\
\hline AO & AO/D14 & PCO & ADCO & PCINT8 & & \\
\hline 13 & D13 & PB5 & SCK & PCINT5 & LED & \\
\hline 12 & D12 & PB4 & MISO & PCINT4 & & \\
\hline 11 & D11 & PB3 & 8-bit & MOSI & PCINT3 & OC2A \\
\hline 10 & D10 & РCB2 & 8-bit & SS & PCINT2 & OC1B \\
\hline
\end{tabular}

\begin{tabular}{|l|lllll|}
\hline A5 & A5/D19 & PC5 & ADC5 & SCL & PCINT13 \\
\hline A4 & A4/D18 & PC4 & ADC4 & SDA & PCINT12 \\
\hline
\end{tabular}

\begin{tabular}{|l|l|l|}
\hline A7 & A7 & ADC7 \\
\hline A6 & A6 & ADC6
\end{tabular}

Power

Raw:5V-16V (6V-12V recommended)

VCC:5V

Maximum current: 150mA @5V
ATMega328P

Absolute maxiumum VCC: $6 \mathrm{~V}$

Maximum current for chip: $200 \mathrm{~mA}$

Maximum current per pin: $40 \mathrm{~mA}$

Recommended current per pin:20mA

8-bit Atmel AVR

Flash Program Memory: 32kB

EEPROM: 1kB

Internal SRAM 2kB

ADC:10-bit

PWM:8bit
LEDs

Power: Red

User (D13): Green

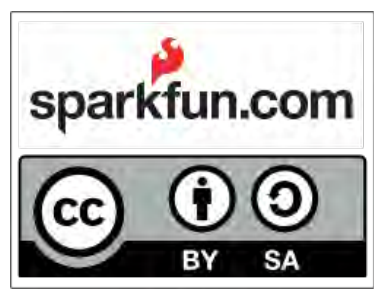

